\title{
Review Article \\ The Concept of Schizophrenia: From Unity to Diversity
}

\author{
Heinz Häfner \\ Schizophrenia Research Group, Central Institute of Mental Health, Mannheim Faculty of Medicine, University of Heidelberg, \\ J5, 68159 Mannheim, Germany \\ Correspondence should be addressed to Heinz Häfner; heinz.haefner@zi-mannheim.de
}

Received 4 May 2014; Accepted 9 July 2014; Published 15 September 2014

Academic Editor: Joseph M. Pierre

Copyright (C) 2014 Heinz Häfner. This is an open access article distributed under the Creative Commons Attribution License, which permits unrestricted use, distribution, and reproduction in any medium, provided the original work is properly cited.

\begin{abstract}
After over 100 years of research without clarifying the aetiology of schizophrenia, a look at the current state of knowledge in epidemiology, genetics, precursors, psychopathology, and outcome seems worthwhile. The disease concept, created by Kraepelin and modified by Bleuler, has a varied history. Today, schizophrenia is considered a polygenic disorder with onset in early adulthood, characterized by irregular psychotic episodes and functional impairment, but incident cases occur at all ages with marked differences in symptoms and social outcome. Men's and women's lifetime risk is nearly the same. At young age, women fall ill a few years later and less severely than men, men more rarely and less severely later in life. The underlying protective effect of oestrogen is antagonized by genetic load. The illness course is heterogeneous and depressive mood the most frequent symptom. Depression and schizophrenia are functionally associated, and affective and nonaffective psychoses do not split neatly. Most social consequences occur at the prodromal stage. Neither schizophrenia as such nor its main symptom dimensions regularly show pronounced deterioration over time. Schizophrenia is neither a residual state of a neurodevelopmental disorder nor a progressing neurodegenerative process. It reflects multifactorial CNS instability, which leads to cognitive deficits and symptom exacerbations.
\end{abstract}

\section{Introduction}

For more than a century, there has been research into the question of what schizophrenia really is. We have developed an array of fascinating new research techniques and amassed a wealth of detailed knowledge, but we are still lacking a comprehensive answer to that question. Since its early days, the disease concept of schizophrenia $[1,2]$ has undergone several modifications. The aim of the present article is to describe, in broad sketches, how the understanding of the disorder has evolved to what it is now.

Comparable reviews have appeared in great numbers before, for example, by Tsuang and Faraone [3], Weinberger and Harrison [4], Andreasen [5] and the series of articles published on the occasion of the founding and the 10th and the 20th anniversaries of the journal "Schizophrenia Research." The first of the latter articles, authored by the journal's cofounder Wyatt together with Alexander, Egan, and Kirch, was entitled "Schizophrenia, Just the Facts" and appeared in 1988 [6]. Further articles carrying that title were to follow [7-11], until the series finally closed with the conclusion "The current construct. . . is in need of reconceptualization" [12].
The ensuing debate, however, prompted the authors to take a conservative stance.

\section{"Giving a new name to a common and well known disease cannot be taken lightly, as it has momen- tous clinical, legal, societal, connotative and eco- nomic implications" [13].}

This explains the authors' reluctance to reform the concept. But there is more into the issue than just finding a new name, because the fundamentals of the diagnosis itself are caught in an "intellectual crisis" [14]. We should, therefore, once more take a look at the disease concept.

In our analysis, we will concentrate on research perspectives [15-20], focusing on the epidemiological and psychopathological aspects involved in the genesis and course of the disorder and leaving therapy and neurobiological issues aside.

\section{Disease Concept and Diagnosis}

In his comprehensive description of the disorder, Emil Kraepelin termed it "dementia praecox" [1]. The Swiss psychiatrist 
Eugen Bleuler changed that name into "schizophrenia" [2], because the disorder does not have its onset exclusively early in life, nor does it invariably lead to dementia. Bleuler also rejected Kraepelin's natural-scientific disease concept, which proceeded from "natural disease entities" [21, 22].

Kraepelin's hope that psychiatric nosology could be placed on a neurobiological footing is still very much alive [23]. In the course of the preparations for the revision of the DSM-IV into the DSM-V, Hyman, prior director of the $\mathrm{NIMH}$, declared that

\section{"Mental disorders are a diverse group of brain disorders. The boundary between mental and neurological disorders is arbitrary" [24].}

Growing disillusionment in the run-up to the DSM-V prompted the NIMH in 2008 to set up a plan to "develop, for research purposes, new ways of classifying mental disorders" [25]. The thus initiated RDoC (research domain criteria) project [25] is looking for a new nosology based on neuroscience and behavioral science rather than descriptive phenomenology. In the face of the reductionism informing this endeavor, several authors have criticized the neglect of psychopathology and the deviation from the long-standing clinical tradition in the field of schizophrenia [17, 19, 20, 26-28].

Unlike Kraepelin, Eugen Bleuler ushered in psychoanalytic influences, changing the schizophrenia concept in a fundamental way. He identified ambivalence, autism, affective incongruity, and association disturbances, the "four A's," as "basic symptoms" (Grundsymptome). Delusions and hallucinations, which occur in other disorders, too, he regarded as resulting from adaptive and defensive reactions, classifying them as "accessory symptoms." Bleuler also assumed continuity between psychosis and normality (for a review see [29]). The continuity hypothesis was to play a key role in the constitution typology proposed by the German psychiatrist Kretschmer [30]. He postulated a continuum ranging from schizophrenic psychosis to schizoid personality and schizothymic character.

The early chasm between Kraepelin's categorical and Bleuler's dimensional diagnostic concepts, boiling down to the question whether they can be "clearly separated from one another or from normality" [31,32], has accompanied the debate about the schizophrenia concept until the present day.

In the 6th edition of his textbook, Kraepelin [33] introduced a new principle to the nosology of functional psychoses. He distinguished dementia praecox, because of its tendency to progressive deterioration, from manic-depressive insanity of a benign illness course leading neither to a defect state nor dementia. Even the misgivings Kraepelin [22] himself later developed about a clear-cut separability of these disorders have been unable to fully unhinge the dichotomy model [34].

In European psychiatry, Jaspers [35] distinguished two levels of gaining insight in psychiatry: the natural-scientific level of causal explaining of neurobiological processes and the psychological level of hermeneutic understanding of meaningful associations [36-38].

The phenomenology Jaspers developed following the German philosopher Edmund Husserl (1859-1938) required a pure perception of conscious phenomena. In psychopathology, that meant getting rid of any kind of personal or theoretical prejudice. A simplified version of that phenomenology, the so-called "descriptive method," became the standard approach to accessing psychopathological phenomena worldwide and has remained so until today [35, 38-40].

Jaspers [35] criticized Meynert's and Wernicke's theories, according to which all mental disorders were brain disorders, as one-sided generalizations, and called them brain mythologies. Kraepelin, who, over the course of his life, kept updating his theories from growing experience and new evidence, first regarded mental disorders, which he believed were caused by known or still unknown neuropathology, as natural disease entities-similar to Carl von Linnè's botanical species. Jaspers criticized Kraepelin's disease concept, too, because in his opinion it was biased and lacked an empirical foundation. In that respect, Kraepelin's theory was just another brain mythology. However, in order to be able to classify psychiatric disorders on the basis of precisely defined diagnoses, Kraepelin came up with a system of syndrome-course units (Syndromverlaufseinheiten) for mental disorders of unknown aetiology. It was a pragmatic way of defining disease constructs and related diagnoses. Originally, he regarded them as a temporary solution, believing that the underlying neuropathological causes would ultimately be detected. In his later works (e.g., [22]), however, he modified the theoretical foundations of his classification system.

Adolf Hitler's antisemitism forced numerous leading German and Austrian psychiatrists to emigrate. Psychoanalysts moved primarily to the USA, spreading there Sigmund Freud's theory. Wilhelm Mayer-Gross, a colleague of Karl Jaspers' at the University of Heidelberg Psychiatric Department, emigrated to Great Britain in 1933. The textbook on "Clinical Psychiatry" (1954; 2nd edn. 1960, 3rd edn. 1969) [41], which he coauthored with the psychiatrist Martin Roth and the geneticist Elliott Slater, introduced Karl Jaspers' "General Psychopathology" to British psychiatrists [42].

It was under this influence that John Wing, head of the Department of Social Psychiatry at the Institute of Psychiatry in London, and Norman Sartorius, director of the World Health Organization (WHO) Mental Health Division, laid the foundation for the WHO's international studies of schizophrenia. On the initiative of these two men, the "Present State Examination" (PSE), including CATEGO, an evaluation programme, was created as a semistandardized instrument for symptom assessment [43]. The instrument permits symptom assessment in different cultures. The PSE has now been superseded by the "Schedules for Clinical Assessment in Neuropsychiatry" (SCAN), including the CATEGO-V system, as a comprehensive tool for assessing and measuring mental illness [44].

The PSE was greatly influenced by "Clinical Psychopathology," a book authored by Jaspers' student Kurt Schneider [45]. In that book, Schneider had attempted to sharpen the schizophrenia diagnosis by discriminating between symptoms of first and second rank. He regarded the presence of one or more of the following 11 first-rank symptoms he had identified purely on the basis of clinical experience as pathogenomic for schizophrenia [46]: delusional perception, 
audible thoughts, voices arguing or discussing, voices commenting on the patient's action, thought withdrawal, thought insertion, thought broadcasting (diffusion of thought), passivity of affect, passivity of impulse, passivity of volition, and somatic passivity $[45,47]$. In contrast, only a multiple presence of second-rank symptoms would permit a diagnosis of schizophrenia.

The frequency of first-rank symptoms varies in patients with schizophrenia. In a review of 13 studies, Fenton et al. [48] reported it ranging from $24 \%$ to $72 \%$. In the WHO determinants of outcome of severe mental disorders (DOSMeD) study [49], 96\% of the probands diagnosed with the PSECATEGO instrument showed one or more symptoms of first rank. First-rank symptoms have been observed in other mental disorders, too, particularly frequently in psychotic depression [50-52].

As the first-rank symptoms included neither negative symptoms nor any course-related criteria, the schizophrenia diagnosis became restricted to psychotic illness and, hence, considerably more narrow in scope. That increased its reliability and benefited transcultural epidemiological studies and therapy research.

While in the DSM-IV and DSM-IV-TR, used by American psychiatrists, the persistence of just one first-rank symptom for more than a month was sufficient to justify a diagnosis of schizophrenia, this special significance of these symptoms has been eliminated in the DSM-V, because it has not been possible to prove their diagnostic specificity. In the DSM-V, they are treated just like other positive symptoms.

In the Kraepelinian tradition, Kurt Schneider regarded symptoms merely as preliminary signs of an as yet undetected somatic process. He adopted "endogeneity," coined by Möbius [53], as a generic term to denote the category of disorders of unknown biological origin as represented by schizophrenia. This differed considerably from the broader and less precise psychodynamic diagnoses in use in the USA.

Over the course of time, the exclusivity of categorical diagnoses became replaced by an assumption of continuity to normality and to related diagnostic groups [54-56]. Nevertheless, the categorical diagnoses continue to be used in clinical practice and are maintained in the two international classification systems. Separate categories have been introduced to denote the intermediate forms of pathology between schizophrenia and affective psychosis-for example, schizoaffective psychoses-and between psychosis and normality-for example, schizotypy and schizophreniform disorder in the International Classification of Diseases, ICD$10[57,58]$, and the Diagnostic and Statistical Manual, DSMIV $[59,60]$. These intermediate forms have permitted taking an aspect of continuity into account without having to give up the categorical nature of the diagnoses.

Several studies have demonstrated the great influence diagnostic definitions have on the incidence of schizophrenia (e.g., [61-64]).

In den USA, the birth of a psychodynamic strand of psychiatry was promoted by Hans Wolfgang Maier (18821945), a Swiss emigrant, and immigrant German psychiatrists, who helped spread psychoanalysis [46]. The differences to the psychopathology practised in Europe grew increasingly visible [65-68]. On the initiative of Zubin [69] and Kramer [65] (USA), the US-UK Study, a comparison of psychiatric diagnoses was launched. First, Gurland et al. [70] compared the diagnoses of patients who had been admitted to the Institute of Psychiatry in London and to New York State Psychiatric Institute. The proportion of patients receiving a diagnosis of schizophrenia was significantly higher in New York $[46,71]$. Then, eight conservative psychiatric interviews were rated by a group of British and a group of U.S. psychiatrists, and the result was the same [72, 73]: the diagnostic definition of schizophrenia applied by the U.S. psychiatrists was considerably broader than that used by their British colleagues $[71,73]$.

The "neo-Kraepelinian" transition in North-American psychiatry fell in the period of the US-UK study [74-80]. In a paper entitled "Establishment of diagnostic validity in psychiatric illness: its application to schizophrenia," Robins and Guze [81] published their critique of the ambiguous psychodynamic method of diagnosing. They introduced a "descriptive" approach to diagnosing psychopathological phenomena.

It was strictly on this descriptive basis that the DSMIII [82] was developed as a classification system. Although designed to be free of any theory, it, in fact, proceeded from Kurt Schneider's conservative view of psychopathology [46, 83 ] and from Kraepelin's speculative assumption "that all disorders are brain biological disorders" [84-86]. A few authors, for example, McHugh and Slavney [87, 88], continued to defend the plurality of methods professed by Jaspers in his "General Psychopathology," but with a modest success [71].

With the introduction of the restrictive diagnosis, the annual rate of first admissions with a diagnosis of schizophrenia to a university hospital in the USA fell from 25\% ( $N=$ $5143)$ in $1975-1979$ to $13 \%(N=5771)$ in $1981-1985$ [67] and at six North-American psychiatric hospitals from $27 \%$ in 1976 to $9 \%$ in 1989 [89]. Simultaneously, the figures for diagnoses from the category of affective disorders rose steeply.

\section{Epidemiology}

3.1. General Epidemiology. Schizophrenic psychosis, characterized by positive symptoms such as hallucinations, delusions, and thought disorders, is encountered in all ethnic groups, cultures, political systems, and socioeconomic classes at frequencies that show only moderate variation when based on a sufficiently reliable and culture-independent diagnosis (e.g., PSE-CATEGO).

The WHO has reported annual incidence rates for schizophrenia from different parts of the world. Figure 1 shows the results from eight study centres for a narrow (CATEGO S+) and a broad definition of the diagnosis (clinical/CATEGO S, $\mathrm{P}, \mathrm{O})$ for populations aged 15 to 54 years. The age-corrected rates based on a restrictive diagnosis, which range from 0.07 to 0.14 per 1000 population, and the much higher rates based on a broad diagnosis, which vary from 0.16 to 0.42 per 1000 population, speak for themselves [46]. The incidence data on schizophrenia collected in the ECA (Epidemiologic Catchment Area) Program in the USA by lay interviewers 


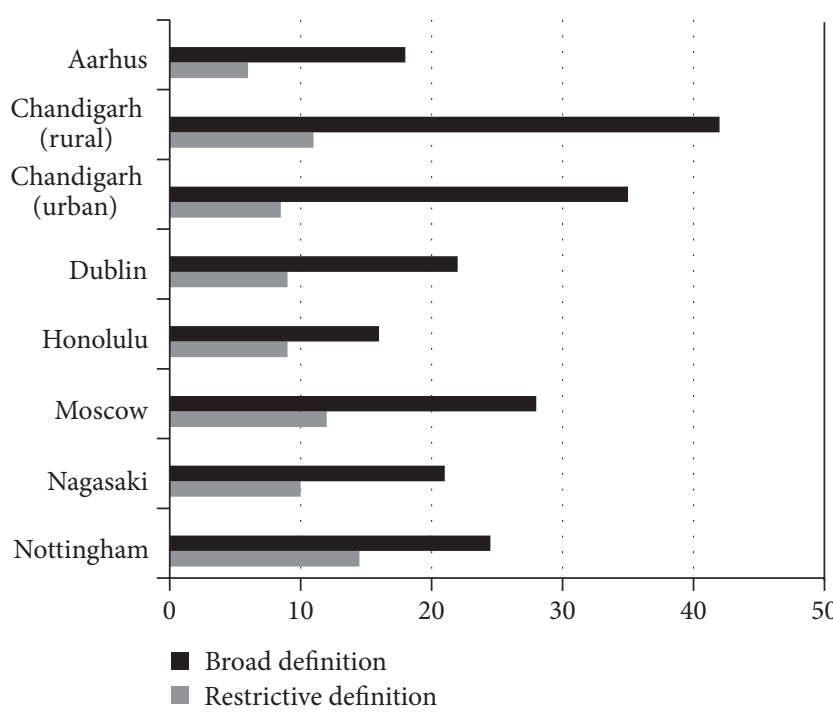

FIGURE 1: Annual incidence of schizophrenia per 100000 population aged 15-54 (both sexes) for the broad and restrictive definitions. Source: [46].

using the DIS (Diagnostic Interview Schedule) [90] yielded considerably higher age-corrected rates, which ranged from 1.0 to $1.7 / 1000$ [91]. Copeland et al. [92] have shown the weaknesses of such an approach.

Tandon et al. [9] calculated an annual incidence of 15/ 100,000 , comparable in size to the WHO rates, a point prevalence of $4.5 / 1000$ and a lifetime risk of $0.7 \%$ as-worldwide-modal rates for both sexes across all age groups.

According to McGrath \& Murray [93], Messias et al. [94], and Eaton [95], the incidence of schizophrenia has fallen considerably over time. But changes in incidence rates over lengthy periods of time are difficult to assess. Fairly comprehensive data would be needed on all new cases based on identical diagnostic definitions from sufficiently large populations not subject to any dramatic upheavals (e.g., wars). National psychiatric case registers-such as those in Denmark, Norway, and Sweden-or national health services that keep records of all persons seeking medical help-such as those in Finland, Israel, or Australia-are fairly recent creations and in place only in few countries [46]. For this reason only trends can be reported, calculated over a maximum of 150 years on the basis of the case records of individual hospitals serving defined populations over long periods of time or on data from other national registers [96-98]. No robust indication of either an increase or a decrease of any considerable size has been found [99].

In the early $1980 \mathrm{~s}$, some authors $[100,101]$ thought to have found signs of a marked increase in the incidence of schizophrenia occurring with growing civilization after the mid 19th century. But no reliable data to prove this assumption have yet emerged. In 1990, some British researchers considered it likely that schizophrenia might be dying out altogether, because schizophrenia admissions to mental hospitals in England and Wales had fallen by about $50 \%$ in the period from 1965 to 1986 [102, 103]. In that same period, however, the number of available mental-hospital beds had decreased by the same magnitude [104-106]. Demonstrating that there had been a shift to diagnoses from the affective spectrum, Kendell et al. [107] called the alleged fall in schizophrenia incidence an artefact.

\subsection{Analytical Epidemiology}

3.2.1. Geographic, Ecological, and Social Patterns of Distribution of Schizophrenia Incidence. Researchers have long been hoping to gain insight into the causes underlying schizophrenia and new approaches to its prevention and therapy by studying ecological and socioeconomic factors associated with the disorder. The first seminal project in this field was the "Ecological study of schizophrenia and other psychoses," conducted by Faris \& Dunham [108-111] and inspired by the urban sociology influential at that time in the USA (Earnest W. Burgess, Albion Woodbury-Small). The authors recorded the residential addresses of all first admissions with a diagnosis of schizophrenia or manic-depressive disorder in the period of 1922 to 1934 by means of ecological mapping in the city of Chicago. They found a close relationship between schizophrenia-clustering in almost concentric circles around the city centre-and the ecological structure of the city. The prevalence rates for schizophrenia ranged from $362 / 100,000$ population in disorganized areas near the centre of the city to $55.4 / 100,000$ population in residential areas at the outskirts. The rates for manic-depressive insanity were randomly distributed.

Further studies conducted in other large cities in the USA (e.g., [112-115]) and Europe [116-124] yielded similar results. Twenty-five years after Faris and Dunham, Levy and Rowitz $[125,126]$ again studied the ecological distribution of schizophrenia in Chicago. They found a concentric pattern of distribution for readmissions only, while first admissions with schizophrenia showed a random distribution. Accounting for this difference were structural changes undertaken in the city, for example, urban development programmes. In Detroit, Dunham [115] found a distribution pattern stable for over 20 years and very similar to that revealed by the first Chicago study. Giggs and Cooper [127] reported a concentric distribution stable over 15 years in the British city of Nottingham.

Changes in the distribution patterns of schizophrenia were also studied in a fairly large German city (Mannheim) with a population of about 330,000 in three waves over a period of 25 years [116, 117, 119, 128]. The result of the first wave (1965) was almost the same concentric distribution as in Chicago $[116,128]$. The stability of that pattern was confirmed, more or less, by the second (1975-81) [117] and the third waves (1989-90) [119]. Smaller changes across municipal districts were attributable to urban renewal programmes.

Only few investigators have found no excess rates for first admissions for schizophrenia from the centres of the cities they have studied: Clausen and Kohn [128-131] in the USA and Stein [132] and Klusmann and Angermeyer [133] in Germany.

The explanations offered for the concentric distribution patterns range from sociogenic hypotheses (e.g., [108, 134137]) to behaviour-genetic and economic forces operating 
through selective mobility (e.g., [111, 138-140]). In the city of Nottingham, Dauncey et al. [141] found that individuals with schizophrenia, as a result of their disorder, tended to remain in neighbourhoods characterized by growing poverty and a deteriorating quality of housing, while the economically more successful individuals preferred to move to better residential areas. Ödegård $[142,143]$ demonstrated that persons later falling ill with schizophrenia showed selective migration, in both geographic and occupational terms, to less attractive neighbourhoods and dying occupations, even before the onset of psychosis.

From fairly early on, research into geographical risk differences has focused on urban-rural differences. Most of these studies have reported lower incidence rates for schizophrenia in rural than urban areas, for example, from the USA, the Netherlands, Ireland, England, and Denmark [118, 143-147]. Using data from the national Danish case register, Mortensen et al. [120] and Eaton et al. [148] found a relative risk for developing schizophrenia of 2.4 and 4.2, respectively, for those born in the capital city (Copenhagen) versus rural areas. The population attributable risk of schizophrenia was $34.6 \%$ for urban birth, whereas the "genetic" population attributable risk for schizophrenia (at least one first-degree relative with a history of schizophrenia) was a mere 5.5\% because of the low number of risk gene carriers [120]. When urbanicity was broken down to five levels [121, 147]: (1) capital city (Copenhagen), (2) capital suburb, (3) provincial city, (4) provincial town, and (5) rural area, a dose-response relationship emerged: the larger the size of population of the place of birth, the higher the relative risk of falling ill with schizophrenia (1.0-2.30) [147]. The authors further demonstrated that, besides the place of birth, also the place of upbringing played a decisive role [122].

A comparison of the influence of urban and rural environment (Southeast London as an urban area and Nottinghamshire as a rural area) on five-symptom dimensions showed that, unlike negative, manic, and disorganisation symptoms, hallucinations (effect size: 0.15 ) and depression (effect size 0.21 ) were significantly more frequent in more densely populated environments [149]. In the Netherlands, according to the Netherlands Mental Health Survey and Incidence Study (NEMESIS), even mentally healthy people with subclinical psychosis-like symptoms (delusions and hallucinations) clearly experienced more of them if they had been brought up in an urban environment (either delusions or hallucinations or both: $18.6 \%$ ) compared with individuals growing up in a rural environment (14.7\%) [150].

A recently published nationwide investigation of psychiatric morbidity in Germany [151], based on four levels of urbanicity defined by population size $(<20,000, \leq 100,000$, $\leq 500,000,>500,000$ ), showed equal annual prevalence rates for psychosis in all big cities with a population of $<500,000$ (levels 1 to 3 ) (total $=2.6 \%)$. In the cities of the highest degree of urbanicity ( $>500,000$ inhabitants), the rate for psychotic disorder, at $5.2 \%$, was significantly elevated, compared with $2.5 \%$ for the lowest degree of urbanicity. Remarkably, the prevalence of mood disorders, too, was equally elevated in the highest category of urbanicity: $13.9 \%$ as against $7.8 \%$ in the lowest category [151].
Unlike the first Chicago study [108], more recent urbanecological and geographical studies have also found comparable distribution patterns for affective psychoses $[151,152]$ and major depression $[153,154]$.

To explain the variation in the risk of schizophrenia in different living environments, two hypotheses have been proposed: (1) life in big cities is more distressing and, hence, associated with a greater risk for mental illness and (2) individuals with an excess genetic risk for psychosis-for example, "schizoid" personalities with bonding problems-are more inclined to leave their families and small neighbourhoods in search for more independent and anonymous life in the city [155-159].

The increasing drift of population to urban areas in the 19th and the 20th centuries in the wake of the Industrial Revolution may have led to a slight overrepresentation of genetically vulnerable individuals among city-dwellers. The proportion of individuals with schizophrenia who have firstdegree relatives with a history of schizophrenia has been found to be slightly elevated in big cities $[122,157,160]$. Van Os et al. $[157,160]$ estimate the genetic contribution at $20 \%$ to $30 \%$.

It is not quite clear yet whether the contribution of urbanicity to schizophrenia risk $[160,161]$ is valid worldwide, because human settlements vary a lot across cultures [162].

Recently, a new approach was adopted to explain the causality. Lederbogen et al. [163] proceeded from the assumption that growing up in a city might be associated with a higher level of stress from early on compared with rural environments. In a controlled morphological and functional MRI study, the authors found that current city dwelling was associated with a significantly increased amygdala activity compared with living in a rural environment. They write that "urban upbringing affected the perigenual anterior cingulate cortex, a key region for regulation of amygdala activity, negative affect and stress." The findings were specific both regionally and behaviourally: none of the other brain structures showed comparable effects. In a control experiment involving cognitive processing without stress in solving arithmetic tasks, no such activation of the amygdala region was observed. The authors presume that vulnerability to social stress associated with urbanicity is reduced later in life. This approach to explaining the elevated rates of schizophrenia associated with urban birth and upbringing is interesting, but it needs replication.

3.2.2. Schizophrenia and Emigration. Results from the innumerable studies into the risk of schizophrenia in immigrant populations are not easy to sum up, because the populations studied and their situations in the countries of immigration vary a great deal. The reasons for immigration range from purely economic motives to severe traumatic experiences. Culturally and economically fairly well-adapted long-term immigrants differ a lot from recent refugees who have suffered traumatic experiences and losses shortly before leaving their countries of origin and are still grappling with economic hardship and acculturation in the host country. 
Ödegård's study [155] was of paradigmatic importance. He found a twofold risk for first admission for schizophrenia among Norwegian immigrants to Minnesota (USA) compared with their Norwegian countrymen. He explained it by the genetic drift hypothesis. Weiser et al. [164], who compared data for 660,000 adolescents from the Israeli National Draft Board Register and the Israeli National Hospitalization Psychiatric Case Registry, calculated a surplus rate for schizophrenia, independent of socioeconomic status, of $60 \%$ for Russian immigrants and of $300 \%$ for culturally more diverse Ethiopian immigrants. Corcoran et al. [165] studied second-generation immigrants from western Asia and North Africa as well as Europe and other industrialized countries to Israel, but could not find a significant increase in their risk for schizophrenia.

Turkish migrant workers, who had moved from Anatolia/Turkey to Germany for economic reasons, showed significantly lower incidence rates of schizophrenia, whereas their spouses and also their children showed rates that were equally high as those for the population of the host country $[166,167]$. Selection factors were presumed to be the cause: a positive self-selection of those men courageous enough to go to work in a foreign country with a foreign culture as well as a mandatory premigration health screeing at German diplomatic missions in Turkey.

The highly elevated incidence rates for schizophrenia among Afro-Caribbean immigrants to Great Britain [168176], among Surinamese immigrants to the Netherlands [177179] and among mostly Asian and African immigrants to Denmark [180] and Sweden [181], are outliers. Most of these immigrants have left their home countries for economic reasons. Reports of an even more markedly elevated incidence of schizophrenia among second- than first-generation immigrants $[170,182,183]$ make the phenomenon even more puzzling. The effects have been found to be in part sexspecific: higher rates for women immigrating from Pakistan and Bangladesh, but not for Indian women. No evidence has emerged in support of the assumption that immigrants' lower socioeconomic status in their home countries would explain their elevated schizophrenia incidence [184-186].

Studies of the incidence of schizophrenia in the immigrants' home countries, for example, in Jamaica [187], Barbados [188], Trinidad [189], and Surinam [178, 190], have yielded rates similar to those of the British or Dutch population.

Evidence has also refused to emerge for the hypotheses that traumatic childhood experiences, a more frequent substance misuse, or a greater inclination to magical thinking would explain the elevated rates of schizophrenia in immigrant populations. Social disintegration, social adversity, and neighbourhood factors have also been proposed $[154,191]$. Immigrant groups living as ethnic minorities in neighbourhoods with a predominantly native population tend to have elevated incidence rates for schizophrenia [192-197]. This also applies to second-generation immigrants. More research is needed to fully understand these phenomena.

3.2.3. Reduced Fertility of People with Schizophrenia. Since the reproductive rates of men and women with schizophrenia are consistently lower than those for the population in general, the incidence of schizophrenia should actually keep falling from generation to generation [198-210]. The lack of such intergenerational decline has been explained by a higher reproductive fitness of the affected persons' siblings [211-213]. The hypothesis has been proven wrong in large northernEuropean population and birth cohort studies, which have failed to produce any evidence in support of significantly higher fertility rates for nonaffected twins or siblings [206, 207, 209].

Modern genetic research helps understand why the reduced fertility rates do not have any effect on incidence. Schizophrenia, for the overwhelming part, is transmitted by genes that account merely for a small share, mostly less than $1.3 \%$, in the overall risk for the disorder [214]. The reproductive failure of affected persons is probably negligible in comparison with the large number of healthy individuals also carrying those risk genes.

\section{Genetics}

Schizophrenia is a heterogeneous and complex neuropsychiatric disorder, whose etiology involves both environmental and genetic factors. In individual cases, the relative contribution of genetic and environmental factors is impossible to ascertain.

Numerous studies have investigated the role of environmental factors in schizophrenia. Established environmental risk factors include pre-, peri-, and early postnatal complications [215-217]; viral infections in childhood [218]; childhood meningitis [219, 220]; being born and growing up in an urban environment [120-122, 179]; immigrant status [170, 173, 221]; substance misuse; and other determinants of mild cerebral dysfunction. Other possible, but still contentious, environmental risk factors are winter birth, prenatal exposure to influenza epidemics, and maternal malnutrition during the second trimester of pregnancy. To date, however, research has failed to identify any environmental factors that increase the risk of schizophrenia by more than a few percentage points.

Multiple formal genetic studies have demonstrated the contribution of genetic factors to schizophrenia risk. These investigations have applied twin (e.g., [222-229]), family (e.g., [230-236]), and adoption approaches [237, 238]. Estimated heritability (i.e., the proportion of variance due to genetic factors) is around 0.8 [234]. The lifetime schizophrenia risk of first degree relatives shows a 5-10-fold increase compared to that observed in the general population (lifetime prevalence $1 \%$ ). However, although some clinical features of schizophrenia (e.g., age at onset, disease course, and degree of impairment) display high familiality (e.g., [239]), the relatives of individuals with schizophrenia also show elevated rates of schizoaffective psychosis, bipolar affective disorder, and major depressive disorder [232, 240, 241]. This indicates that schizophrenia cannot be conceptualized as a homogeneously-transmitted clinical entity [242].

Over the past decade, advances in genomic technology, in particular the advent of genome-wide association studies (GWAS), have led to the identification of a substantial 
number of genetic risk variants for schizophrenia [243]. The number of identified independent risk loci, which is already above 100 [244], continues to increase. At the time of writing, research has implicated around 6,000 to 10,000 common variants in the aetiology of schizophrenia [243]. GWAS have identified long known candidate genes such as genes with an involvement in glutamatergic and dopaminergic neurotransmission, thus, providing independent support for the long-standing hypothesis that these pathways are involved in schizophrenia development. The most consistently implicated locus is the HLA region. This finding is consistent with the hypothesis that infectious/immunological mechanisms underlie a proportion of schizophrenia cases. However, most of the loci identified in molecular-genetic studies to date are novel, and these findings will guide further multidisciplinary research into neuronal pathology.

GWAS are designed to identify common risk variants with allele frequencies of $>1 \%$. They involve the use of genomic markers, that is, several-hundred-thousand to millions of single nucleotide polymorphisms (SNPs). These nucleotides are evenly dispersed across the genome, and show interindividual variation. As in other complex disorders large samples are necessary to achieve genome-wide significance, and the most recent GWAS meta-analysis for schizophrenia involved more than 35,000 patients [244]. Given the large amount of markers tested, the significance threshold is very low $\left(5 \times 10^{-8}\right)$, and it has been shown that many more SNPs not reaching the threshold level contribute to the disorder. The identified risk SNPs are also quite common in the general population, and each accounts for only a small proportion (normally below 1.3\%) of the risk for schizophrenia [214].

An approach to refine such association findings is the investigation of genotype-endophenotype correlations. Research suggests that association with an endophenotype is stronger than with a heterogeneous entity, such as a categorical diagnosis [245]. A host of successful reverse genetic studies have been published, in particular imaging genetic studies, which explore the correlation between the identified risk variant and endophenotypes that have been assessed through neuropsychological and fMRI examination. A review of the results of these studies is beyond the scope of the present chapter. However, an example may serve to illustrate the reverse genetic approach. For the first genome-wide significant variant identified for schizophrenia, that is, in the gene ZNF804A, an imaging genetic study demonstrated alterations in the functional coupling of the dorsolateral prefrontal cortex (DLPFC) across hemispheres in risk-variant carriers [246]. This finding attracted much attention and led to the performance of numerous follow-up studies. While this effect was replicated in subsequent studies, others found associations with further endophenotpyes [247]. Until they are replicated, researchers cannot be sure whether the latter indicate pleiotropy (i.e., the phenomenon whereby one variant causes diverse phenotypic effects) or whether they represent chance findings. Meanwhile, large international research consortia merge their GWAS and imaging data, and these genotype-endophenotype data are made available to the public (http://www.brainmapping.org/NITP/images/ Summer2012Slides/ENIGMA-Thompson.pdf), an approach which will facilitate multidisciplinary research into schizophrenia and other neuropsychiatric disorders.

To optimize exploitation of GWAS data and improve upon the "single phenotype-single variant" analysis approach, researchers have developed a range of more sophisticated biostatistical methods. Two examples, both of which examine the joint effect of SNPs, are (i) polygenic score analysis [248] and (ii) genome complex trait analysis (GCTA) [249]. Polygenic score analysis uses sets of top risk, SNPs (above and below the threshold for genome wide significance), from a "discovery" GWAS in order to generate risk-scores in individuals from independent "target" samples. This allows testing whether individuals with higher risk scores differ from those with lower risk scores and, if so, in which particular phenotypic dimensions. The GCTA approach estimates the variance for a complex trait, as explained by all SNPs. Since it is based on the assumption of an additive model, GCTA does not account for gene-gene interactions. The GCTA approach is used to investigate SNP-based genetic overlap between phenotypes/disorders.

In accordance with the hypothesis that schizophrenia is a polygenic disorder, the novel biostatistical approaches have shown that common, yet unidentified, SNPs explain approximately $30 \%$ of the total variation in schizophrenia susceptibility. These methods have generated a multitude of other interesting results. These findings include evidence, for example: (i) a significant enrichment of risk variants in brain genes; (ii) distribution of the risk variants across the entire genome [243, 250]; (iii) no major differences between men and women in the genetic variance for schizophrenia [250]; (iv) a high correlation between schizophrenia and bipolar disorder, a moderate correlation between schizophrenia and major depression, and a low correlation between schizophrenia and autism spectrum disorders [251]; and (v) a correlation in schizophrenia patients between a higher schizophrenia risk score and a more severe disease course [252]. Furthermore, these approaches have demonstrated that individuals from the general population with higher schizophrenia risk scores had lower cognitive abilities and that schizophrenia patients had higher "poor cognitive performance" scores, as based on GWAS data on cognitive performance [253].

The heritability estimate from formal genetic studies is more than twice as high as the variance explained by common variants. This raises the issue of how the "missing" heritability can be explained. One possibility is that since the methods do not consider gene-gene interactions, this approach underestimates the genetic contribution. A further likely possibility is that many rare variants with moderate-to-large effects still await identification. The first genome-wide exome sequencing studies have already been published, and this approach may uncover many more of these rare variants [254].

Some rare variants with larger effects have already been identified. These are mainly structural variants, so-called copy number variants (CNVs) (microdeletions and/or duplications of thousands to millions of DNA bases).

Although these are relatively potent risk factors for schizophrenia, they are not specific to schizophrenia; they also 
enhance the risk for other mental disorders, such as autism, bipolar affective psychosis, major depression, and personality disorder. Despite being extremely rare, the implicated single CNVs are found in $4 \%$ to $5 \%$ of individuals with schizophrenia. Hence, their aggregate contribution to schizophrenia is substantial $[255,256]$.

In a recent genetic-epidemiological study [257] investigated $26 \mathrm{CNVs}$ with a reported association with schizophrenia or autism in order to determine whether cognitive deficits and brain morphological changes were also present in mentally healthy carriers. The investigated variants were relatively rare. They occurred at frequencies of $0.002 \%$ to $0.2 \%$ and showed a combined prevalence of $1.6 \%$ in the investigated population, and some of the CNVs were associated with reduced fecundity. The authors demonstrated an association between the investigated CNVs and cognitive test outcomes that ranked between those for schizophrenia cases and healthy population controls. Different CNVs were associated with different cognitive domains. Non-mentally ill carriers of the 15q11.2 (BP1-BP2) showed a history of dyslexia and dyscalculia rather than any other discernible cognitive autonomous.

In conclusion, GWAS of schizophrenia have generated important findings, and these have opened up a diversity of novel avenues for multidisciplinary research. Experts in the field are hopeful that increasing biostatistical sophistication, refinement of neuropsychiatric phenotypes, and the application of convergent approaches (integrating results from expression, pathway, epigenetic, and animal studies) will lead to genuine breakthroughs in our understanding of the molecular-genetic background of this devastating disorder. Important goals for future schizophrenia research are the establishment of a verifiable genetic model and the identification of robust biomarkers. The array of results generated through molecular-genetic research to date thus represents a complex and intriguing puzzle which still awaits resolution in order to translate findings to the benefit of patients.

\section{From Predisposition to Manifest Illness}

5.1. Risk Factors, Precursors, and Precipitants of Psychosis. Factors at work before the onset of schizophrenia enhance the risk for it. The most frequent risk factor predisposing for schizophrenia is genetic in nature, but environmental factors, too, as discussed above, play a role [93, 94, 258-260]. Such factors are pre- or perinatal brain injury, mostly due to anoxia [217, 261], viral childhood encephalitis [218], infant bacterial meningitis [219], and, to a lesser extent, other factors impacting the development of the central nervous system. Most of these factors, however, have been found to increase the risk not only for schizophrenia, but also for other mental disorders: affective psychosis, autism, intellectual deficits, neurological symptoms, and epilepsy [217-220, 262, 263].

Probands with a predisposition for schizophrenia, for example, offspring of women with schizophrenia or carriers of risk genes [264], have elevated rates of neurointegrative deficits and cognitive [265] and social impairment as well as an earlier onset of schizophrenia [233, 266-280]. An increased genetic vulnerability has frequently been found to be a precondition for the risk-enhancing effect of environmental factors [93, 281].

Predisposition factors increase the lifetime risk. They must be distinguished from exogenous precipitants capable of triggering the onset of manifest episodes. One such precipitant of health-policy relevance is the misuse of cannabis and other psychoactive substances, for example, amphetamine combinations [282, 283], cocaine and psychomimetics such as phencyclidine [284], psilocybine, and LSD. These substances can provoke a short-term intoxication psychosis, which usually remits as soon as the substance in question is excreted from the body. But they may also trigger an autonomous course of schizophrenia [285-293]. A long-term use of cannabis may also have adverse effects, as shown in a study with the longest observation period yet, 34 years (19732007), in a sample of 50,087 Swedish conscripts with data on cannabis use at the ages of 18 to 20 years [293]. The authors identified 357 cases of schizophrenia from in-patient care and followed them up from 1973 to 2007. Patients with a history of cannabis use at baseline had a more unfavourable illness course compared with nonusers in terms of a significantly higher frequency of both readmissions to hospital and hospital stays lasting for 2 years or more.

5.2. Individual Development from Birth to Psychosis. Progression from birth to psychosis onset has been studied intensively. In two British studies-the National Survey of Health and Development (NSHD) study ( $N=5362$ ) [294-296] and the National Child Development Study (NCDS) $(N=$ 15.398) [297] - persons later developing schizophrenia were followed up from birth to adult age. The same was done in the New-Zealand Dunedin Study [217, 298, 299] and the northern-Finland birth cohort study [262, 263, 300-302]. Compared with controls, the probands in these and comparable studies consistently showed mild developmental delays in their first years of life [217, 269, 270, 295, 303, 304], mild deficits in cognitive and social functioning, and minor neuromotor deficits in infancy, childhood, and adolescence [275, 299]. Like genetic vulnerability, these early antecedents also enhanced the risk for affective and other mental disorders [305-307].

Studies based on male Swedish adolescent conscripts (aged 18-20 years) [308, 309] and Israeli conscripts, both male and female (aged 16-17 years) [310, 311], have identified further risk factors. All inpatient admissions for schizophrenia during the period of risk were counted on data from the national psychiatric case registers at 15-year follow-up in the Swedish study and at 4- to 15 -year follow-up in the Israeli study.

The Swedish conscripts who later developed schizophrenia showed, on average, a slightly lower IQ and a significantly higher frequency of four behavioural items: "having fewer than two friends," "preference for socializing in small groups," "feeling more sensitive than others," and "not having a steady girlfriend." $3 \%$ of the conscripts who endorsed all four items went on to develop schizophrenia in the 15-year period [309]. Because these behavioural items were also quite prevalent in 
the same-age Swedish male population who did not develop schizophrenia, their population-based predictive power was not very high. In the Israeli study, mild cognitive deficitsabout 0.5 standard deviation - and indicators of social autonoimpairment turned out to predict schizophrenia incidence [310], but interindividual variance was considerable. There have also been reports of schizophrenia being associated with above-average intelligence [263, 312].

A further risk factor for schizophrenia as well as for bipolar disorder, mental retardation and autism spectrum disorder, is a higher paternal age ( $\geq 30$ years) [313-318], confirmed in several birth cohort studies, record-linkage analyses, and large collectives [314, 319]. In a meta-analysis, Miller et al. [320] estimated a 3.1-fold excess risk up to a paternal age of 55 years. The factor accounting for this phenomenon is presumed to be an age-related increase in de novo mutations in paternal sperm [321]. But a low paternal age (below 18 years), too, seems to increase the risk for schizophrenia in the offspring [318].

In a recent study, Jaffe et al. [319] studied 371 families with at least two children, of whom at least one had developed schizophrenia. The authors found that an increase in schizophrenia risk was associated with a significantly higher paternal age at the time when the first child was born-a similar finding had previously been reported by Petersen et al. [322] on data from the Danish case register. A higher maternal age was associated with a higher rate of pre- and perinatal complications in the offspring diagnosed with schizophrenia. This finding slightly weakens the etiological relevance of paternal de novo mutations.

To sum up, like the genetic risk factors, each of the exogenous factors discussed accounts only for a small share in the risk for schizophrenia and other mental disorders, such as affective psychosis, autism, and learning disability.

5.3. Subclinical Symptoms as Precursors of Psychosis. In about $2 / 3$ of cases, transition from mental health to psychosis takes more than a year. It is characterized by the onset of symptoms and aberrant behaviour, eventually culminating in the climax of the first illness episode [323]. Highly acute transitions, within four weeks or less, are much rarer; in the sample of the German Age Beginning Course (ABC) Schizophrenia Study it was the case only in $18 \%$ [323].

Isolated subclinical psychosis-like symptoms frequently occur as precursors at the beginning of the prodromal stage. Subclinical psychotic-like symptoms (delusions and hallucinations), affective and negative symptoms and signs of cognitive impairment are also prevalent in individuals without a history of psychotic illness in the general population [161, 324-328]. In the population-based Netherlands Mental Health Survey and Incidence Study (NEMESIS) the prevalence of isolated psychotic symptoms in the population aged 18 to 64 years was $4.2 \%$ for definite delusions and hallucinations and $17.5 \%$ for all such, including uncertain, symptoms $[329,330]$. In the German population-based Early Developmental Stages of Psychopathology (EDSP) study of young adults (age 14 to 24 years), the prevalence of hallucinations was $4.6 \%$ and that of delusions was $15.7 \%$ (definite or probable) $[331]$.
In a New-Zealand birth cohort study, $25 \%$ of the children who, at age 9 to 11 years, had experienced hallucinatory symptoms had a 16-fold excess risk of developing psychotic illness by age 26 years [298]. In the Dutch NEMESIS study, $8 \%$ of the adults (aged 18-64 years) who had experienced subclinical hallucinations developed clinical psychosis within two years, which corresponded to an excess risk of about $60 \%$ compared with symptom-free controls [161, 332, 333]. In the German EDSP study, in which probands initially aged 14 to 17 years were assessed four times over a period of 8.4 years, transitions to psychosis depended, in a dose-response relationship, on the persistence of subclinical psychotic symptoms at the follow-up assessments over the first five years: persistence at one measurement was associated with an odds ratio (OR) of 1.5, at two measurements with an OR of 5.0 and at all three measurements with an OR of 9.9 [334].

Multiple subclinical symptoms increase the risk for clinical psychosis: in the Dutch study, $3 \%$ of the probands who had experienced a single psychotic symptom developed clinical psychosis within two years, whereas $14 \%$ of those with two symptoms and $20 \%$ of those with three symptoms did so [335].

Several studies have addressed the question of how long the risk of transiting to psychosis persists, after characteristic subclinical symptoms have manifested themselves [328, 336, 337]. Most studies on the topic have looked at risk periods of one year [328] and only few studies at periods of two or more years [336]. In a systematic review of 35 cohort studies with follow-up periods of up to 20 years, van Os et al. [161] found that, after the first year, the frequency of transitions decreased by $10 \%$ and after 20 years by a total of $25 \%$ (cumulatively). The overwhelming majority of the subclinical symptoms either remitted or persisted without progressing to psychosis [161, 325].

The risks associated with the different symptom dimensions of schizophrenia have recently been placed at the centre of interest. Lyne et al. [338] studied the predictive specificity of prodromal negative symptoms. The authors found a significant increase in these symptoms after first admission, while the symptoms of the other dimensions showed no increase. Other studies have indicated that a decrease or an increase in subclinical affective symptoms and anxiety at the prodromal stage in persons also experiencing subclinical hallucinatory symptoms is associated with a significant decrease or increase in transitions to clinical psychosis $[326,339,340]$. Obviously, there is a functional association between the affective and the psychotic symptom dimension at the prodromal stage.

A different picture emerges when, instead of representative population samples, probands at ultra-high risk for schizophrenia are studied. Klosterkötter et al. [341, 342], using the Bonn Scale for the Assessment of Basic Symptoms (BSABS) [343], assessed the presence of "basic symptoms" in 160 hospitalized patients suspected of suffering from schizophrenia and checked their diagnoses in their medical records at follow-up an average of 9.6 years later. The basic symptoms yielded correct predictions in $78.1 \%$ and falsepositive predictions in $20.6 \%$ of the cases. In this study, too, risk assessment was done fairly close to the timepoint of maximum risk. 
As part of the North-American Prodrome Longitudinal Study (NAPLS) [344], 291 help-seeking persons were identified as high-risk cases by means of an early-recognition instrument [337]. At follow-up 6 months later $12.7 \%$, at 12 months $21.7 \%$ (cumulative), at 18 months $26.8 \%$, and at 24 months $35.3 \%$ of the patients had developed a psychosis. Over the 30-month follow-up period, the transition rate decelerated continuously by $13 \%, 9 \%, 5 \%, 5 \%$, and $2.7 \%$. No transitions to psychosis occurred among healthy controls [337].

The cumulative transition rates calculated in a recent meta-analysis [345] based on 2502 (clinical) high-risk and ultra-high-risk [346] individuals from 27 studies from different countries were $18 \%$ at 6-month follow-up, $22 \%$ at 1 year, $29 \%$ at 2 years, $32 \%$ at 3 years, and $36 \%$ after 3 years [ 346,347$]$. This meta-analysis, however, has considerable weaknesses. Because the transition rates calculated in the studies included in the analysis varied a great deal (from $0.09 \%$ to $79 \%$ ), as did the study populations in size (from 9 to 365 persons) and the baseline risk status of the probands examined (randomly selected population cohorts versus inpatient admissions for suspected schizophrenia), the results should be taken with caution.

To conclude, the research discussed indicates that a maximum of transitions occurs quite soon after a high-risk status has been established and that, with increasing time, transitions become rarer. In most cases, subclinical psychosislike symptoms either remit fully or continue to persist without further progression.

\section{The Clinical Symptoms of Schizophrenia}

The three characteristic syndromes of schizophrenia, which, though in different degrees, manifest themselves in the prodromal phase and sometimes even before that, comprise psychotic or positive symptoms, a variety of negative symptoms, and a repertoire of subjectively experienced and objectively identifiable thought disorders. Further symptoms are cognitive disturbances in a stricter sense, disintegrative symptoms, and affective disturbances, depression in particular-the latter were ignored in the past and sometimes still are todayand an array of individually heterogeneous forms of aberrant experiences and behaviours.

Numerous attempts have been made to establish the empirical symptom structure of schizophrenia [348-354]. Factor-analytical approaches have yielded only partly comparable results, for example, five-factor solutions resembling the five sections of the Scale for the Assessment of Negative Symptoms (SANS) [355, 356]. Two- and three-factor solutions, too, have been proposed [354, 357-359]. The threefactor model presented by Liddle and Barnes [348] enjoys wide acceptance: "reality distortion" is more or less equivalent to positive symptoms and "psychomotor poverty" to negative symptoms, whereas "disintegration" includes an overload of acute and chronic symptoms [360]. A depression factor was not detected until the assessment tools were expanded to permit screening for other than positive and negative symptoms [361-366].
6.1. Negative Symptoms and Cognitive Impairment. The negative symptoms of psychosis reflect deficits in cognitive functioning, in experience of pleasure and interest, in motivation and engagement in the world [367-369]. A broad definition like that makes it difficult to distinguish between a negative syndrome and cognitive deficits, although, according to Harvey et al. [370], Nuechterlein et al. [371], and Blanchard et al. [368], they are "separable domains of illness." According to Goldberg et al. [372] and Nuechterlein et al. [371], "cognitive factors are core features of schizophrenia" [371]. They consider schizophrenia a cognitive disorder. Keefe [373] even suggested including cognitive impairment as a diagnostic criterion for schizophrenia in the DSM-V [374]. The suggestion triggered a lively debate [375], because comparable cognitive deficits are also encountered in other mental disorders [274, 376].

A fact common to both syndromes is that despite more than a century of schizophrenia research there are very few treatments, if any, that have proven efficacious [377]. Since both involve functional impairment in course and outcome [377] and deficits in social cognition play a crucial role in everyday functioning [371], negative symptoms and cognitive impairment have been placed at the centre of interest in therapy research and efforts to develop new treatments, though without much success yet [371, 378-385].

Cognitive deficits and negative symptoms can be operationally distinguished from one another by neuropsychological tests that measure cognitive functioning. Reduced to a lack of pleasure and motivation, the negative syndrome can be ascertained primarily by the observation of behaviour and by self-rating [367, 369].

Since both phenomena are characterized mainly by diminution or lack of normal functions and are difficult to distinguish clearly in phenomenological terms, they are usually treated as one category in clinical practice, which is a drawback both to research and therapy trials and to targeted training measures.

Prevalence rates for negative symptoms ranging from $50 \%$ to $90 \%$ at the climax of the first episode and at first admission have been reported [386-389]. With the remission of the first episode, negative symptoms, too, decrease to rates varying from $35 \%$ to $70 \%$ [389-392]. Depending on the initial diagnosis, some $15 \%$ to $40 \%$ of patients with schizophrenia never develop any negative symptoms [393].

It is an established fact that both cognitive deficits and negative symptoms run a stable course after the first psychotic episode [274, 371, 378, 382, 394-396].

In the 2010 Australian National Psychosis Survey, which included all persons ever diagnosed with and treated for schizophrenia, patients' mean IQ was, regardless of their duration of illness, 0.5 standard deviation below that of the general population [397]. Comparisons of cognitive function profiles between patients and healthy controls have shown that only few deficits, that is, impairment in attention, memory, and executive functioning, are clearly attributable to schizophrenia [354, 377, 398, 399].

Elevated rates of cognitive deficits have also been observed in first-degree relatives of people with schizophrenia [400-402]. As the population-cohort and the conscript 
studies cited showed, they are measurable already at the prodromal stage $[308,309,333,371,403,404]$. The birth cohort studies $[273,299,301,302,391,394]$ and the Israeli [311, $404,405]$ and the Swedish $[308,309]$ conscript studies have demonstrated that minor delays in cognitive development and/or deficits in academic attainment and verbal skills are already manifest in childhood and adolescence in individuals later developing schizophrenia.

No reliable body of evidence has turned up either from methodologically sound cross-sectional comparisons of patients at first admission and after long histories of illness or from longitudinal studies for the notion that cognitive deficits progress during the illness course [371, 403, 406]. Negative symptoms clearly increase in prevalence and severity only in the prodromal phase $[323,407]$. In the further course of the disorder they have been found to increase only in a small proportion of patients $[408,409]$.

During the run-up to the revision of the DSM-IV to DSM-V, it was intensively debated whether cognitive impairment should be included as a diagnostic criterion for schizophrenia [410]. It was decided not to do so, because cognitive deficits have not been found to sufficiently distinguish between schizophrenia and several other "boundary" disorders. In the course of that revision, the subtypes of schizophrenia dating back to Kraepelin were removed from the DSM-V and replaced by empirically founded psychopathological dimensions with cognitive impairment included as one such dimension [410].

6.1.1. Types of Negative Symptoms. A distinction has been drawn between primary and secondary negative symptoms [411]. The secondary negative syndrome [412] has been explained as representing a corollary of depression, substance abuse, and side-effects of neuroleptic medications [413, 414]. The primary or "deficit" syndrome has been presumed to originate in the disease process itself, to be independent of environmental factors, to have a persistent course, and not to be amenable to therapy $[385,415]$. The deficit syndrome described by Wing \& Brown [416] as secondary impairment is caused by social and cognitive deprivation during long hospital stays.

In the long-term illness course, the symptom complexes of abulia-apathy and anhedonia-asociality have proven to be the most stable components of the negative syndrome [407, $417,418]$.

The increased risk of schizophrenia associated with minor early brain lesions, the lifelong persistence of cognitive impairment, and findings from morphological MRI studies have prompted some authors to conclude that schizophrenia is a neurodevelopmental disorder [419-423]. According to Crow [424], the hypothesis applied only to one of the two subtypes of schizophrenia he postulated. Type I, characterized by positive symptoms, an acute and benign illness course, he presumed, was attributable to dopamine dysfunction. Type 2, characterized by negative symptoms, cognitive impairment, and a poor, often chronic illness course, he saw as a neurodevelopmental disorder exogenously caused by pre- and/or perinatal brain damage. However, the hypothesis could not be verified [425].
6.1.2. The Assessment of Negative Symptoms. The Scale for the Assessment of Negative Symptoms (SANS), developed by Andreasen [355], comprises the following five sections:

(1) Affective Flattening or Blunting

(2) Alogia

(3) Avolition-Apathy

(4) Anhedonia-Asociality

(5) Attention.

It is used worldwide for measuring negative symptoms. It is included in the Positive and Negative Symptom Scale for Schizophrenia (PANSS) [426], which permits the assessment of other symptoms, too.

In 2006, a conference at the National Institute of Mental Health (NIMH) adopted a "Consensus Statement on Negative Symptoms" [427] and initiated the development of a "nextgeneration negative symptoms scale," the Clinical Assessment Instrument for Negative Symptoms (CAINS) $[428,429]$ as an NIMH project. The CAINS, now completed, has been designed to ensure a reliable assessment of negative symptoms. Included in it are the following five domains: asociality, avolition, anhedonia, blunted affect, and alogia, and, thus, most of the SANS items.

First trials have been run with satisfactory results. They have shown "that amotivation and avolition-and, thus, negative symptoms-constitute the core deficits in schizophrenia" [398]. Conclusive evidence is still lacking that the CAINS permits more valid measurements of negative symptoms to replace the SANS.

In rare studies, negative symptoms have been found to be weakly correlated with positive symptoms. There is no consistent evidence showing that cognitive impairment and psychotic symptoms are associated with each other. Psychosis frequently involves cognitive deficits, but the two symptom dimensions evolve independently over time [360, 403, 430432]. Cognitive deficits are not specific for schizophrenia. They also occur in other mental disorders, for example, severe mood disorders [433], and in mild psychoorganic syndromes.

\section{The Prodromal Stage of Psychosis}

With the aim of creating the preconditions for therapeutic early intervention, Sullivan [434] and Cameron [435] attempted a systematic analysis of the prodromal stage of schizophrenia, but with little success. Conrad [436] later proposed a stage model based on gestaltpsychologie and Docherty et al. [437] a psychodynamically influenced stage model of incipient schizophrenia. Neither Docherty et al's nor Conrad's model has been confirmed on empirical data, apart from a prepsychotic stage (trema) turning out to be distinguishable from a psychotic (apopheny) prodromal stage $[350,438,439]$.

An array of studies have recently investigated the prodromal phase of schizophrenia with regard to both the time involved (course) and its nature (symptoms) (e.g., [323, 327, $341,342,350,440-452])$. The first symptoms to appear-apart from mild cognitive deficits frequently preceding them-are 
mostly depression and anxiety, followed by negative symptoms and, finally, by rapidly accumulating positive symptoms [323]. The so-called prepsychotic prodrome, from the onset of the first symptom to the onset of the first psychotic symptom, takes, on average, several years to unfold. In the ABC Schizophrenia Study, its mean duration was 4.8 years (median 2.3) [323]. A psychotic prodromal stage, counted from the onset of the first (new) psychotic symptom to the climax of the first episode, defined by maximum symptom prevalence, had a mean duration of 1.1 years (median 0.6 years) and, when the 0.2 months until first admission were included, a total duration of 1.3 years (median 0.8 years) [323].

Type and temporal sequence of prodromal symptom manifestation are very similar in major depressive disorder and schizophrenia. The two disorders become diagnostically distinguishable only with the onset of and a steep increase in psychotic symptoms in the cases transiting to psychosis [453].

This finding has theoretical implications for the disease concept of schizophrenia. It is conceivable to assume a preformed sequence of the two syndromes, in which the affective syndrome represents the expression of milder neural dysfunction and the psychotic syndrome considerably more severe dysfunction $[60,453]$.

Prodromal depression has consequences. Patients experiencing prodromal depression develop more positive and depressive symptoms in the first psychotic episode, but this excess symptomatology soon levels off in the further (1to 2-year) illness course [444]. Patients without prodromal depression tend to develop significantly more negative symptoms, almost exclusively affective blunting, in the first episode and medium-term (5-year) course, [444]. The reason could be reduced emotional responsiveness either caused by the disorder or representing a personality trait.

The duration of untreated psychosis (DUP) $[454,455]$ has turned out be a predictor of the illness course. A lengthy DUP is associated with a more severe first episode, with a greater amount of adverse social consequences, more inpatient days and higher costs, and so forth [440, 454-461]. Whether it is also associated with a greater number of relapses, as presumed by Altamura et al. [462], is not yet clear. More longitudinal studies on the topic are needed.

An extended duration of untreated illness (DUI), characterized primarily by depressive and negative symptoms and functional impairment, is mainly associated with more negative symptoms and social impairment in the further illness course [461].

DUP and DUI are determined by the availability of mental health services and by patients' help-seeking behaviour $[459,463]$. Cognitive deficits, which can be ascertained by neuropsychological tests, are independent of the prodromal symptoms of psychosis and, thus, not affected by DUP [464].

Some of these findings lie behind the speculative theory that psychotic symptoms might exert a toxic impact on the brain and that that effect can be warded off by antipsychotic medication, for example, olanzapine, if administered early enough [465-469]. The toxicity hypothesis has not been confirmed, but the insight is still prevailing that early intervention is worthwhile pursuing.
Given the chances offered by early intervention to benignly influence the onset and course of schizophrenia, the idea was entertained during the revision of the DSM-IV to include an "attenuated psychosis syndrome" as an indicator of the schizophrenia prodrome in the diagnosis of schizophrenia in Section 1 of the DSM-V [470]. After an intensive discussion, the idea was dismissed because of the fairly low rates of transition to psychosis, the high risk of transition to other types of mental disorder, and the fairly high rates of remission. Instead, attenuated psychosis syndrome has been integrated as a diagnostic category in Section 3 (Appendix) of the DSM-V [471].

7.1. Early Intervention. Early intervention at the psychotic prodromal stage should be targeted not only at the persisting prepsychotic symptoms, but also at functional impairment and newly appearing positive symptoms. Most earlyintervention trials [442, 472-477] have tested combinations of psychological treatment, mostly cognitive behavioural therapy [478-483], and a low-dose neuroleptic medication $[474,475]$. Compared with controls, significantly fewer probands have been found to transit to full-blown psychosis over one or two years. Psychological intervention without neuroleptic medication, tested on high-risk probands, has also turned out to be effective in significantly postponing transition to psychosis $[479,484]$.

\section{Schizophrenia and Depression}

In a review of literature, Bartels \& Drake [485] reported prevalence rates for depressive symptoms in manifest schizophrenia ranging from $20 \%$ to $70 \%$. According to another review, the rates vary from $6 \%$ to $75 \%$ [486]. Reasons for the great discrepancy are differences in study designs, for example, whether single depressive symptoms, syndromes, or diagnoses are used for calculating point or period prevalences.

As mentioned, Emil Kraepelin himself ultimately came to question the validity of the dichotomy hypothesis [22]. And indeed there is reason for doubt. Kendell and Brockington [54] showed that continuity exists and no "point of rarity" can be found between schizophrenia and mood disorders at the symptom level. Anxiety, depressive mood, and excessive worrying are the most frequent initial symptoms in schizophrenic psychosis [450, 453]. In the ABC Schizophrenia study, around $85 \%$ of the probands experienced one or more episodes of depressive mood for at least two weeks [453, 487]. Furthermore, depressive mood is the most frequent symptom in the entire course of schizophrenia $[453,487]$.

\section{The Influence of Age and Sex on Symptom Manifestation}

9.1. Sex Difference in Age at Onset. Schizophrenia, as based on the ICD-10 or DSM-IV diagnosis, manifests itself primarily in adolescence and at early adult age. Kraepelin had already observed an age difference of several years between men and women at first admission for dementia praecox [488, 489]. This also applies to age at first-ever onset, as confirmed in 


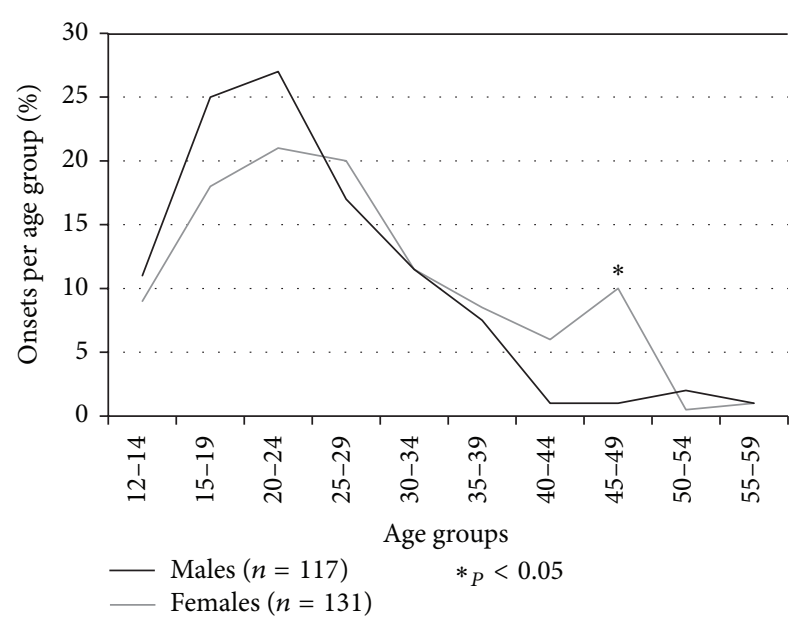

FIgURE 2: Age distribution of schizophrenia onsets of a broad diagnostic definition (ICD-9: 295, 297, 298.3, 298.4) for men and women. Source: [494].

numerous studies [490-492] and described by Castle [493] as "universally accepted."

In the ABC study sample of patients with first-ever admission with schizophrenia of either a broad or restricted diagnostic definition (ICD-9), the patients were compared with age- and sex-matched healthy controls from the same catchment area-male patients showed a peak of illness onsets at age 15 to 24 years and, hence, earlier than female patients did [494]. After that peak the rates fell to a low plateau. The first peak of female onsets was lower and occurred somewhat later, at age 15 to 29 years. After a decline similar to that in the male rates, a second peak, narrower and lower than the first one, occurred at age 45 to 49 years, again followed by a decline [494] (Figure 2).

The mean age difference, calculated both for a restricted and broad diagnosis, was 3 to 4 years [323, 495]. Data from the national Danish case register, analysed using the same study design, yielded almost identical values, thus, confirming the finding $[495,496]$.

A recent meta-analysis looked into the sex difference on the basis of 46 studies published in English-language journals between 1987 and 2009 [497]. The definitions of onset used in the studies differed. The diagnoses were based on the ICD9 and its later versions or the DSM-III and its later versions. The age differences found were considerably smaller: women's mean age was 1.63 years higher at first-ever sign of schizophrenia, 1.48 years higher at first psychotic symptom, 1.22 years higher at first contact, and 1.07 years higher at first admission to inpatient care. The DSM-based diagnoses yielded slightly higher age differences compared to the ICD diagnoses. The age difference attained significance only in developed countries, whereas in developing (Asian) countries women's age at first admission was 1.54 lower than men's.

This deviating result concerning a "universally accepted" phenomenon requires a closer look. And indeed the metaanalysis has weaknesses. Because of the small number of studies included, single values from developing countries have influenced the means: for example, the study conducted by Gangadhar et al. [498] in India-published only as a short communication-reported a 4.2-year higher mean age for men. The study was based on the case records of two samples $(N=70$ each $)$ admitted with a clinical diagnosis of schizophrenia to the Department of Psychiatry of the National Institute of Mental Health and Neuroscience (NIMHANS) in Bangalore. One sample came from the Indian state of Karnataka and the other from the southern Indian state of Kerala. In a previous study [499] from the same institute, coauthored by Gangadhar, such a design was described as a "limited approach." Gangadhar et al. do not tell why patients from two different states were admitted for inpatient care at the Bangalore institute. Unlike the Karnataka sample with a sex difference of 4.2 years in age of onset, the Kerala sample did not show any significant difference. The number of probands ( 32 women and 38 men from the state of Karnataka), on the basis of which the means were calculated, was unusually small to ensure valid results across the total age range.

The previous study [499] avoided some of the weaknesses of the Gangadhar study. 100 male and 100 female patients with a DSM-IV diagnosis of schizophrenia consecutively admitted to a hospital were examined individually. Whether the sample was representative of the population is not quite clear. In about half the sample, patients' date of birth was not officially documented, so it had to be estimated. This was probably the case in Ghangadhar's study, too, but was not mentioned by the authors. Murthy et al. [499] could not find any significant age difference between male and female patients.

The study by Stöber et al. [500], also included in the metaanaylsis, is questionable, too. It focused only on two rare syndromes, systematic catatonia and periodic catatonia, using the internationally little known classification by Leonhard [501]. Age at onset was lower for males in one group and higher in the other compared with females.

These examples suffice to illustrate the quality of the meta-analysis by Eranti et al. [497].

Good epidemiological studies looking into age at onset of schizophrenia in developing countries are rare and difficult to conduct for various reasons. The WHO 10-country study covering the same age range (15 to 54 years) and using cultureindependent techniques of measuring symptoms reported a higher age of onset for women from all the three developing countries participating: Columbia (Cali): 3.0 , Nigeria (Ibadan): 2.9, India (Agra): 0.4, (Chandigarh): 1.0 years [49, 502].

The finding that women are several years older than men at the onset of the first symptom of schizophrenia, at the onset of the first positive symptom and also at first admission in countries with well-developed mental-health care systems, has been confirmed in numerous studies and included in the ICD-10 [502, 503]: "This gender difference is currently assumed to be among the few robust, well replicated findings in the entire field of schizophrenia research" [504, p.171]. It cannot be explained by men's higher mortality or shorter lifeexpectancy [505].

Since social hypotheses have failed to explain this sexdifference $[496,505]$, biological explanations have been 
sought: women's second peak of onsets at menopausal age (cf. Figure 2) makes one think of the age curve of oestrogen secretion. Animal experiments have shown that oestrogen applications are capable of attenuating dopaminergic behaviour by downregulating $\mathrm{D}_{2}$-receptor sensitivity $[506,507]$. Testosterone has no such effect [506].

It must be assumed that oestrogen secretion downregulates $\mathrm{D}_{2}$ receptor function at young age [508-514]. As a consequence, either the onset of schizophrenia is delayed or the disorder produces less severe symptoms in part of the women at risk for developing the disorder. With diminishing oestrogen secretion in menopause, some of the at-risk women finally fall ill, thus, producing the second peak of onsets $[506,507,515]$. The oestrogen hypothesis has been confirmed in studies demonstrating the efficacy of adjunctive oestrogen treatment in patients with schizophrenia [516-518].

The sex difference in age of onset has turned out to be smaller or nonexistent in twins and siblings with schizophrenia [519-522]. Hence, it has been presumed that the riskreducing hormonal effect of oestrogen might be antagonized by a risk-increasing effect of genetic vulnerability $[60,522]$. The hypothesis was confirmed in the ABC Schizophrenia Study, in which first-onset patients with schizophrenia and equally affected first-degree relatives were compared with patients without familial schizophrenia $[60,522]$.

9.2. Late-Onset Psychosis. As schizophrenia is regarded primarily as a disorder of the first half of life, the upper age limits are remarkably low in several diagnostic classification systems: 40 years in the Research Diagnostic Criteria [523], 45 years in the Feighner criteria [74] and the DSM-III [82]. As a result, schizophrenias manifesting themselves at higher ages have been neglected in most large-scale incidence studies. The few studies covering the entire age range have revealed that new cases, mainly based on the schizophrenia spectrum diagnoses, occur at considerable frequencies at higher age, too $[494,524,525]$. The main symptoms presented by these late-onset cases are the first-rank symptoms defined by Schneider.

In the first half of the life span, incident cases tend to be more frequent and more severe in men than women [526]. Beyond age 60 years, however, there is a "massive female preponderance in very-late schizophrenia (late paraphrenia, usually with an onset after the age of 60)" [527], a fact often ignored.

At ages after 60 years, incident schizophrenia is associated with more severe symptoms in women than men [493, 528531]. In practice, patients with late-onset psychoses are often given a diagnosis of late paraphrenia [532-534] or of a similar disorder rather than schizophrenia. This leaves one wondering whether the symptoms of schizophrenia might vary with age, especially since paranoid symptoms tend to be very prevalent in old age [531, 532, 534].

A comparison of the most frequent syndromes across 5year age groups over the entire age range in a sample of consecutive first admissions for schizophrenia spectrum disorder (ICD-9) from a catchment area in Germany $(N=1109)$ revealed that most of the syndromes studied showed no significant age differences $[531,535]$. There were only two exceptions: paranoid and systematized delusions in incident schizophrenia showed linear and significant increases with age: delusions of persecution from $\leq 10 \%$ (for males and females) at young age to over 20\% (males) and over $45 \%$ (females) at age 75+; systematized delusions from just over $30 \%$ (for males and females) to $65 \%$ (females) and $50 \%$ (males) in old age. The age-related rates for patients presenting incoherence of thought and disorders of self sank almost inversely from maximum values of just over $30 \%$ (females) and 55\% (males) for the former to below 10\% (both sexes) in old age and from just over $45 \%$ (both sexes) for the latter to about 20\% (females) and almost zero (males) [531, 535]. These significant inverse trends could not be explained by an age-related decrease in the influence of genetic and environmental risk factors.

The authors proposed a heuristic explanation [60, 531]: the onset of psychosis at a very early age interferes with basic mental functions, causing severe anxiety, inappropriate affect, thought disorder, and a disordered sense of self and perception of the world [536-538]. At an early age, when the developing brain and personality are still malleable, psychosis onset can easily cause severe mental disturbance. At an advanced age, when psychological reaction patterns have grown stable over the course of life, basic mental functions are not easily disturbed and severe psychotic disintegration is, thus, less likely to occur. Both brain and personality have developed defense mechanisms protecting them against the destructive influences of the disease process. Rather than mental disintegration, elderly persons develop paranoid and systematized delusions as a rational way of coping with neural dysfunction [539].

9.3. Early Social Course. The early social course, too, depends on age. Social consequences become manifest primarily in the prodromal phase and early illness course. The peak of illness onsets falls in the period of life in which major socioeconomic development takes place. Equal proportions of high-risk individuals and controls, in the mean, are capable of finishing basic school education, but the former frequently drop out of lengthy further education, for example, university. In terms of marriage, patients do not differ from controls at illness onset, but they fall behind their healthy peers during the prodromal phase. This also applies to their occupational career (e.g., having a regular job and earning one's living) [526]. Due to their lower age at illness onset, male patients suffer a greater number of and more pronounced social deficits at illness onset compared with women.

Men's more unfavourable socioeconomic starting conditions at illness onset-despite a stable course of the core symptoms-are the reason for their more unfavourable medium-term social course. Another factor influencing the social course-mediated by therapy adherence and coping behaviour-is the adverse social behaviour exhibited by young men falling ill with schizophrenia: self-neglect, lack of hygiene, lack of interest in finding or keeping a job, and lack of interest in leisure activities and social contacts [540]. In contrast, women with schizophrenia tend to exhibit 
TABLE 1: Five selected (older) European studies on the long-term outcome of schizophrenia.

\begin{tabular}{|c|c|c|c|c|c|}
\hline \multirow{2}{*}{ Author(s) } & \multirow{2}{*}{$N$} & \multirow{2}{*}{ Sample } & \multirow{2}{*}{$\begin{array}{l}\text { Length of illness up to } \\
\text { follow-up }\end{array}$} & \multicolumn{2}{|c|}{ Outcome } \\
\hline & & & & Good & Poor \\
\hline Bleuler 1972/Zurich [555] & 208 & First-/readmitted patients treated by the author & $>20$ years & $20 \%$ & $24 \%$ \\
\hline Hinterhuber 1973/Innsbruck [556] & 157 & First admissions & $30-40$ years & $29 \%$ & $31 \%$ \\
\hline Ciompi and Müller 1976/Lausanne [557] & 289 & First admissions & $\begin{array}{c}\varnothing 37 \text { years } \\
\text { (Range 10-65) }\end{array}$ & $27 \%$ & $27 \%$ \\
\hline Huber et al. 1979/Bonn [558] & 502 & First-/readmissions & $\begin{array}{c}\varnothing 22 \text { years } \\
\text { (Range 9-59) }\end{array}$ & $22 \%$ & $35 \%$ \\
\hline Marneros et al. 1991/Cologne [554] & 148 & First admissions & $\begin{array}{c}\varnothing 25 \text { years } \\
\text { (Range } 10-50)\end{array}$ & $7 \%$ & $42 \%$ \\
\hline
\end{tabular}

Source: [559], modified.

socially positive behaviour, for example, over-adaptiveness and conformity [526].

All these conclusions apply only to the age range studied (12 to 59 years) [526]. The situation is different after 60 years of age when working life comes to an end and certain risk factors and the living conditions change. Males' adverse social behaviour becomes less frequent at later age. In countries with well-developed social safety nets, pension systems guarantee the socioeconomic status of the elderly. Long-standing partnerships tend to reduce losses in this domain. A stable matrix of psychological reaction patterns reduces the risk of extremely severe symptoms appearing at illness onset. As a consequence, the risk of experiencing adverse effects in the socioeconomic and personal domains is also reduced. Although the features of mental disintegration and social deterioration are lacking, late-onset psychoses must be classified as part of the disease construct currently called schizophrenia.

\section{Course and Outcome of Full-Blown Disorder}

Unlike in the prodromal phase, it is the treated rather than the natural course of schizophrenia that can be studied after first admission, because it would be unethical to withhold treatment for research purposes.

Like incidence and prevalence, the results of followup studies, too, depend on the underlying diagnosis. The requirement for a diagnosis of schizophrenia according to the DSM-III to $-\mathrm{V}$ that functional impairment has persisted for at least six months and positive symptoms for at least four weeks prior to initial assessment yields an excess of poor illness courses. In contrast, the criteria of the ICD-9 and - 10 (four weeks of symptoms without an indication of functional impairment) lead to a selection of more acute and benign illness courses. This has prognostic implications for course and outcome.

In studies proceeding from population-based cohorts of first-episode cases of ICD-9 or -10 schizophrenia, the psychotic symptom dimension, as based on mean scores for males and females, displays neither significant deterioration nor significant amelioration over the medium-term course
(5 years or so) following the remission of the first episode $[60,444]$.

There is an important distinction to make between outcome studies and longitudinal studies. Outcome studies compare findings between an initial and a follow-up assessment (pre-post comparisons). The illness course between these timepoints has to be reconstructed: the longer the period in question, the higher the risk of misinterpretation. More assessments done over the period covered yield a more realistic picture of the illness course [392].

According to the results of a wealth of longitudinal studies, the proportions of patients with a good outcome vary from 0 to $68 \%$ [392, 541-553]. Reasons for this variation are differences in the definitions of good/poor outcome, in the inclusion criteria of the cohorts studied, for example, first admissions versus hospitalized patients in general, and in the lengths of illness [546]. Allardyce \& van Os [333] have listed the possible confounders and biases involved.

In the 1970s, a few European longitudinal studies covering histories of illness of 20 years or more were published (Table 1). Although the information provided on the inclusion criteria, histories of illness (20 to 40 years), and the assessment and evaluation methods used was in part incomplete or lacking and these parameters varied a lot across the studies, the simple outcome rates were fairly similar in size, except for the study listed at the bottom of Table 1 [554]. These surprisingly favourable results attracted a lot of interest in the USA, especially since they fell in the period when convergence to European diagnostic definitions was under way in the USA $[72,73,77]$.

Examples of more recent longitudinal investigations are the long-term follow-ups of samples from the former WHO schizophrenia studies: ISoS [549-551, 560-562] and DOSMeD $[49,563,564]$. The DOSMeD Study reported higher proportions of acute psychosis showing rapid remissions in developing countries compared with industrialized countries. This transcultural difference has not yet been explained conclusively despite several attempts.

Two recent longitudinal studies from a high-income country (Germany) are worth mentioning: the one assessed first-admission patients with schizophrenia (Schneiderian first-rank symptoms) in age range 15 to 44 years at nine crosssections ( $N=70$ initial; $N=51$ follow-up) over a period 
of 15.6 years [548-550], the other was a population-based study of a sample of first-episode patients with schizophrenia (ICD-9) $(N=232)$ aged 12 to 59 years-including healthy individuals and patients diagnosed with moderately severe or major depression as controls matched for age and sexfrom illness onset to final follow-up an average of 12.3 years after first admission [60, 388, 396]. Seven cross-sectional assessments were done with half of the sample $(n=115)$ and only one follow-up assessment was conducted with the rest $(n=117)$. Both studies showed that, compared with healthy controls, the majority of patients with schizophrenia are considerably worse off in socioeconomic terms after a 12year history of illness: for example, $33 \%$ of the patients had a regular job compared with $70 \%$ of the healthy controls from the same catchment area [396]. But, as already mentioned, the bulk of social impairment is suffered in the prodromal phase.

At final follow-up, sex differences were visible in patients' marital status and living situation: fewer female patients were living alone, as had been the case at first admission. More female than male patients were married, but their number was lower than that for married healthy controls. Both male and female patients showed a high rate of divorce, but it was almost exclusively female patients that had remarried after illness onset. Large proportions of male patients, but very few women with schizophrenia, were living in residential homes or supervised apartments [396].

More or less similar results have been reported from the follow-up assessments of samples from the WHO longitudinal studies of schizophrenia, comparable in their methods and designs-done, besides in Mannheim (Germany) [548550], in Nottingham (UK) [564], and in Groningen (NL) [562].

Both the medium and the long-term course of schizophrenia are influenced by age. Illness onset in youth and adolescence is associated with social stagnation rather than social decline, because illness at this early age impedes typical social ascent. Late-onset illness, after a long period of life lived in health, usually permits patients to experience normal social ascent. This is why these patients tend to suffer considerable social decline. Patients with illness onset at an intermediate age occupy an intermediate position between these two groups [396]. In sum, the risk of social decline is first and foremost determined by patients' social status at illness onset.

Modal values for the overall course of schizophrenia that would be valid worldwide are impossible to calculate due to the heterogeneity of sociocultural environments, due to differences in the proportions of acute, rapidly remitting cases and due to the variation in the quality of the studies on the topic. This has not deterred Allardyce and van Os [333] from estimating good outcome at $42 \%$, intermediate outcome at $35 \%$, and poor outcome at $27 \%$ on the basis of a review of 37 studies published between 1966 and 2003 [565].

A finding that has implications for our understanding of schizophrenia is the missing or only modest deterioration in both the symptom-related and social course, as based on mean values, in the period starting some time after the remission of the first episode (on average about 2 years), while individual illness courses vary a lot. The way Kraepelin understood the disease concept, that is, as a progressive process leading to increasing deficits, is applicable only to a tiny proportion of cases.

Typical of the symptom-related course of schizophrenia are irregular relapse episodes with intervals occurring in between with only few, if any, symptoms present [388, 391]. The number of episodes depends on their definition.

To ensure comparability of the results, the authors of the ABC Schizophrenia Study $[60,388,391]$ right censored history of illness (mean 12.3 years) by the earliest follow-up assessment of a patient (11.2 years after initial assessment) on the basis of IRAOS data (Interview for the Retrospective Assessment of the Onset and Course of Schizophrenia and Other Psychoses) $[566,567]$. To compensate for this errorprone approach, a subsample $(n=130)$ of the initial sample $(N=232)$ was assessed at seven cross sections using another instrument (PSE-CATEGO). Over the period of 134 months, the authors counted a total of 333 psychotic relapse episodes, operationalized by an at least 14-day period of increasing symptoms between two at least 4-week intervals of decreasing symptoms. The fact that the number of episodes varied from 0 to 29 with a mean of three per patient reflects the heterogeneity of the illness course [388, 396].

Besides the psychotic relapse episodes, a total of 73 (=18\%) purely depressive episodes without psychotic symptoms were counted [388, 391, 487]. Depressive relapse episodes free of psychotic symptoms in patients with schizophrenia were also found by Jablensky [568] in 16\% of a cohort of the WHO 10-country study over a period of two years and by Bressan et al. [569] in an identical proportion of a cohort of first-admission patients prospectively studied over 1.5 years (as based on the DSM-IV definition of major depressive episodes).

10.1. Types of Illness Course. The great variation observed in the illness courses was one of the reasons why attempts have been made to identify simple course types that would be of prognostic relevance in clinical practice.

Harding [570] compared longitudinal studies, two from Switzerland and one from the USA, on the basis of eight course types. We have added in that comparison another US study and a WHO study. The criteria Harding used for defining the course types and estimating the proportions of patients exhibiting them are not precise enough, so the results are not really comparable (Figure 3 ).

For this reason, British authors [572] limited the number of course types to four and defined them by simple criterianumber of episodes, presence of functional impairment, and persistence of versus increase in symptoms and impairment (Figure 4). Simple models like this are more useful in clinical practice.

As stated, individual illness courses differ a great deal. Around 20\% of persons affected experience only one psychotic episode without further relapses and any discernible social consequences [392]. In a small proportion-about equal in size-the disorder has a progressive course sometimes leading to need for residential care. 


\begin{tabular}{|c|c|c|c|c|c|c|c|c|}
\hline & Onset & Course type & End state & $\begin{array}{c}\text { Lausanne } \\
\text { study }\end{array}$ & $\begin{array}{l}\text { Burghölzli } \\
\text { study }\end{array}$ & $\begin{array}{l}\text { Vermont } \\
\text { study }\end{array}$ & $\begin{array}{l}\text { Chicago } \\
\text { study }\end{array}$ & ISoS study ${ }^{1}$ \\
\hline (1) & Acute & Undulating & Recovery/mild & 25.4 & $\begin{array}{l}30-40 \\
25-35\end{array}$ & 7 & 10.8 & 29.4 \\
\hline (2) & Chronic & Simple & Moderate/severe & 24.1 & $10-20$ & 4 & 36.5 & 14.4 \\
\hline (3) & Acute & Undulating & $\begin{array}{l}\text { Moderate/ } \\
\text { severe }\end{array}$ & 11.9 & 5 & 4 & 9.5 & 4.9 \\
\hline (4) & Chronic & Simple & Recovery/mild & 10.1 & $5-10$ & 12 & 4.1 & 10.4 \\
\hline (5) & Chronic & Undulating & Recovery/mild & 9.6 & - & 38 & 6.8 & 22.6 \\
\hline (6) & Acute & Simple & Moderate/severe & 8.3 & $5-15$ & 3 & 13.5 & 9.1 \\
\hline (7) & Chronic & Undulating & Moderate/severe & 5.3 & - & 27 & 12.2 & 4 \\
\hline (8) & Acute & Simple & Recovery/mild & 5.3 & 5 & 5 & 6.8 & 5.3 \\
\hline
\end{tabular}

\footnotetext{
$1_{\text {Incidence studies only }}$

Lausanne study: Ciompi and Muller [557]

Burghölzli study: Bleuler [555]

Vermont study: Harding et al. [543, 544]

Chicago study: Marengo et al. [553]

ISoS study: Harrison et al. [564]
}

FIGURE 3: Course types in schizophrenia. On the right, each of the five columns represents a study. The numbers indicate the percentage of patients with the course type depicted on the left; for example, 7\% of the patients in the Vermont Study demonstrated an acute onset, an undulating course, and a recovered/mild end state (type 1), in contrast to the ISoS Study, where $29.4 \%$ of the patients belong to this course type. Based on [570] data from the Chicago and the ISoS study were added by the authors. Source: [571].

\section{Reduced Life-Expectancy}

The life-expectancy of patients with schizophrenia is considerably reduced compared with that of general populations $[392,573]$. The figures vary. A meta-analysis of 37 studies calculated a median standard mortality rate of 2.6 for individuals with schizophrenia [574]. It means that the risk of dying in the following year is 2.6 times higher for people with schizophrenia than for the population in general. Brown et al. [575] found a two to three times higher mortality risk for people with schizophrenia in Southampton/UK. According to Seeman [576], the life-expectancy of persons with schizophrenia was 61 years compared with 76 years for the general population. Controlling for age, Colton and Manderscheid [577] found a median of lost years of life varying from 25 to 30 years in several US states, a surprisingly high figure. 


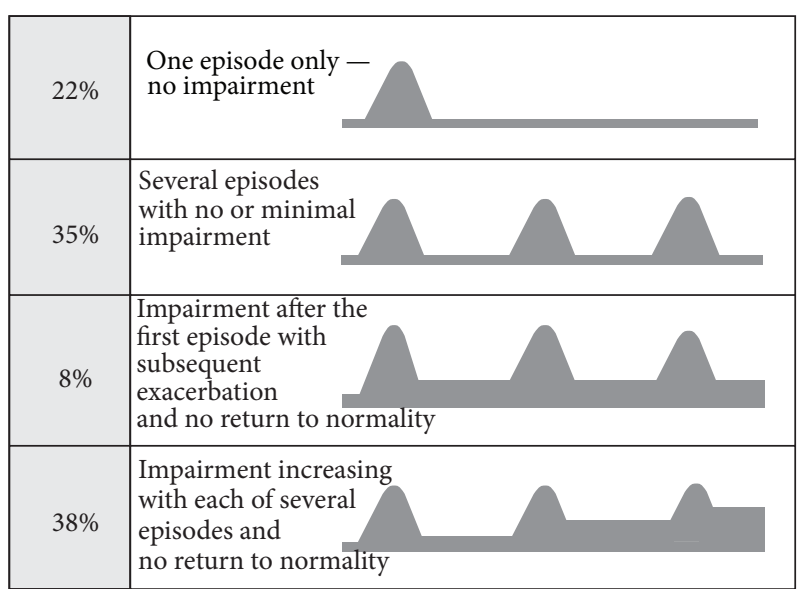

FIGURE 4: Graded course of illness in first-admission patients with schizophrenia as indicated by episodes of illness, symptomatology, and social impairment at assessment during 5 years $(N=49)$. Source: [572], modified.

A direct comparison of age at death for persons with schizophrenia on data from the national psychiatric case register in Denmark and for the Danish general population revealed considerable differences [578]. Men with schizophrenia had a mean of 18.7 years and women had a mean of 16.3 years shorter lives than their peers in the general population. An excess mortality risk for patients with schizophrenia can, thus, be regarded as established.

11.1. The Causes of Premature Death. Schizophrenia as such is not a deadly disease. Only the extremely severe subtype of "pernicious catatonia" can lead to death as a result of severe cardiovascular crises and electrolyte disorders. Nowadays, when the risk of death can be successfully warded off by timely recognition and appropriate treatment, it is nearly exclusively from countries with inadequate health care systems that fatal outcomes of pernicious catatonia are reported $[579,580]$.

As long as patients with schizophrenia used to be hospitalized under poor hygienic conditions over extended periods of time, infectious diseases, tuberculosis in particular, were the main cause of premature death [581-583]. Today, long hospital stays are an exception in industrialized countries and, if necessary, they take place under adequate hygienic conditions. In addition, most infectious diseases can nowadays be cured.

Contributing to the excess risk of death in schizophrenia used to be suicide and other unnatural causes (accidents, etc.), and this is still the case today. Recent reports are consistent in indicating that cardiovascular disorders have overtaken the other causes of extra deaths in schizophrenia [575, 577, 582, 584-587]. According to Laursen et al. [585], death from heart disease is now nearly three times more common in people with severe mental illness. In a review of the topic, Leucht et al. [584] found elevated rates of neoplasms (cancer) and capillary-vascular disease (CVD). Since this spectrum of causes of death was, more or less, similar to that of the general population, it was only natural to see whether the same risk factors showed excess frequencies in schizophrenia, too, and indeed, the rates for nearly all relevant risk factors were found to be elevated $[573,588]$.

The prevalence of risk behaviour is illustrated by the results of the 2010 Australian National Psychosis Survey conducted among persons with psychotic disorder (ICD10 schizophrenia) aged 18 to 64 years: $65 \%$ were current smokers, $49.8 \%$ had a lifetime history of alcohol abuse or dependence, and 50.8\% abused cannabis [397]. Responsible for these elevated prevalences were, in part, an unhealthy way of life and lack of prevention, in part also addiction $[573,588]$.

Obesity plays a key role as a risk factor for cardiovascular disease [589-591]: it is up to twice as frequent in patients with schizophrenia as in the general population [592-595]. Obesity and weight gain increase the risk for hypertension, elevated blood fat levels, and type- 2 diabetes. These factors lead to a metabolic syndrome, which in the Australian study was the case in $68 \%$ of the patients with psychotic illness [397], and also contribute to the risk for cardiovascular disease $[589,590]$.

These metabolic risks can also be associated with neuroleptic medications, which is a severe problem. Various neuroleptics, especially the new ones, have adverse metabolic effects in different degrees, so research results in this field urgently need to be translated into preventive action.

The elevated risk of suicide in patients with schizophrenia is associated with the same demographic risk factors as in the general population: male sex, social isolation, being single, and recent loss [596]. They are compounded by illness-related factors, depressive mood in particular in the early course of the disorder [392, 596-600], and preserved insight [601603], which, on the other hand, is an indicator of good outcome.

\section{Dimensional Models of Schizophrenia}

Recently, the question was raised again whether the disease construct of schizophrenia should be continued to be defined categorically or better broken down to dimensions. A dimensional understanding of the disease process was intensively debated during the preliminary consultations for the 5th edition of the DSM [410, 604-606]. However, it was finally decided not to adopt the dimensional approach in the interest of a more than 100-year history of the disease concept, its worldwide use, and the role it plays in clinical practice. For research purposes, however, dimensional models are preferred.

The empirical course of symptom dimensions, for example, of the factors proposed by Liddle and Barnes [348]: "reality distortion," "psychomotor poverty," and "disintegration," was studied by Arndt et al. [607] over two years and by Salokangas [364] and Löffler and Häfner [360] over five years in first-episode patients of schizophrenia. The negative dimension turned out to be the most stable one and fairly independent of the other symptom dimensions. 


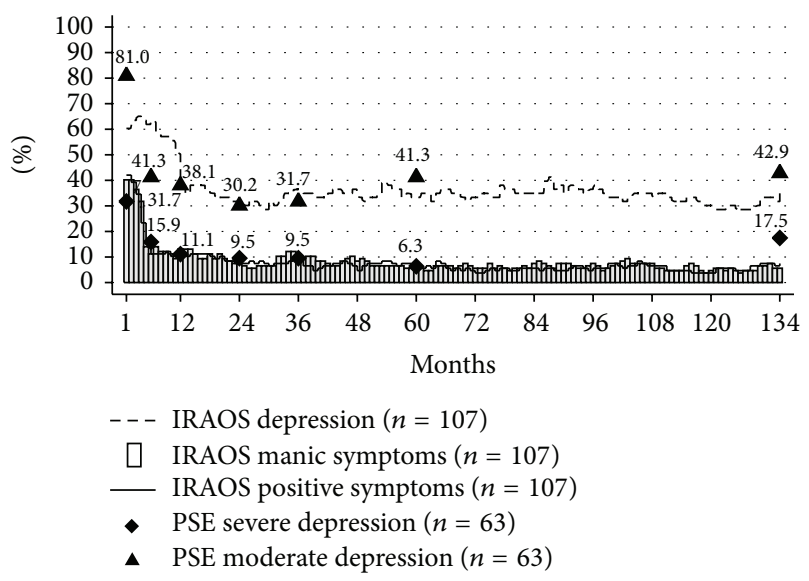

FigURE 5: Long-term course of three-symptom dimensions of schizophrenia-percentages of patients with core symptoms of each dimension. Source: [487].

In the $\mathrm{ABC}$ long-term follow-up study, the authors defined four clinical symptom dimensions phenomenologically: a psychotic, negative, depressive, and manic dimension. Since many of the symptoms belonged to multiple dimensions, the four most prevalent symptoms with the least overlap with the other dimensions were chosen on each dimension as constituting a core dimension. The course of these core dimensions (as based on the prevalence of symptoms present at least for $50 \%$ of the time in each month) was mapped in monthly intervals over 11.2 years $[60,388,396]$.

The depression rates depicted in Figure 5 were assessed both retrospectively in the total sample using the IRAOS (dotted line) and prospectively for validation purposes in the half-split subsample using the PSE (black triangles = CATEGO moderately severe depression, black rhombuses = major depression). As the figure illustrates, the rates for depressive, positive, and manic symptoms exhibit plateaulike trajectories after 1 to 2 years following first admission without any change in their frequencies relative to each other. The pronounced decrease in symptoms on all three symptom dimensions after the first psychotic episode is accounted for by treatment effects and spontaneous remissions, but it is partially also attributable to an artefact: because first psychotic episode was used as the inclusion criterion, the patients studied all had maximum symptom scores at entry in the study. Afterwards, they showed the usual sequence of episodes and intervals.

The trajectories depicted only confirm what the mediumterm course had already indicated, namely, that, under the study conditions described, the core dimensions of schizophrenia show no clear-cut trend of either improvement or deterioration after the remission of the first psychotic episode (1 to 2 years after first admission). And the same was true for the overall symptomatology $[60,388,396]$.

12.1. Duration and Frequency of Symptom Exacerbations. To find out whether there are factors at work on the individual level that influence the seemingly uniform, but interindividually heterogeneous illness course the investigators in the $\mathrm{ABC}$ Schizophrenia study ascertained the individual durations of all symptom exacerbations on the psychosis and the depression dimension over the 134-month period-instead of just counting the number of relapse episodes operationally limited in their duration $[60,391,392,396,487,608]$. The manic dimension could not be included because of low values. The median duration of symptom exacerbations was five months (mean: 20 months) on the depression dimension and two months (mean: 6.3 months) on the psychosis dimension. Symptoms persisting over the entire illness course-the purest form of chronicity-were very rare, occurring only in $6 \%$ on the depression and in $1 \%$ on the psychotic dimension.

Negative symptomatology, not yet broken down to dimensions, was assessed on the basis of a sum score of 19 IRAOS items. After the remission of the first episode the prevalence of negative symptoms decreased markedly, showing a plateau-like course after five years of initial assessment in male patients and after three years in female patients. An explanation for this unexpected finding has not yet been found.

\section{Stigma and Discrimination}

In the past, persons who fell ill with schizophrenia and sought help at mental-health services used to be-and still are today-subject to social isolation in many countries. In part, they are also discriminated against in the family, at workplace, and in public [609-613]. The consequences are an increased psychological strain on the patients and their families, reduced help-seeking and shortcomings in mental-health care and therapy. It was for these reasons that the WHO and the World Psychiatric Association launched the WPA "Open the doors" Programme "Against Stigma and Discrimination Because of Schizophrenia" (http://www.wpanet.org/detail.php?section $\mathrm{id}=8 \&$ content $\mathrm{id}=397)$ and initiatives and programmes combating stigma and discrimination have sprung up in many countries. In Japan, psychiatrists have gone as far as introducing "integration disorder" as a diagnosis to reduce stigma, but with limited success $[614,615]$.

How public opinion can be influenced by national initiatives is reflected in people's attitudes towards schizophrenia, depression, and alcohol dependence surveyed between 1990 and 2011 in Germany (former West-Germany) [616]. By 2011, people had become more open-minded towards individuals suffering from these disorders, knowledge on mental disorders had increased, and mental health care had considerably improved. Although more people than 20 years earlier regarded schizophrenia as a biological disorder and willingness to seek help at mental health services, if need be, had considerably increased, individual attitudes towards persons with schizophrenia had even worsened. An investigation of attitudes in the aftermath of an antistigma and antidiscrimination campaign in New Zealand yielded a similar result [617].

These are just two examples for an issue still of current relevance worldwide. 


\section{Conclusions}

The diagnosis of schizophrenia and the underlying disease concept have recently been subject of debate, and not for the first time. Today, it can be considered established that there is a continuum ranging from the spectrum of schizophrenia symptoms to related syndromes, affective psychosis in particular, to mild schizophrenia-like disorders and normality. The continuity also seems to be reflected on the neurobiological and genetic level. This multilevel picture of a continuum is better compatible with a dimensional than a categorical disease model. However, bidding farewell to the categorical diagnosis of schizophrenia would have far-reaching consequences, so it has been deferred for the time being.

Approaching an answer to the question of what schizophrenia is, we must start by accepting the fact that, contrary to a widespread belief, it is not just a disorder of the young, but can strike at any age. Age at onset, severity of illness, some of the symptoms, and the social consequences involved are influenced by genetic factors, environmental risk factors, hormones (oestrogen secretion), and sociocultural factors, depending on age. As a consequence, symptoms, illness course, and social outcome vary a great deal between the sexes and between young, medium, and old age. Men fall ill with schizophrenia more frequently and more severely in the first half of life, women more frequently and more severely in the second.

Late- and very-late-onset "schizophrenic" psychoses are characterized by rational delusions rather than a severe psychotic breakdown, and mostly no social decline occurs. In spite of this, mild late- and very-late-onset psychoses should be classified as representing the disease process currently called schizophrenia. When this is done, the sex difference in schizophrenia incidence disappears almost completely over the entire age range.

Among the most important recent (re)discoveries are the findings on the precursors and the prodromal phase of psychosis and the underlying psychopathological, neurophysiological, and functional-morphological associations. Thanks to these advances, early recognition and early intervention are now possible and capable of delaying psychosis onset and reducing the adverse effects psychosis typically has on patients' personal lives and socioeconomic situations.

The discovery that oestrogen secretion, probably by reducing the sensitivity of $\mathrm{D}_{2}$ receptors, is capable of postponing psychosis onset and reducing symptom severity has opened up new avenues of therapy. Although their efficacy has already been confirmed, they are not yet in widespread use because of the risk of unwanted side-effects.

Genetic vulnerability reduces or eliminates altogether the sex difference in age of onset by reducing women's age at onset, thus, indicating that the genetic penetrance of schizophrenia antagonizes the hormonal protection against psychosis.

Based on the ICD-9 or -10 diagnosis with emphasis on the psychotic symptomatology, the schizophrenia syndrome seems to be encountered and to be fairly evenly distributed in all cultures and ethnicities. This is at least what the results of the WHO 10-country study of schizophrenia (DOSMeD) indicate. In that multisite study conducted with fairly similar designs and culture-independent assessment techniques, annual incidence rates for (ICD-9) schizophrenia were calculated for populations aged 15 to 54 years in ten countriesfour centres in three developing countries and six in industrialized countries. A restrictively defined, precise diagnostic definition produced annual incidence rates showing fairly little variation, while the incidence based on a broader, less precise diagnostic definition varied more markedly across the centres. None of the later transnational and transcultural studies have provided more reliable incidence data, although, strictly speaking, in the WHO study, too, the number of countries adequately researched was too small.

The course of schizophrenia is characterized by irregularly alternating episodes of exacerbation and remission of psychotic, partly also of depressive symptoms. If all exacerbations on the positive, negative, and depressive symptom dimensions are counted irrespective of their duration, differences will emerge in their frequency, with the exacerbations on the positive dimension showing the highest frequency and the shortest duration and those on the depression dimension a considerably lower frequency and longer duration. Negative symptom exacerbations, not yet analysed as a dimension, are even less frequent and of a longer duration than the depressive ones. But negative symptoms, too, show an episodic course over time despite stable mean values.

The construct of a disease entity, the way the early Kraepelin understood dementia praecox or schizophrenia, has become untenable, no matter which way we look at it, and the Kraepelinian dichotomy of affective and schizophrenic psychosis is now questionable.

Schizophrenia is very unlikely to have a uniform aetiology. It rather represents the expression of recurring functional vulnerability of various neural networks in the human brain caused by different types of neurobiological disorder. It is the resulting neural dysfunction that brings forth the exacerbations described and their combinations, thus, leading to schizophrenia, which, hence, is nothing else than the final common pathway of various influences. Quite frequently neuroreparative mechanisms seem to be capable of bringing that dysfunction to remission, partly or completely.

In sum, we still do not really know what schizophrenia is, but at least we have a better idea of what it is not. And it is uncertain whether we will ever know its real cause, because single causation does not exist and, given the diversity of the aetiological factors involved, it is difficult to single out those ultimately responsible for it.

\section{Conflict of Interests}

The author declares that, concerning this paper, there is no conflict of interests.

\section{Acknowledgments}

The author wishes to thank Professor Marcella Rietschel, head of the Department of Genetic Epidemiology in Psychiatry, Central Institute of Mental Health, for the intensive 
discussions and her active support in writing the Genetics chapter. The author also thanks his research assistant Auli Komulainen-Tremmel for her help in preparing the various drafts of the paper and for compiling the References section.

\section{References}

[1] E. Kraepelin, Psychiatrie. Ein Lehrbuch für Studierende und Aerzte, Barth, Leipzig, Germany, 4th edition, 1893, (German).

[2] E. Bleuler, "Dementia praecox oder Gruppe der Schizophrenien," in Handbuch der Psychiatrie, G. Aschaffenburg, Ed., pp. 1-420, Deuticke, Leipzig, Germany, 1911, (German).

[3] M. T. Tsuang and S. V. Faraone, Schizophrenia, Oxford University Press, New York, NY, USA, 2nd edition, 2005.

[4] D. R. Weinberger and P. J. Harrison, Schizophrenia, WileyBlackwell, Oxford, UK, 3rd edition, 2011.

[5] N. C. Andreasen, "Concept of schizophrenia: past, present, and future," in Schizophrenia, D. R. Weinberger and P. J. Harrison, Eds., pp. 3-8, Wiley-Blackwell, Oxford, UK, 3rd edition, 2011.

[6] R. J. Wyatt, R. C. Alexander, M. F. Egan, and D. G. Kirch, "Schizophrenia, just the facts. What do we know, how well do we know it?” Schizophrenia Research, vol. 1, no. 1, pp. 3-18, 1988.

[7] M. S. Keshavan, R. Tandon, N. N. Boutros, and H. A. Nasrallah, "Schizophrenia, "just the facts": What we know in 2008. Part 3: neurobiology," Schizophrenia Research, vol. 106, no. 2-3, pp. 89107, 2008.

[8] R. Tandon, M. S. Keshavan, and H. A. Nasrallah, "Schizophrenia, "Just the Facts": what we know in 2008. Part 1: overview," Schizophrenia Research, vol. 100, no. 1-3, pp. 4-19, 2008.

[9] R. Tandon, M. S. Keshavan, and H. A. Nasrallah, "Schizophrenia, "Just the Facts" what we know in 2008. 2. Epidemiology and etiology," Schizophrenia Research, vol. 102, no. 1-3, pp. 1-18, 2008.

[10] R. Tandon, H. A. Nasrallah, and M. S. Keshavan, "Schizophrenia, "just the facts" 4. Clinical features and conceptualization," Schizophrenia Research, vol. 110, no. 1-3, pp. 1-23, 2009.

[11] R. Tandon, H. A. Nasrallah, and M. S. Keshavan, "Schizophrenia, "Just the Facts" 5. Treatment and prevention past, present, and future," Schizophrenia Research, vol. 122, no. 1'3, pp. 1-23, 2010.

[12] M. S. Keshavan, H. A. Nasrallah, and R. Tandon, "Schizophrenia, "Just the Facts" 6: moving ahead with the schizophrenia concept: From the elephant to the mouse," Schizophrenia Research, vol. 127, no. 1-3, pp. 3-13, 2011.

[13] M. S. Keshavan, R. Tandon, and H. A. Nasrallah, "Renaming schizophrenia: keeping up with the facts," Schizophrenia Research, vol. 148, no. 1-3, pp. 1-2, 2013.

[14] G. A. Fava, "The intellectual crisis of psychiatric research," Psychotherapy and Psychosomatics, vol. 75, no. 4, pp. 202-208, 2006.

[15] R. Kendell and A. Jablensky, "Distinguishing between the validity and utility of psychiatric diagnoses," The American Journal of Psychiatry, vol. 160, no. 1, pp. 4-12, 2003.

[16] M. Maj, "Are psychiatrists an endangered species?" World Psychiatry, vol. 9, no. 1, pp. 1-2, 2010.

[17] M. Maj, "Mental disorders as "brain diseases" and Jaspers' legacy," World Psychiatry, vol. 2, no. 1, pp. 1-3, 2013.

[18] A. Jablensky and F. Waters, "RDoC: a roadmap to pathogenesis?” World Psychiatry, vol. 13, no. 1, pp. 43-44, 2014.
[19] J. Parnas, L. A. Sass, and D. Zahavi, "Rediscovering psychopathology: the epistemology and phenomenology of the psychiatric object," Schizophrenia Bulletin, vol. 39, no. 2, pp. 270-277, 2013.

[20] J. Parnas, "The RDoC program: psychiatry without psyche?" World Psychiatry, vol. 13, pp. 46-67, 2014.

[21] E. Kraepelin, "The German institute of psychiatric research," Journal of Nervous and Mental Disease, vol. 51, pp. 505-513, 1920.

[22] E. Kraepelin, “Die Erscheinungsformen des Irreseins," Zeitschrift für die gesamte Neurologie und Psychiatrie, vol. 62, no. 1, pp. 1-29, 1920 (German).

[23] W. Maier, "Psychiatrie als Beruf-wie sieht die Zukunft aus? Leserbrief zum Beitrag von H. Häfner in Der Nervenarzt (2002) 73: 33-40," Nervenarzt, vol. 73, pp. 96-99, 2002 (German).

[24] S. E. Hyman, "Can neuroscience be integrated into the DSMV?" Nature Reviews Neuroscience, vol. 8, no. 9, pp. 725-732, 2007.

[25] B. N. Cuthbert, “The RDoC framework: facilitating transition from ICE/DSM to dimensional approaches that integrate neuroscience and psychopathology," World Psychiatry, vol. 13, no. 1, pp. 28-35, 2014.

[26] M. Maj, "Keeping an open attitude towards the RDoC project," World Psychiatry, vol. 13, pp. 1-4, 2014.

[27] G. A. Fava, C. Rafanelli, and E. Tomba, "The clinical process in psychiatry: a clinimetric approach," Journal of Clinical Psychiatry, vol. 73, no. 2, pp. 177-184, 2012.

[28] G. A. Fava, "Road to nowhere," World Psychiatry, vol. 13, no. 1, pp. 49-50, 2014.

[29] L. E. DeLisi, "The concept of progressive brain change in schizophrenia: implications for understanding schizophrenia," Schizophrenia Bulletin, vol. 34, no. 2, pp. 312-321, 2008.

[30] E. Kretschmer, Körperbau und Charakter, Springer, Berlin, Germany, 1921, (German).

[31] A. Jablensky, "Boundaries of mental disorders," Current Opinion in Psychiatry, vol. 18, no. 6, pp. 653-658, 2005.

[32] A. Jablensky, "The diagnostic concept of schizophrenia: its history, evolution, and future prospects," Dialogues in Clinical Neuroscience, vol. 12, no. 3, pp. 271-287, 2010.

[33] E. Kraepelin, Psychiatrie. Ein Lehrbuch für Studierende und Ärzte, Barth, Leipzig, Germany, 6th edition, 1899, (German).

[34] N. Craddock and M. J. Owen, "The Kraepelinian dichotomygoing, going... but still not gone," The British Journal of Psychiatry, vol. 196, no. 2, pp. 92-95, 2010.

[35] K. Jaspers, Allgemeine Psychopathologie. Ein Leitfaden für Studierende, Ärzte und Psychologen, Julius Springer, Berlin, Germany, 1913 (German).

[36] G. E. Berríos, "Psychiatry and its objects," Revista de Psiquiatria y Salud Mental, vol. 4, no. 4, pp. 179-182, 2011.

[37] G. E. Berrios, "Jaspers and the first edition of Allgemeine Psychopathologie," The British Journal of Psychiatry, vol. 202, p. 433, 2013.

[38] H. Häfner, "Karl Jaspers. 100 Jahre 'Allgemeine Psychopathologie,", Der Nervenarzt, vol. 84, no. 11, pp. 1281-1290, 2013 (German).

[39] K. Jaspers, "Die phänomenologische Forschungsrichtung in der Psychopathologie," Zeitschrift für die gesamte Neurologie und Psychiatrie, vol. 9, no. 1, pp. 391-408, 1912 (German).

[40] G. E. Berrios, "Phenomenology, psychopathology and Jaspers: a conceptual history." History of psychiatry, vol. 3, no. 11, pp. 303327, 1992.

[41] W. Mayer-Gross, E. Slater, and M. Roth, Eds., Clinical Psychiatry, Baillière, Tindall \& Cassell, London, UK, 1954. 
[42] V. Roelcke and F. Schneider, "Psychiatrists under National Socialism. Biographies of perpetrators, Einführung zum Thema: Psychiater im Nationalsozialismus. Täterbiographien," Der Nervenarzt, vol. 83, no. 3, pp. 291-292, 2012.

[43] J. K. Wing, J. E. Cooper, and N. Sartorius, Measurement and Classification of Psychiatric Symptoms: An Instruction Manual for the PSE and CATEGO Program, Cambridge University Press, London, UK, 1974.

[44] J. K. Wing, T. Babor, T. Brugha et al., "SCAN: schedules for clinical assessment in neuropsychiatry," Archives of General Psychiatry, vol. 47, no. 6, pp. 589-593, 1990.

[45] K. Schneider, Clinical Psychopathology, translated by M. W. Hamilton, Grune \& Stratton, New York, NY, USA, 1959.

[46] R. Warner and G. de Girolamo, Schizophrenia, Epidemiology of Mental Disorders and Psychological Problems, World Health Organization, Geneva, Switzerland, 1995.

[47] C. Arango and W. T. Carpenter, "The schizophrenia construct: symptomatic presentation," in Schizophrenia, D. R. Weinberger and P. J. Harrison, Eds., pp. 9-23, Wiley-Blackwell, Oxford, UK, 3rd edition, 2011.

[48] W. S. Fenton, L. R. Mosher, and S. M. Matthews, "Diagnosis of schizophrenia: a critical review of current diagnostic systems," Schizophrenia Bulletin, vol. 7, no. 3, pp. 452-476, 1981.

[49] A. Jablensky, N. Sartorius, G. Ernberg et al., "Schizophrenia: manifestations, incidence and course in different cultures. A World Health Organization ten-country study," Psychological Medicine Monograph Supplement, vol. 20, pp. 1-97, 1992.

[50] W. T. Carpenter Jr. and J. S. Strauss, "Cross cultural evaluation of Schneider's first rank symptoms of schizophrenia: a report from the International Pilot Study of Schizophrenia," The American Journal of Psychiatry, vol. 131, no. 6, pp. 682-687, 1974.

[51] H. G. Pope Jr. and J. F. Lipinski Jr., "Diagnosis in schizophrenia and manic-depressive illness. A reassessment of the specificity of "schizophrenic" symptoms in the light of current research," Archives of General Psychiatry, vol. 35, no. 7, pp. 811-828, 1978.

[52] M. A. Taylor and R. Abrams, "Manic-depressive illness and good prognosis schizophrenia," The American Journal of Psychiatry, vol. 132, no. 7, pp. 741-742, 1975.

[53] P. J. Möbius, Abriss der Lehre von den Nervenkrankheiten, Abel, Leipzig, Germany, 1893, (German).

[54] R. E. Kendell and I. F. Brockington, "The identification of disease entities and the relationship between schizophrenic and affective psychoses," The British Journal of Psychiatry, vol. 137, no. 4, pp. 324-331, 1980.

[55] A. Frances, "RDoC is necessary, but very oversold," World Psychiatry, vol. 13, no. 1, pp. 47-49, 2014.

[56] U. Ettinger, I. Meyhöfer, M. Steffens, M. Wagner, and N. Koutsouleris, "Genetics, cognition, and neurobiology of schizotypal personality: a review of the overlap with schizophrenia," Frontiers in Psychiatry, vol. 5, article 18, 2014.

[57] World Health Organization, The ICD-10 Classification of Mental and Behavioural Disorders, WHO, Geneva, Switzerland, 1992.

[58] World Health Organization, International Statistical Classification of Diseases and Related Health Problems 10th Revision (ICD-10) Version for 2010, 2010, http://apps.who.int/classifications/icd10/browse/2010/en\#/F20-F29.

[59] American Psychiatric Association, Diagnostic and Statistical Manual of Mental Disorders, American Psychiatric Publishing, Washington, DC, USA, 4th edition, 2005.

[60] H. Häfner, K. Maurer, and W. an der Heiden, "Schizophrenieeine einheitliche Krankheit?” Der Nervenarzt, vol. 84, no. 9, pp. 1093-1103, 2013 (German).
[61] I. F. Brockington, R. E. Kendell, and J. P. Leff, "Definitions of schizophrenia: concordance and prediction of outcome," Psychological Medicine, vol. 8, no. 3, pp. 387-398, 1978.

[62] H. Sass, "The classification of schizophrenia in the different diagnostic systems," in Search for the Causes of Schizophrenia, $\mathrm{H}$. Häfner, W. F. Gattaz, and W. Janzarik, Eds., pp. 19-43, Springer, Berlin, Germany, 1987.

[63] J. Endicott, J. Nee, J. Fleiss, J. Cohen, J. B. Williams, and R. Simon, "Diagnostic criteria for schizophrenia: reliabilities and agreement between systems," Archives of General Psychiatry, vol. 39, no. 8, pp. 884-889, 1982.

[64] D. J. Castle, S. Wessely, and R. M. Murray, "Sex and schizophrenia: effects of diagnostic stringency, and associations with premorbid variables," The British Journal of Psychiatry, vol. 162, pp. 658-664, 1993.

[65] M. Kramer, "Cross-national study of diagnosis of the mental disorders: origin of the problem," The American Journal of Psychiatry, vol. 10, pp. 1-11, 1969.

[66] R. L. Spitzer and J. L. Fleiss, "A reanalysis of the reliability of psychiatric diagnosis," The British Journal of Psychiatry, vol. 125, no. 10, pp. 341-347, 1974.

[67] A. W. Loranger, "The impact of DSM-III on diagnostic practice in a university hospital. A comparison of DSM-II and DSM-III in 10,914 patients," Archives of General Psychiatry, vol. 47, no. 7, pp. 672-675, 1990.

[68] J. de Leon, "A post-DSM-III wake-up call to European psychiatry," Acta Psychiatrica Scandinavica, vol. 129, pp. 76-77, 2014.

[69] J. Zubin, "Crosss-national study of diagnosis of the mental disorders: methodology and planning," The American Journal of Psychiatry, vol. 10, pp. 12-20, 1969.

[70] B. J. Gurland, J. L. Fleiss, L. Sharpe, P. Roberts, J. E. Cooper, and R. E. Kendell, "Cross-national study of diagnosis of mental disorders: hospital diagnoses and hospital patients in New York and London," Comprehensive Psychiatry, vol. 11, no. 1, pp. 18-25, 1970.

[71] J. de Leon, “One hundred years of limited impact of Jaspers' General Psychopathology on US psychiatry," The Journal of Nervous and Mental Disease, vol. 202, no. 2, pp. 79-87, 2014.

[72] R. E. Kendell, J. E. Cooper, A. J. Gourlay, J. R. Copeland, L. Sharpe, and B. J. Gurland, "Diagnostic criteria of American and British psychiatrists," Archives of General Psychiatry, vol. 25, no. 2, pp. 123-130, 1971.

[73] J. E. Cooper, R. E. Kendell, B. J. Gurland, L. Sharpe, J. R. M. Copeland, and R. Simon, Psychiatric Diagnosis in New York and London, Maudsley Monograph no. 20, Oxford University Press, London, UK, 1972.

[74] J. P. Feighner, E. Robins, S. B. Guze, R. A. Woodruff Jr., G. Winokur, and R. Munoz, "Diagnostic criteria for use in psychiatric research," Archives of General Psychiatry, vol. 26, no. 1, pp. 57-63, 1972.

[75] R. L. Spitzer, N. C. Andreasen, and J. Endicott, "Schizophrenia and other psychotic disorders in DSM-III," Schizophrenia Bulletin, vol. 4, no. 4, pp. 489-511, 1978.

[76] R. L. Spitzer, J. Endicott, and E. Robins, "Research diagnostic criteria: rationale and reliability," Archives of General Psychiatry, vol. 35 , no. 6, pp. 773-782, 1978.

[77] G. L. Klerman, "The evolution of a scientific nosology", in Schizophrenia: Science and Practice, J. C. Shershow, Ed., pp. 99121, Harvard University Press, Cambridge, Mass, USA, 1978.

[78] R. K. Blashfield, "Feighner et al., invisible colleges, and the Matthew effect," Schizophrenia Bulletin, vol. 8, no. 1, pp. 1-12, 1982. 
[79] H. S. Decker, "How Kraepelinian was Kraepelin? How Kraepelinian are the neo-Kraepelinians?-from Emil Kraepelin to DSM-III," History of Psychiatry, vol. 18, no. 3, pp. 337-360, 2007.

[80] N. C. Andreasen, "DSM and the death of phenomenology in America: an example of unintended consequences," Schizophrenia Bulletin, vol. 33, no. 1, pp. 108-112, 2007.

[81] E. Robins and S. B. Guze, "Establishment of diagnostic validity in psychiatric illness: its application to schizophrenia," The American Journal of Psychiatry, vol. 126, no. 7, pp. 983-987, 1970.

[82] American Psychiatric Association, Diagnostic and Statistical Manual of Mental Disorders (DSM-IIII), American Psychiatric Association, Washington, DC, USA, 3rd edition, 1980.

[83] N. C. Andreasen and M. Flaum, "Schizophrenia: the characteristic symptoms," Schizophrenia Bulletin, vol. 17, no. 1, pp. 27-50, 1991.

[84] G. E. Berrios and I. S. Marková, "Symptoms-historical perspective and effect on diagnosis," in Psychosomatic Medicine, M. Blumenfield and J. J. Strain, Eds., pp. 27-38, Lippincott Williams \& Wilkins, Philadelphia, Pa, USA, 2006.

[85] S. N. Ghaemi, "Nosologomania: DSM \& Karl Jaspers' critique of Kraepelin," Philosophy, Ethics, and Humanities in Medicine, vol. 4, article 10, 2009.

[86] P. R. McHugh, "Rendering mental disorders intelligible: addressing psychiatry's urgent challenge," in Philosophical Issues in Psychiatry II. Nosology: International Perspectives in Philosophy and Psychiatry, K. S. Kendler and J. Parnas, Eds., pp. 269280, Oxford University Press, Oxford, UK, 2012.

[87] P. R. McHugh and P. R. Slavney, "Methods of reasoning in psychopathology: conflict and resolution," Comprehensive Psychiatry, vol. 23, no. 3, pp. 197-215, 1982.

[88] P. R. Slavney and P. R. McHugh, "Explanation and understanding," in Psychiatric Polarities, P. R. Slavney and P. R. McHugh, Eds., pp. 29-44, The Johns Hopkins University Press, Baltimore, Md, USA, 1987.

[89] A. L. Stoll, M. Tohen, R. J. Baldessarini et al., "Shifts in diagnostic frequencies of schizophrenia and major affective disorders at six North American psychiatric hospitals, 1972-1988," The American Journal of Psychiatry, vol. 150, no. 11, pp. 1668-1673, 1993.

[90] L. N. Robins, J. E. Helzer, J. L. Croughan, J. B. W. Williams, and R. L. Spitzer, NIMH Diagnostic Interview Schedule: Version III, National Institute of Mental Health, Washington, DC, USA, 1981.

[91] A. Y. Tien and W. W. Eaton, "Psychopathologic precursors and sociodemographic risk factors for the schizophrenia syndrome," Archives of General Psychiatry, vol. 49, no. 1, pp. 37-46, 1992.

[92] J. R. M. Copeland, M. E. Dewey, and P. Saunders, "The epidemiology of dementia: GMS-AGECAT studies of prevalence and incidence, including studies in progress," European Archives of Psychiatry and Clinical Neuroscience, vol. 240, no. 4-5, pp. 212217, 1991.

[93] J. J. McGrath and R. M. Murray, "Environmental risk factors for schizophrenia," in Schizophrenia, D. R. Weinberger and P. J. Harrison, Eds., pp. 226-233, Wiley-Blackwell, Oxford, UK, 3rd edition, 2011.

[94] E. L. Messias, C. Chen, and W. W. Eaton, "Epidemiology of schizophrenia: review of findings and myths," Psychiatric Clinics of North America, vol. 30, no. 3, pp. 323-338, 2007.

[95] W. W. Eaton, "Evidence for universitality and uniformity of schizophrenia around the world: assessment and implications," in Search for the Causes of Schizophrenia, vol IV. Balance of the Century, H. W. F. Gattaz and H. Häfner, Eds., pp. 21-33, Steinkopff, Darmstadt, Germany, 1999.

[96] T. Helgason, "Epidemiology of mental disorders in Iceland," Acta Psychiatrica Scandinavica, supplement 173, 1964.

[97] C. Astrup, “The increase of mental disorders," The National Case Register of Mental Disorder, Gaustad Hospital, Oslo, Norway, 1982.

[98] J. Krupinski and L. Alexander, "Patterns of psychiatric morbidity in Victoria, Australia, in relation to changes in diagnostic criteria 1848-1978," Social Psychiatry, vol. 18, no. 2, pp. 61-67, 1983.

[99] H. Häfner, "Epidemiology of schizophrenia," in Search for the Causes of Schizophrenia, H. Häfner, W. F. Gattaz, and W. Janzarik, Eds., pp. 47-74, Springer, Berlin, Germany, 1987.

[100] E. G. Torrey, Schizophrenia and Civilization, Aronson, London, UK, 1980.

[101] E. H. Hare, "Was insanity on the increase?" The British Journal of Psychiatry, vol. 142, no. 5, pp. 439-455, 1983.

[102] G. Der, S. Gupta, and R. M. Murray, "Is schizophrenia disappearing?” The Lancet, vol. 335, no. 8688, pp. 513-516, 1990.

[103] G. Harrison, J. E. Cooper, and R. Gancarczyk, "Changes in the administrative incidence of schizophrenia," The British Journal of Psychiatry, vol. 159, pp. 811-816, 1991.

[104] H. Häfner and W. F. Gattaz, "Is schizophrenia disappearing? (letter)," European Archives of Psychiatry and Clinical Neuroscience, vol. 240, pp. 373-378, 1991.

[105] R. M. Murray, S. W. Lewis, and A. M. Reveley, "Towards an aetiological classification of schizophrenia," The Lancet, vol. 1, no. 8436, pp. 1023-1026, 1985.

[106] R. M. Murray, "Neurodevelopmental schizophrenia: the rediscovery of dementia praecox," The British Journal of Psychiatry, vol. 165, no. 25, pp. 6-12, 1994.

[107] R. E. Kendell, D. E. Malcolm, and W. Adams, "The problem of detecting changes in the incidence of schizophrenia," The British Journal of Psychiatry, vol. 162, pp. 212-218, 1993.

[108] R. E. Faris and W. Dunham, Mental Disorders in Urban Areas. An Ecological Study of Schizophrenia and Other Psychoses, University of Chicago Press, Chicago, Ill, USA, 1939.

[109] H. W. Dunham, "Current status of ecological research in mental disorder," Social Forces, vol. 25, no. 3, pp. 321-326, 1947.

[110] H. W. Dunham, "Social class and schizophrenia," American Journal of Orthopsychiatry, vol. 34, pp. 634-642, 1964.

[111] H. W. Dunham, Community and Schizophrenia. An Epidemiological Analysis, Wayne Sstate University Press, Detroit, Mich, USA, 1965.

[112] C. W. Schroeder, "Mental disorders in cities," American Journal of Sociology, vol. 48, no. 1, pp. 40-48, 1942.

[113] E. A. Gardner and H. M. Babigian, "A longitudinal comparison of psychiatric service to selected socioeconomic areas of Monroe County, New York," American Journal of Orthopsychiatry, vol. 36, no. 5, pp. 818-828, 1966.

[114] G. D. Klee, E. Spiro, A. K. Bahn, and K. Gorwitz, "An ecological analysis of diagnosed mental illness in Baltimore," in Psychiatric Epidemiology and Mental Health Planning, R. P. Monroe, G. D. Klee and, and E. B. Brody, Eds., pp. 107-148, American Psychiatric Association, Washington, DC, USA, 1967.

[115] H. W. Dunham, "City core and suburban fringe: distribution pattern of mental illness," in Changing Perspectives in Mental Illness, S. C. Plog and R. Edgerton, Eds., pp. 336-363, Holt, Rinehard and Winstin, New York, NY, USA, 1969. 
[116] H. Häfner, H. Reimann, H. Immich, and H. Martini, "Inzidenz seelischer Erkrankungen in Mannheim 1965," Social Psychiatry, vol. 4, no. 3, pp. 126-135, 1969 (German).

[117] S. Weyerer and H. Häfner, "The stability of the ecological distribution of the incidence of treated mental disorders in the city of Mannheim," Social Psychiatry and Psychiatric Epidemiology, vol. 24, no. 2, pp. 57-62, 1989.

[118] M. Marcelis, F. Navarro-Mateu, R. Murray, J. P. Selten, and J. van Os, "Urbanization and psychosis: a study of 1942-1978 birth cohorts in The Netherlands," Psychological Medicine, vol. 28, no. 4, pp. 871-879, 1998.

[119] W. Löffler and H. Häfner, "Ecological pattern of first admitted schizophrenics in two German cities over 25 years," Social Science and Medicine, vol. 49, no. 1, pp. 93-108, 1999.

[120] P. B. Mortensen, C. B. Pedersen, T. Westergaard et al., "Effects of family history and place and season of birth on the risk of schizophrenia," The New England Journal of Medicine, vol. 340, no. 8, pp. 603-608, 1999.

[121] C. B. Pedersen and P. B. Mortensen, "Family history, place and season of birth as risk factors for schizophrenia in Denmark: a replication and reanalysis," The British Journal of Psychiatry, vol. 178, pp. 46-52, 2001.

[122] C. B. Pedersen and P. B. Mortensen, "Evidence of a doseresponse relationship between urbanicity during upbringing and schizophrenia risk," Archives of General Psychiatry, vol. 58, no. 11, pp. 1039-1046, 2001.

[123] C. B. Pedersen and P. B. Mortensen, "Are the cause(s) responsible for urban-rural differences in schizophrenia risk rooted in families or in individuals?" American Journal of Epidemiology, vol. 163, no. 11, pp. 971-978, 2006.

[124] J. B. Kirkbride, P. Fearon, C. Morgan et al., "Heterogeneity in incidence rates of schizophrenia and other psychotic syndromes: findings from the 3-center ÆSOP study," Archives of General Psychiatry, vol. 63, no. 3, pp. 250-258, 2006.

[125] L. Levy and L. Rowitz, "The spatial distribution of treated mental disorders in Chicago," Social Psychiatry, vol. 5, no. 1, pp. 1-11, 1970.

[126] L. Levy and L. Rowitz, The Ecology of Mental Disorders in Chicago, Behavioral Publications, New York, NY, USA, 1973.

[127] J. A. Giggs and J. E. Cooper, "Ecological structure and the distribution of schizophrenia and affective psychoses in Nottingham," The British Journal of Psychiatry, vol. 151, pp. 627-633, 1987.

[128] H. Häfner and H. Reimann, "Spatial distribution of mental disorders in Mannheim 1965," in Psychiatric Epidemiology, E. H. Hare and J. K. Wing, Eds., pp. 341-354, Oxford University Press, London, UK, 1970.

[129] J. A. Clausen and M. L. Kohn, "The ecological approach in social psychiatry," American Journal of Sociology, vol. 60, pp. 140-149, 1954.

[130] J. A. Clausen and M. L. Kohn, "Social isolation and schizophrenia," American Sociological Review, vol. 20, pp. 265-273, 1955.

[131] J. A. Clausen and M. L. Kohn, "Relation of schizophrenia to the social structure of a small city," in Epidemiology of Mental Disorder, B. Pasamanick, Ed., pp. 69-86, AAAS Publisher, Washington, DC, USA, 1959.

[132] L. Stein, "Social class' gradient in schizophrenia," British Journal Of Preventive \& Social Medicine, vol. 11, no. 4, pp. 181-195, 1957.

[133] D. Klusmann and M. C. Angermeyer, "Urban ecology and psychiatric admission rates: results from a study in the city of Hamburg," in From Social Class to Social Stress, M. C. Angermeyer and D. Klusmann, Eds., pp. 16-45, Springer, Berlin, Germany, 1987.

[134] R. E. L. Faris, "Cultural isolation and the schizophrenic personality," American Journal of Sociology, vol. 40, no. 2, pp. 155-164, 1934.

[135] E. G. Jaco, "The social isolation hypothesis and schizophrenia," American Sociological Review, vol. 19, pp. 567-577, 1954.

[136] A. Hollingshead and F. Redlich, Social Class and Mental Illness, Wiley, New York, NY, USA, 1958.

[137] E. H. Hare and G. K. Shore, Mental Health on a New Housing Estate, Oxford University Press, New York, NY, USA, 1965.

[138] D. L. Gerard and L. G. Houston, "Family setting and the social ecology of schizophrenia," The Psychiatric Quarterly, vol. 27, no. 1-4, pp. 90-101, 1953.

[139] R. Lapouse, M. A. Monk, and M. Terris, "Drift hypothesis and socioeconomic differentials in schizophrenia," American Journal of Public Health, vol. 46, pp. 978-986, 1956.

[140] B. P. Dohrenwend, I. Levav, P. E. Shrout et al., "Socioeconomic status and psychiatric disorders: the causation-selection issue," Science, vol. 255, no. 5047, pp. 946-952, 1992.

[141] K. Dauncey, J. Giggs, K. Baker, and G. Harrison, "Schizophrenia in Nottingham: lifelong residential mobility of a cohort," The British Journal of Psychiatry, vol. 163, pp. 613-619, 1993.

[142] Ö. Ödegård, "The incidence of psychoses in various occupations," International Journal of Social Psychiatry, vol. 2, pp. 85104,1956

[143] Ö. Ödegård, "Hospitalized psychoses in Norway: time trends 1926-1965," Social Psychiatry, vol. 6, no. 2, pp. 53-58, 1971.

[144] W. W. Eaton, "Residence, social class, and schizophrenia," Journal of Health and Social Behavior, vol. 15, no. 4, pp. 289-299, 1974.

[145] E. F. Torrey, A. E. Bowler, and K. Clark, "Urban birth and residence as risk factors for psychoses: an analysis of 1880 data," Schizophrenia Research, vol. 25, no. 3, pp. 169-176, 1997.

[146] J. Allardyce, J. Boydell, J. van Os et al., "Comparison of the incidence of schizophrenia in rural Dumfries and Galloway and urban Camberwell," The British Journal of Psychiatry, vol. 179, pp. 335-339, 2001.

[147] P. B. Mortensen and C. B. Pedersen, "Urban/rural life as a risk factor?" in Risk and Protective Factors in Schizophrenia, H. Häfner, Ed., pp. 123-131, Steinkopff, Darmstadt, Germany, 2002.

[148] W. W. Eaton, P. B. Mortensen, and M. Frydenberg, "Obstetric factors, urbanization and psychosis," Schizophrenia Research, vol. 43, no. 2-3, pp. 117-123, 2000.

[149] F. J. Oher, A. Demjaha, D. Jackson et al., "The effect of the environment on symptom dimensions in the first episode of psychosis: a multilevel study," Psychological Medicine, vol. 44, no. 11, pp. 2419-2430, 2014.

[150] M. Hanssen, M. Bak, R. Bijl, W. Vollebergh, and J. van Os, "Outcome of self-reported psychotic experiences in the general population: a prospective study," in Continuous Psychosis Phenotype: From Description to Prediction, M. Hanssen, Ed., SouthLimburg Mental Health Research and Teaching Network PHD Series, pp. 95-107, M.S.S. Hanssen, Maastricht, The Netherlands, 2004.

[151] F. Jacobi, M. Höfler, J. Siegert et al., “Twelve-month prevalence, comorbidity and correlates of mental disorders in Germany: the Mental Health Module of the German Health Interview and Examinatiion Survey for Adults (DEGS1-MH)," International Journal of Methods in Psychiatric Research, 2014. 
[152] P. B. Mortensen, "Urban-Rural Differences in the Risk for Schizophrenia," International Journal of Mental Health, vol. 29, no. 3, pp. 101-110, 2000.

[153] R. Welz, "Räumliche Verteilung von Selbstmordversuchen in einer städtischen Region. Forschungsartefakte, Aggregierungseffekte und Clusterbildung," in Raumbezogenheit sozialer Probleme (Beiträge zur sozialwissenschaftlichen Forschung, Bd. 35), L. A. Vaskovics, Ed., pp. 250-272, Westdeutscher, Opladen, Germany, 1982, (German).

[154] E. Silver, E. P. Mulvey, and J. W. Swanson, "Neighborhood structural characteristics and mental disorder: Faris and Dunham revisited," Social Science and Medicine, vol. 55, no. 8, pp. 14571470, 2002.

[155] Ö. Ödegård, Emigration and Insanity: A Study of Mental Disease among the Norwegianborn Population of Minnesota, Acta Psychiatrica et Neurologica Scandinavica, supplement 4, 1932.

[156] J. Van Os, M. Hanssen, M. Bak, R. V. Bijl, and W. Vollebergh, "Do urbanicity and familial liability coparticipate in causing psychosis?" The American Journal of Psychiatry, vol. 160, no. 3, pp. 477-482, 2003.

[157] J. van Os, C. B. Pedersen, and P. B. Mortensen, "Confirmation of synergy between urbanicity and familial liability in the causation of psychosis," The American Journal of Psychiatry, vol. 161, no. 12, pp. 2312-2314, 2004.

[158] J. Spauwen, L. Krabbendam, R. Lieb, H. Wittchen, and J. van Os, "Evidence that the outcome of developmental expression of psychosis is worse for adolescents growing up in an urban environment," Psychological Medicine, vol. 36, no. 3, pp. 407$415,2006$.

[159] M. Weiser, J. van Os, A. Reichenberg et al., "Social and cognitive functioning, urbanicity and risk for schizophrenia," The British Journal of Psychiatry, vol. 191, pp. 320-324, 2007.

[160] L. Krabbendam and J. van Os, "Schizophrenia and urbanicity: a major environmental influence-conditional on genetic risk," Schizophrenia Bulletin, vol. 31, no. 4, pp. 795-799, 2005.

[161] J. Van Os, R. J. Linscott, I. Myin-Germeys, P. Delespaul, and L. Krabbendam, "A systematic review and meta-analysis of the psychosis continuum: evidence for a psychosis pronenesspersistence-impairment model of psychotic disorder," Psychological Medicine, vol. 39, no. 2, pp. 179-195, 2009.

[162] D. March, S. L. Hatch, C. Morgan et al., "Psychosis and place," Epidemiologic Reviews, vol. 30, no. 1, pp. 84-100, 2008.

[163] F. Lederbogen, P. Kirsch, L. Haddad et al., "City living and urban upbringing affect neural social stress processing in humans," Nature, vol. 474, no. 7352, pp. 498-501, 2011.

[164] M. Weiser, N. Werbeloff, T. Vishna et al., "Elaboration on immigration and risk for schizophrenia," Psychological Medicine, vol. 38, no. 8, pp. 1113-1119, 2008.

[165] C. Corcoran, M. Perrin, S. Harlap et al., "Incidence of schizophrenia among second-generation immigrants in the Jerusalem Perinatal Cohort," Schizophrenia Bulletin, vol. 35, no. 3, pp. 596602, 2008.

[166] H. Häfner, G. Moschel, and M. Özek, "Psychische Störungen bei türkischen Gastarbeitern. Eine prospektive Studie zur Untersuchung der Reaktion auf Einwanderung und partielle Anpassung," Nervenarzt, vol. 48, pp. 268-275, 1977 (German).

[167] T. J. Gaber, S. Bouyrakhen, B. Herpertz-Dahlmann et al., "Migration background and juvenile mental health: a descriptive retrospective analysis of diagnostic rates of psychiatric disorders in young people," Global Health Action, vol. 6, Article ID 20187, 2013.
[168] R. Littlewood and M. Lipsedge, "Some social and phenomenological characteristics of psychotic immigrants," Psychological Medicine, vol. 11, no. 2, pp. 289-302, 1981.

[169] D. McGovern and R. V. Cope, "First psychiatric admission rates of first and second generation Afro Caribbeans," Social Psychiatry, vol. 22, no. 3, pp. 139-149, 1987.

[170] G. Harrison, D. Owens, A. Holton, D. Neilson, and D. Boot, "A prospective study of severe mental disorder in Afro-Caribbean patients," Psychological Medicine, vol. 18, no. 3, pp. 643-657, 1988.

[171] D. Castle, S. Wessely, G. Der, and R. M. Murray, “The incidence of operationally defined schizophrenia in Camberwell, 196584," The British Journal of Psychiatry, vol. 159, pp. 790-794, 1991.

[172] S. Wessely, D. Castle, G. Der, and R. Murray, "Schizophrenia and Afro-Caribbeans. A case-control study," The British Journal of Psychiatry, vol. 159, pp. 795-801, 1991.

[173] G. Harrison, J. J. Brewin, R. Cantwell et al., "The increased risk of psychosis in African-Caribbean migrants to the UK: a replication," Schizophrenia Research, vol. 18, p. 102, 1996.

[174] D. Bhugra, J. Leff, R. Mallett, G. Der, B. Corridan, and S. Rudge, "Incidence and outcome of schizophrenia in Whites, AfricanCaribbeans and Asians in London," Psychological Medicine, vol. 27, no. 4, pp. 791-798, 1997.

[175] W. Eaton and G. Harrison, "Ethnic disadvantage and schizophrenia," Acta Psychiatrica Scandinavica, Supplement, vol. 102, no. 407, pp. 38-43, 2000.

[176] P. Fearon, J. B. Kirkbride, C. Morgan et al., "Incidence of schizophrenia and other psychoses in ethnic minority groups: results from the MRC AESOP Study," Psychological Medicine, vol. 36, no. 11, pp. 1541-1550, 2006.

[177] J. P. Selten, J. P. J. Slaets, and R. S. Kahn, "Schizophrenia in Surinamese and Dutch Antillean immigrants to The Netherlands: evidence of an increased incidence," Psychological Medicine, vol. 27, no. 4, pp. 807-811, 1997.

[178] J. P. Selten, N. Veen, W. Feller et al., "Incidence of psychotic disorders in immigrant groups to the Netherlands," The British Journal of Psychiatry, vol. 178, pp. 367-372, 2001.

[179] W. Veling, J.-P. Selten, N. Veen, W. Laan, J. D. Blom, and H. W. Hoek, "Incidence of schizophrenia among ethnic minorities in the Netherlands: a four-year first-contact study," Schizophrenia Research, vol. 86, no. 1-3, pp. 189-193, 2006.

[180] E. Cantor-Graae, C. B. Pedersen, T. F. McNeil, and P. B. Mortensen, "Migration as a risk factor for schizophrenia: a Danish population-based cohort study," The British Journal of Psychiatry, vol. 182, pp. 117-122, 2003.

[181] K. Zolkowska, E. Cantor-Graae, and T. F. McNeil, "Increased rates of psychosis among immigrants to Sweden: is migration a risk factor for psychosis?" Psychological Medicine, vol. 31, no. 4, pp. 669-678, 2001.

[182] P. A. Sugarman and D. Craufurd, "Schizophrenia in the AfroCaribbean community," The British Journal of Psychiatry, vol. 164, pp. 474-480, 1994.

[183] J. W. Coid, J. B. Kirkbride, D. Barker et al., "Raised incidence rates of all psychoses among migrant groups: findings from the East london first episode psychosis study," Archives of General Psychiatry, vol. 65, no. 11, pp. 1250-1258, 2008.

[184] J. B. Kirkbride, D. Barker, F. Cowden et al., "Psychoses, ethnicity and socio-economic status," The British Journal of Psychiatry, vol. 193, no. 1, pp. 18-24, 2008.

[185] A. Hjern, S. Wicks, and C. Dalman, "Social adversity contributes to high morbidity in psychoses in immigrants-a national 
cohort study in two generations of Swedish residents," Psychological Medicine, vol. 34, no. 6, pp. 1025-1033, 2004.

[186] T. S. Leão, J. Sundquist, G. Frank, L. Johansson, S. Johansson, and K. Sundquist, "Incidence of schizophrenia or other psychoses in first- and second-generation immigrants: a national cohort study," Journal of Nervous and Mental Disease, vol. 194, no. 1, pp. 27-33, 2006.

[187] F. W. Hickling and P. Rodgers-Johnson, "The incidence of first contact schizophrenia in Jamaica," The British Journal of Psychiatry, vol. 167, pp. 193-196, 1995.

[188] G. E. Mahy, R. Mallett, J. Leff, and D. Bhugra, "First-contact incidence rate of schizophrenia on Barbados," The British Journal of Psychiatry, vol. 175, pp. 28-33, 1999.

[189] D. Bhugra, M. Hilwig, B. Hossein et al., "First-contact incidence rates of schizophrenia in Trinidad and one-year follow-up," The British Journal of Psychiatry, vol. 169, no. 5, pp. 587-592, 1996.

[190] J. Selten, E. Cantor-Graae, J. Slaets, and R. S. Kahn, “Ødegaard's selection hypothesis revisited: schizophrenia in Surinamese immigrants to the Netherlands," The American Journal of Psychiatry, vol. 159, no. 4, pp. 669-671, 2002.

[191] J. Allardyce, H. Gilmour, J. Atkinson, T. Rapson, J. Bishop, and R. G. McCreadie, "Social fragmentation, deprivation and urbanicity: relation to first-admission rates for psychoses," The British Journal of Psychiatry, vol. 187, pp. 401-406, 2005.

[192] J. Boydell, J. van Os, K. McKenzie et al., "Incidence of schizophrenia in ethnic minorities in London: ecological study into interactions with environment," The British Medical Journal, vol. 323, no. 7325, pp. 1336-1338, 2001.

[193] E. Cantor-Graae and J. Selten, "Schizophrenia and migration: a meta-analysis and review," The American Journal of Psychiatry, vol. 162, no. 1, pp. 12-24, 2005.

[194] W. Veling, J. Selten, J. P. Mackenbach, and H. W. Hoek, "Symptoms at first contact for psychotic disorder: comparison between native Dutch and ethnic minorities," Schizophrenia Research, vol. 95, no. 1-3, pp. 30-38, 2007.

[195] W. Veling, J. Selten, E. Susser, W. Laan, J. P. Mackenbach, and H. W. Hoek, "Discrimination and the incidence of psychotic disorders among ethnic minorities in The Netherlands," International Journal of Epidemiology, vol. 36, no. 4, pp. 761-768, 2007.

[196] W. Veling, E. Susser, J. van Os, J. P. Mackenbach, J. Selten, and H. W. Hoek, "Ethnic density of neighborhoods and incidence of psychotic disorders among immigrants," The American Journal of Psychiatry, vol. 165, no. 1, pp. 66-73, 2008.

[197] J. B. Kirkbride, C. Morgan, P. Fearon, P. Dazzan, R. M. Murray, and P. B. Jones, "Neighbourhood-level effects on psychoses: Reexamining the role of context," Psychological Medicine, vol. 37, no. 10, pp. 1413-1425, 2007.

[198] E. Essen-Möller, "Untersuchungen über die Fruchtbarkeit gewisser Gruppen von Geisteskranken," Acta Psychiatrica et Neurologica Scandinavica, vol. 8, 1935 (German).

[199] Ö. Ödegård, "Fertility of psychiatric first admissions in Norway 1936-1975," Acta Psychiatrica Scandinavica, vol. 62, no. 3, pp. 212-220, 1980.

[200] F. Haverkamp, P. Propping, and T. Hilger, "Is there an increase of reproductive rates in schizophrenics? I. Critical review of the literature," Archiv für Psychiatrie und Nervenkrankheiten, vol. 232, no. 5, pp. 439-450, 1982.

[201] T. Hilger, P. Propping, and F. Haverkamp, "Is there an increase of reproductive rates in schizophrenics? III. An investigation in Nordbaden (SW Germany): results and discussion," Archiv für Psychiatrie und Nervenkrankheiten, vol. 233, no. 3, pp. 177-186, 1983.
[202] P. Propping, T. Hilger, and F. Haverkamp, "Is there an increase of reproductive rates in schizophrenics? II. An investigation in Nordbaden (SW Germany): methods and description of the patient sample," Archiv fur Psychiatrie und Nervenkrankheiten, vol. 233, no. 3, pp. 167-175, 1983.

[203] L. Fananas and J. Bertranpetit, "Reproductive rates in families of schizophrenic patients in a case-control study," Acta Psychiatrica Scandinavica, vol. 91, no. 3, pp. 202-204, 1995.

[204] J. J. McGrath, J. Hearle, L. Jenner, K. Plant, A. Drummond, and J. M. Barkla, "The fertility and fecundity of patients with psychoses," Acta Psychiatrica Scandinavica, vol. 99, no. 6, pp. 441-446, 1999.

[205] V. L. Nimgaonkar, S. E. Ward, H. Agarde, N. Weston, and R. Ganguli, "Fertility in schizophrenia: results from a contemporary US cohort," Acta Psychiatrica Scandinavica, vol. 95, no. 5, pp. 364-369, 1997.

[206] J. Haukka, J. Suvisaari, and J. Lönnqvist, "Fertility of patients with schizophrenia, their siblings, and the general population: a cohort study from 1950 to 1959 in Finland," The American Journal of Psychiatry, vol. 160, no. 3, pp. 460-463, 2003.

[207] J. H. MacCabe, I. Koupil, and D. A. Leon, "Lifetime reproductive output over two generations in patients with psychosis and their unaffected siblings: the Uppsala 1915-1929 Birth Cohort Multigenerational Study," Psychological Medicine, vol. 39, no. 10, pp. 1667-1676, 2009.

[208] D. Ropeter, Fertilitätsraten schizophren Erkrankter-Trends über 5 Jahrzehnte und Versuche ihrer Erklärung (Doctoral thesis), Faculty of Clinical Medicine Mannheim, Ruprecht Karls University of Heidelberg, Heidelberg, Germany, 2006, (German).

[209] A. C. Svensson, P. Lichtenstein, S. Sandin, and C. M. Hultman, "Fertility of first-degree relatives of patients with schizophrenia: a three generation perspective," Schizophrenia Research, vol. 91, no. 1-3, pp. 238-245, 2007.

[210] B. Xu, J. L. Roos, P. Dexheimer et al., "Exome sequencing supports a de novo mutational paradigm for schizophrenia," Nature Genetics, vol. 43, no. 9, pp. 864-868, 2011.

[211] J. L. Waddington and H. A. Youssef, "Familial-genetic and reproductive epidemiology of schizophrenia in rural Ireland: age at onset, familial morbid risk and parental fertility," Acta Psychiatrica Scandinavica, vol. 93, no. 1, pp. 62-68, 1996.

[212] M. Avila, G. Thaker, and H. Adami, "Genetic epidemiology and schizophrenia: a study of reproductive fitness," Schizophrenia Research, vol. 47, no. 2-3, pp. 233-241, 2001.

[213] A. Jablensky, J. B. Kirkbride, and P. B. Jones, "Schizophrenia: the epidemiological horizon," in Schizophrenia, D. R. Weinberger and P. J. Harrison, Eds., pp. 185-225, Wiley-Blackwell, Oxford, UK, 3rd edition, 2011.

[214] H. Stefansson, R. A. Ophoff, S. Steinberg et al., "Common variants conferring risk of schizophrenia," Nature, vol. 460, pp. 744747, 2009.

[215] J. R. Geddes and S. M. Lawrie, "Obstetric complications and schizophrenia: a meta-analysis," The British Journal of Psychiatry, vol. 167, pp. 786-793, 1995.

[216] C. M. Hultman, A. Öhman, S. Cnattingius, I. M. Wieselgren, and L. H. Lindstrom, "Prenatal and neonatal risk factors for schizophrenia," The British Journal of Psychiatry, vol. 170, pp. 128-133, 1997.

[217] M. Cannon, P. B. Jones, and R. M. Murray, "Obstetric complications and schizophrenia: historical and meta-analytic review," The American Journal of Psychiatry, vol. 159, no. 7, pp. 1080-1092, 2002. 
[218] P. Rantakallio, P. Jones, J. Moring, and L. von Wendt, "Association between central nervous system infections during childhood and adult onset schizophrenia and other psychoses: a 28year follow-up," International Journal of Epidemiology, vol. 26, no. 4, pp. 837-843, 1997.

[219] W. F. Gattaz, A. L. Abrahao, and R. Foccacia, "Childhood meningitis and adult schizophrenia," in Search for the Causes of Schizophrenia, W. F. Gattaz and H. Häfner, Eds., pp. 26-31, Steinkopff, Darmstadt, Germany, 2004.

[220] A. L. Abrahao, R. Focaccia, and W. F. Gattaz, "Childhood meningitis increases the risk for adult schizophrenia," World Journal of Biological Psychiatry, vol. 6, supplement 2, pp. 44-48, 2005.

[221] G. Harrison, C. Glazebrook, J. Brewin et al., "Increased incidence of psychotic disorders in migrants from the Caribbean to the United Kingdom," Psychological Medicine, vol. 27, no. 4, pp. 799-806, 1997.

[222] E. Kringlen, Heredity and Environment in the Functional Psychoses: An Epidemiological-Clinical Study, University Press, Oslo, Norway, 1967, reprinted by Heinemann, London, UK, 1968.

[223] E. Kringlen, “Twins: still our best method," Schizophrenia Bulletin, vol. 2, no. 3, pp. 429-433, 1976.

[224] I. I. Gottesman and J. Shields, Schizophrenia: The Epigenetic Puzzle, Sage, New York, NY, USA, 1982.

[225] P. McGuffin, A. E. Farmer, I. I. Gottesman, R. M. Murray, and A. M. Reveley, "Twin concordance for operationally defined schizophrenia. Confirmation of familiality and heritability," Archives of General Psychiatry, vol. 41, no. 6, pp. 541-545, 1984.

[226] A. E. Farmer, P. McGuffin, and I. I. Gottesman, "Twin concordance for DSM-III schizophrenia: scrutinizing the validity of the definition," Archives of General Psychiatry, vol. 44, no. 7, pp. 634-641, 1987.

[227] T. D. Cannon, J. Kaprio, J. Lönnqvist, M. Huttunen, and M. Koskenvuo, "The genetic epidemiology of schizophrenia in a Finnish twin cohort: a population-based modeling study," Archives of General Psychiatry, vol. 55, no. 1, pp. 67-74, 1998.

[228] S. Onstad, I. Skre, S. Torgersen, and E. Kringlen, "Twin concordance for DSM-III-R schizophrenia," Acta Psychiatrica Scandinavica, vol. 83, no. 5, pp. 395-401, 1991.

[229] A. G. Cardno and I. I. Gottesman, “Twin studies of schizophrenia: from bow-and-arrow concordances to STAR WARS Mx and functional genomics," American Journal of Medical Genetics, vol. 97, no. 1, pp. 12-17, 2000.

[230] W. Coryell and M. Zimmerman, "The heritability of schizophrenia and schizoaffective disorder. A family study," Archives of General Psychiatry, vol. 45, no. 4, pp. 323-327, 1988.

[231] E. S. Gershon, L. E. DeLisi, J. Hamovit et al., "A controlled family study of chronic psychoses. Schizophrenia and schizoaffective disorder," Archives of General Psychiatry, vol. 45, no. 4, pp. 328336, 1988.

[232] W. Maier, D. Lichtermann, J. Minges et al., "Continuity and discontinuity of affective disorders and schizophrenia: results of a controlled family study," Archives of General Psychiatry, vol. 50, no. 11, pp. 871-883, 1993.

[233] J. Parnas, T. D. Cannon, B. Jacobsen, H. Schulsinger, F. Schulsinger, and S. A. Mednick, "Lifetime DSM-III-R diagnostic outcomes in the offspring of schizophrenic mothers: results from the Copenhagen high-risk study," Archives of General Psychiatry, vol. 50, no. 9, pp. 707-714, 1993.
[234] P. F. Sullivan, K. S. Kendler, and M. C. Neale, "Schizophrenia as a complex trait: evidence from a meta-analysis of twin studies," Archives of General Psychiatry, vol. 60, no. 12, pp. 1187-1192, 2003.

[235] I. I. Gottesman, Schizophrenia Genesis: The Origins of Madness, W. H. Freeman, New York, NY, USA, 1991.

[236] B. Riley and K. S. Kendler, "Classical genetic studies of schizophrenia," in Schizophrenia, D. R. Weinberger and P. J. Harrison, Eds., pp. 245-268, Wiley-Blackwell, Oxford, UK, 3rd edition, 2011.

[237] P. Tienari, L. C. Wynne, K. Läksy et al., "Genetic boundaries of the schizophrenia spectrum: evidence from the Finnish adoptive family study of schizophrenia," The American Journal of Psychiatry, vol. 160, no. 9, pp. 1587-1594, 2003.

[238] C. Wynne, P. Tienari, P. Nieminen et al., "I. Genotype-environment interaction in the schizophrenia spectrum: genetic liability and global family ratings in the Finnish adoption study," Family Process, vol. 45, no. 4, pp. 419-434, 2006.

[239] H. Wickham, C. Walsh, P. Asherson et al., "Familiality of clinical characteristics in schizophrenia," Journal of Psychiatric Research, vol. 36, no. 5, pp. 325-329, 2002.

[240] W. Maier, J. Hallmayer, J. Minges, and D. Lichtermann, “Morbid risks in relatives of affective, schizoaffective and schizophrenic patients. Results of a family study," in Affective and Schizoaffective Disorders. Similarities and Differences, A. Marneros and M. T. Tsuang, Eds., pp. 201-207, Springer, Berlin, Germany, 1990.

[241] J. X. van Snellenberg and T. de Candia, "Meta-analytic evidence for familial coaggregation of schizophrenia and bipolar disorder," Archives of General Psychiatry, vol. 66, no. 7, pp. 748-755, 2009.

[242] M. Baron and N. Risch, "The spectrum concept of schizophrenia: evidence for a genetic-environmental continuum," Journal of Psychiatric Research, vol. 21, no. 3, pp. 257-267, 1987.

[243] S. Ripke, C. O’Dushlaine, K. Chambert et al., "Genome-wide association analysis identifies 13 new risk loci for schizophrenia," Nature Genetics, vol. 45, pp. 1150-1159, 2013.

[244] Schizophrenia Working Group of the Psychiatric Genomics Consortium, "Biological insights from 108 schizophreniaassociated genetic loci," Nature, vol. 511, no. 7510, pp. 421-427, 2014.

[245] I. I. Gottesman and T. D. Gould, "The endophenotype concept in psychiatry: etymology and strategic intentions," The American Journal of Psychiatry, vol. 160, no. 4, pp. 636-645, 2003.

[246] C. Esslinger, H. Walter, P. Kirsch et al., "Neural mechanisms of a genome-wide supported psychosis variant," Science, vol. 324, no. 5927, p. 605, 2009.

[247] J. L. Hess and S. J. Glatt, "How might ZNF804A variants influence risk for schizophrenia and bipolar disorder? A literature review, synthesis, and bioinformatic analysis," The American Journal of Medical Genetics B: Neuropsychiatric Genetics, vol. 165, no. 1, pp. 28-40, 2014.

[248] International Schizophrenia Consortium, S. M. Purcell, N. R. Wray et al., "Common polygenic variation contributes to risk of schizophrenia and bipolar disorder," Nature, vol. 460, pp. 748$752,2009$.

[249] J. Yang, S. H. Lee, M. E. Goddard, and P. M. Visscher, "GCTA: a tool for genome-wide complex trait analysis," The American Journal of Human Genetics, vol. 88, no. 1, pp. 76-82, 2011.

[250] S. H. Lee, T. R. DeCandia, S. Ripke et al., "Estimating the proportion of variation in susceptibility to Schizophrenia captured by common SNPs," Nature Genetics, vol. 44, pp. 247-250, 2014. 
[251] Cross-Disorder Group of the Psychiatric Genomics, S. H. Lee, S. Ripke et al., "Genetic relationship between five psychiatric disorders estimated from genome-wide SNPs," Nature Genetics, vol. 45, no. 9, pp. 984-994, 2013.

[252] J. Frank, M. Lang, S. H. Witt et al., "Identification of increased genetic risk scores for schizophrenia in treatment-resistant patients," Molecular Psychiatry, 2014.

[253] T. Lencz, E. Knowles, and G. Davies, "Molecular genetic evidence for overlap between general cognitive ability and risk for schizophrenia: a report from the Cognitive Genomics consortium (COGENT)," Molecular Psychiatry, vol. 19, pp. 168-174, 2014.

[254] A. Hoischen, N. Krumm, and E. E. Eichler, "Priorization of neurodevelopmental disease genes by discovery of new mutations," Nature Neuroscience, vol. 17, pp. 764-772, 2014.

[255] J. P. Szatkiewicz, C. O’Dushlaine, G. Chen et al., "Copy number variation in schizophrenia in Sweden," Molecular Psychiatry, vol. 19, pp. 762-773, 2014.

[256] J. L. Doherty and M. J. Owen, "Genomic insights into the overlap between psychiatric disorders: implications for research and clinical practice," Genome Medicine, vol. 6, pp. 29-42, 2014.

[257] H. Stefansson, A. Meyer-Lindenberg, S. Steinberg et al., "CNVs conferring risk of autism or schizophrenia affect cognition in controls," Nature, vol. 505, no. 7483, pp. 361-366, 2014.

[258] T. F. McNeil, "Perinatal risk factors and schizophrenia: selective review and methodological concerns," Epidemiologic Reviews, vol. 17, no. 1, pp. 107-112, 1995.

[259] J. R. Geddes, H. Verdoux, N. Takei et al., "Schizophrenia and complications of pregnancy and labor: an individual patient data meta-analysis," Schizophrenia Bulletin, vol. 25, no. 3, pp. 413-423, 1999.

[260] C. McDonald and R. M. Murray, "Early and late environmental risk factors for schizophrenia," Brain Research Reviews, vol. 31, no. 2-3, pp. 130-137, 2000.

[261] T. D. Cannon, I. M. Rosso, J. M. Hollister, C. E. Bearden, L. E. Sanchez, and T. Hadley, "A prospective cohort study of genetic and perinatal influences in the etiology of schizophrenia," Schizophrenia Bulletin, vol. 26, no. 2, pp. 351-366, 2000.

[262] P. B. Jones, P. Rantakallio, A. Hartikainen, M. Isohanni, and P. Sipilä, "Schizophrenia as a long-term outcome of pregnancy, delivery, and perinatal complications: a 28 -year follow-up of the 1966 North Finland general population birth cohort," The American Journal of Psychiatry, vol. 155, no. 3, pp. 355-364, 1998.

[263] M. Isohanni, E. Lauronen, K. Moilanen et al., "Predictors of schizophrenia: evidence from the Northern Finland 1966 Birth Cohort and other sources," The British Journal of Psychiatry, vol. 187, no. 48, pp. s4-s7, 2005.

[264] A. Heck, M. Fastenrath, S. Ackermann et al., "Converging genetic and functional brain imaging evidence links neural excitability to working memory, psychiatric disease, and brain activity," Neuron, vol. 81, no. 5, pp. 1203-1213, 2014.

[265] L. J. Seidman, S. L. Buka, J. M. Goldstein, and M. T. Tsuang, "Intellectual decline in schizophrenia: evidence from a prospective birth cohort 28 year follow-up study," Journal of Clinical and Experimental Neuropsychology, vol. 28, no. 2, pp. 225-242, 2006.

[266] S. A. Mednick and F. Schulsinger, "A longitudinal study of children with a high risk for schizophrenia: a preliminary report," in Methods and Goal in Human Behavior Genetics, S. Vangenberg, Ed., pp. 255-296, Academic Press, New York, NY, USA, 1965.
[267] S. A. Mednick and F. Schulsiger, "Some premorbid characteristics related to breakdown in children with schizophrenic mothers," in Transmission of Schizophrenia, D. Rosenthal and S. S. Kety, Eds., pp. 267-291, Pergamon Press, New York, NY, USA, 1968.

[268] J. R. Asarnow, "Children at risk for schizophrenia: converging lines of evidence," Schizophrenia Bulletin, vol. 14, no. 4, pp. 613631, 1988.

[269] L. Erlenmeyer-Kimling, D. Rock, E. Squires-Wheeler, S. Roberts, and J. Yang, "Early life precursors of psychiatric outcomes in adulthood in subjects at risk for schizophrenia or affective disorders," Psychiatry Research, vol. 39, no. 3, pp. 239-256, 1991.

[270] L. Erlenmeyer-Kimling, B. A. Cornblatt, D. Rock, S. Roberts, M. Bell, and A. West, "The New York high-risk project: anhedonia, attentional deviance, and psychopathology," Schizophrenia Bulletin, vol. 19, no. 1, pp. 141-153, 1993.

[271] L. Erlenmeyer-Kimling, E. Squires-Wheeler, U. H. Adamo, and A. S. Bassett, "The New York high-risk project," Archives of General Psychiatry, vol. 52, pp. 857-865, 1995.

[272] L. Erlenmeyer-Kimling, U. H. Adamo, D. Rock et al., “The New York high-risk project," Archives of General Psychiatry, vol. 54, pp. 1096-1102, 1997.

[273] M. Dragovic, F. A. V. Waters, and A. Jablensky, "Estimating premorbid intelligence in schizophrenia patients: demographically based approach," Australian \& New Zealand Journal of Psychiatry, vol. 42, no. 9, pp. 814-818, 2008.

[274] V. A. Morgan, H. Leonard, J. Bourke, and A. Jablensky, "Intellectual disability co-occurring with schizophrenia and other psychiatric illness: population-based study," The British Journal of Psychiatry, vol. 193, no. 5, pp. 364-372, 2008.

[275] B. Cornblatt, M. Obuchowski, S. Roberts, S. Pollack, and L. Erlenmeyer-Kimling, "Cognitive and behavioral precursors of schizophrenia," Development and Psychopathology, vol. 11, no. 3, pp. 487-508, 1999.

[276] J. Marcus, J. Auerbach, L. Wilkinson, and C. M. Burack, "Infants at risk for schizophrenia: the Jerusalem Infant Development Study," Archives of General Psychiatry, vol. 38, no. 6, pp. 703-713, 1981.

[277] J. Marcus, S. L. Hans, E. Lewow, L. Wilkinson, and C. M. Burack, "Neurological findings in high-risk children: childhood assessment and 5-year followup," Schizophrenia Bulletin, vol. 11, no. 1, pp. 85-100, 1985.

[278] B. Fish, J. Marcus, S. L. Hans, J. G. Auerbach, and S. Perdue, "Infants at risk for schizophrenia: sequelae of a genetic neurointegrative defect. A review and replication analysis of pandysmaturation in the Jerusalem infant development study," Archives of General Psychiatry, vol. 49, no. 3, pp. 221-235, 1992.

[279] E. F. Walker, T. Savoie, and D. Davis, "Neuromotor precursors of schizophrenia," Schizophrenia Bulletin, vol. 20, no. 3, pp. 441451, 1994.

[280] E. E. Walker, J. Weinstein, K. Baum, and C. S. Neumann, "Antecedents of schizophrenia: Moderating effects of development and biological sex," in Search for the Causes of Schizophrenia, $\mathrm{H}$. Häfner and W. F. Gattaz, Eds., vol. 3, pp. 21-42, Springer, Berlin, Germany, 1995.

[281] O. D. Howes, C. McDonald, M. Cannon, L. Arseneault, J. Boydell, and R. M. Murray, "Pathways to schizophrenia: the impact of environmental factors," International Journal of Neuropsychopharmacology, vol. 7, no. 1, pp. S7-S13, 2004.

[282] P. H. Connell, Amphetamine Psychosis, Chapman \& Hall, London, UK, 1958. 
[283] K. Nakamura, C. Chen, Y. Sekine et al., "Association analysis of SOD2 variants with methamphetamine psychosis in Japanese and Taiwanese populations," Human Genetics, vol. 120, no. 2, pp. 243-252, 2006.

[284] R. Näkki, J. Koistinaho, F. R. Sharp, and S. M. Sagar, "Cerebellar toxicity of phencyclidine," Journal of Neuroscience, vol. 15, part 2, no. 3, pp. 2097-2108, 1995.

[285] S. Andreasson, P. Allebeck, A. Engstrom, and U. Rydberg, "Cannabis and schizophrenia. A longitudinal study of Swedish conscripts," The Lancet, vol. 2, no. 8574, pp. 1483-1486, 1987.

[286] P. Allebeck, C. Adamsson, and A. Engstrom, "Cannabis and schizophrenia: a longitudinal study of cases treated in Stockholm county," Acta Psychiatrica Scandinavica, vol. 88, no. 1, pp. 21-24, 1993.

[287] M. Hambrecht and H. Häfner, "Substance abuse and the onset of schizophrenia," Biological Psychiatry, vol. 40, no. 11, pp. 1155$1163,1996$.

[288] L. Arseneault, M. Cannon, R. Poulton, R. Murray, A. Caspi, and T. E. Moffitt, "Cannabis use in adolescence and risk for adult psychosis: longitudinal prospective study," British Medical Journal, vol. 325, no. 7374, pp. 1212-1213, 2002.

[289] S. Zammit, P. Allebeck, S. Andreasson, I. Lundberg, and G. Lewis, "Self reported cannabis use as a risk factor for schizophrenia in Swedish conscripts of 1969: historical cohort study," The British Medical Journal, vol. 325, no. 7374, pp. 1199-1201, 2002.

[290] C. Henquet, R. Murray, D. Linszen, and J.van Os, "The environment and schizophrenia: the role of cannabis use," Schizophrenia Bulletin, vol. 31, no. 3, pp. 608-612, 2005.

[291] T. H. Moore, S. Zammit, A. Lingford-Hughes et al., "Cannabis use and risk of psychotic or affective mental health outcomes: a systematic review," The Lancet, vol. 370, no. 9584, pp. 319-328, 2007.

[292] D. J. Foti, R. Kotov, L. T. Guey, and E. J. Bromet, "Cannabis use and the course of schizophrenia: 10-year follow-up after first hospitalization," The American Journal of Psychiatry, vol. 167, no. 8, pp. 987-993, 2010.

[293] E. Manrique-Garcia, S. Zammit, C. Dalman, T. Hemmingsson, S. Andreasson, and P. Allebeck, "Prognosis of schizophrenia in persons with and without a history of cannabis use," Psychological Medicine, 2014.

[294] P. Jones, B. Rodgers, R. Murray, and M. Marmot, "Child developmental risk factors for adult schizophrenia in the British 1946 birth cohort," The Lancet, vol. 344, no. 8934, pp. 1398-1402, 1994.

[295] P. Jones and D. J. Done, "From birth to onset: a developmental perspective of schizophrenia in two national birth cohorts," in Neurodevelopmental Models of Psychopathology, M. S. Keshavan and R. M. Murray, Eds., pp. 119-136, Cambridge University Press, Cambridge, UK, 1997.

[296] P. B. Jones and C. J. Tarrant, "Vorläufersymptome funktioneller Psychosen," ZNS Journal, vol. 18, pp. 4-15, 1998 (German).

[297] D. J. Done, T. J. Crow, E. C. Johnstone, and A. Sacker, "Childhood antecedents of schizophrenia and affective illness: social adjustment at ages 7 and 11," British Medical Journal, vol. 309, no. 6956, pp. 699-703, 1994.

[298] R. Poulton, A. Caspi, T. E. Moffitt, M. Cannon, R. Murray, and H. Harrington, "Children's self-reported psychotic symptoms and adult schizophreniform disorder: a 15-year longitudinal study," Archives of General Psychiatry, vol. 57, no. 11, pp. 10531058, 2000.
[299] M. Cannon, T. E. Moffitt, A. Caspi, R. M. Murray, H. Harrington, and R. Poulton, "Neuropsychological performance at the age of 13 years and adult schizophreniform disorder: prospective birth cohort study," The British Journal of Psychiatry, vol. 189, pp. 463-464, 2006.

[300] M. Isohanni, P. Rantakallio, P. Jones et al., "The predictors of schizophrenia in the 1966 Northern Finland Birth Cohort study," Schizophrenia Research, vol. 29, p. 11, 1998.

[301] I. Isohanni, M.-R. Järvelin, P. Nieminen et al., "School performance as a predictor of psychiatric hospitalization in adult life. A 28-year follow-up in the Northern Finland 1966 Birth Cohort," Psychological Medicine, vol. 28, no. 4, pp. 967-974, 1998.

[302] M. Isohanni, P. B. Jones, S. Räsänen et al., "Early developmental milestones in adult schizophrenia. A 28-year follow-up of the North Finland birth cohort," Schizophrenia Research, vol. 52, pp. $1-19,2001$.

[303] P. B. Jones, R. M. Murray, and B. Rodgers, "Childhood risk factors for schizophrenia in a general population birth cohort at age 43 years," in Neural Development in Schizophrenia: Theory and Practice, S. A. Mednick and J. M. Hollister, Eds., pp. 151-176, Plenum Press, New York, NY, USA, 1995.

[304] P. B. Jones, "Risk factors for schizophrenia in childhood and youth," in Risk and Protective Factors in Schizophreni, H. Häfner, Ed., pp. 141-162, Steinkopff, Darmstadt, Germany, 2002.

[305] M. Solomon, E. Olsen, T. Niendam et al., "From lumping to splitting and back again: atypical social and language development in individuals with clinical-high-risk for psychosis, first episode schizophrenia, and autism spectrum disorders," Schizophrenia Research, vol. 131, no. 1-3, pp. 146-151, 2011.

[306] A. Piton, J. Gauthier, F. F. Hamdan et al., "Systematic resequencing of X-chromosome synaptic genes in autism spectrum disorder and schizophrenia," Molecular Psychiatry, vol. 16, no. 8, pp. 867-880, 2011.

[307] R. Waltereit, T. Banaschewski, A. Meyer-Lindenberg, and L. Poustka, "Interaction of neurodevelopmental pathways and synaptic plasticity in mental retardation, autism spectrum disorder and schizophrenia: Implications for psychiatry," World Journal of Biological Psychiatry, 2013.

[308] A. S. David, A. Malmberg, L. Brandt, P. Allebeck, and G. Lewis, "IQ and risk for schizophrenia: A population-based cohort study," Psychological Medicine, vol. 27, no. 6, pp. 1311-1323, 1997.

[309] A. Malmberg, G. Lewis, A. David, and P. Allebeck, "Premorbid adjustment and personality in people with schizophrenia," The British Journal of Psychiatry, vol. 172, pp. 308-313, 1998.

[310] M. Davidson, A. Reichenberg, J. Rabinowitz, M. Weiser, Z. Kaplan, and M. Mark, "Behavioral and intellectual markers for schizophrenia in apparently healthy male adolescents," The American Journal of Psychiatry, vol. 156, no. 9, pp. 1328-1335, 1999.

[311] M. Weiser, "Association between cognitive and behavioral functioning, non-psychotic psychiatric diagnoses, and drug abuse in adolescence, with later hospitalization for schizophrenia," in Risk and Protective Factors in Schizophrenia, H. Häfner, Ed., pp. 163-175, Steinkopff, Darmstadt, Germany, 2002.

[312] I. Isohanni, M.-R. Järvelin, P. Jones, J. Jokelainen, and M. Isohanni, "Can excellent school performance be a precursor of schizophrenia? A 28-year follow-up in the Northern Finland 1966 birth cohort," Acta Psychiatrica Scandinavica, vol. 100, no. 1, pp. 17-26, 1999. 
[313] J. Bertranpetit and L. Fananas, "Parental age in schizophrenia in a case-controlled study," The British Journal of Psychiatry, vol. 162, p. 574, 1993.

[314] D. Malaspina, S. Harlap, S. Fennig et al., "Advancing paternal age and the risk of schizophrenia," Archives of General Psychiatry, vol. 58, no. 4, pp. 361-367, 2001.

[315] A. S. Brown, C. A. Schaefer, R. J. Wyatt et al., "Paternal age and risk of schizophrenia in adult offspring," The American Journal of Psychiatry, vol. 159, no. 9, pp. 1528-1533, 2002.

[316] A. Jung, H. C. Schuppe, and W. B. Schill, "Are children of older fathers at risk for genetic disorders?" Andrologia, vol. 35, no. 4, pp. 191-199, 2003.

[317] M. C. Perrin, A. S. Brown, and D. Malaspina, "Aberrant epigenetic regulation could explain the relationship of paternal age to schizophrenia," Schizophrenia Bulletin, vol. 33, no. 6, pp. 12701273, 2007.

[318] J. J. McGrath, L. Petersen, E. Agerbo, O. Mors, P. B. Mortensen, and C. B. Pedersen, "A comprehensive assessment of parental age and psychiatric disorders," The Journal of the American Medical Association Psychiatry, vol. 71, no. 3, pp. 301-309, 2014.

[319] A. E. Jaffe, W. W. Eaton, R. E. Straub, S. Marenco, and D. R. Weinberger, "Paternal age, de novo mutations and schizophrenia," Molecular Psychiatry, vol. 19, pp. 274-283, 2014.

[320] B. Miller, E. Messias, J. Miettunen et al., "Meta-analysis of paternal age and schizophrenia risk in male versus female offspring," Schizophrenia Bulletin, vol. 37, no. 5, pp. 1039-1047, 2011.

[321] A. Kong, M. L. Frigge, G. Masson et al., "Rate of de novo mutations and the importance of father's age to disease risk," Nature, vol. 488, no. 7412, pp. 471-475, 2012.

[322] L. Petersen, P. B. Mortensen, and C. B. Pedersen, "Paternal age at birth of first child and risk of schizophrenia," The American Journal of Psychiatry, vol. 168, pp. 82-88, 2011.

[323] H. Häfner, K. Maurer, W. Löffler et al., "Onset and early course of schizophrenia," in Search for the Causes of Schizophrenia III, H. Häfner and W. F. Gattaz, Eds., pp. 43-66, Springer, Berlin, Germany, 1995.

[324] N. C. Stefanis, M. Hanssen, N. K. Smirnis et al., "Evidence that three dimensions of psychosis have a distribution in the general population," Psychological Medicine, vol. 32, no. 2, pp. 347-358, 2002.

[325] J. van Os, H. Verdoux, S. Maurice-Tison et al., "Self-reported psychosis-like symptoms and the continuum of psychosis," Social Psychiatry and Psychiatric Epidemiology, vol. 34, no. 9, pp. 459-463, 1999.

[326] H.-U. Wittchen, M. Höfler, R. Lieb, J. Spauwen, and J. van Os, "Depressive und psychotische Symptome in der BevölkerungEine prospektiv-longitudinale Studie (EDSP) an 2.500 Jugendlichen und jungen Erwachsenen," Nervenarzt, vol. 75, supplement 2, p. 87, 2004 (German).

[327] R. L. Loewy, J. K. Johnson, and T. D. Cannon, "Self-report of attenuated psychotic experiences in a college population," Schizophrenia Research, vol. 93, no. 1-3, pp. 144-151, 2007.

[328] T. D. Cannon, "Prediction of psychosis through the prodromal syndrome," in Advances in Schizophrenia Research 2009, W. F. Gattaz and G. G. Busatto, Eds., pp. 251-266, Springer, New York, NY, USA, 2010.

[329] J. van Os, M. Hanssen, R. V. Bijl, and A. Ravelli, "Strauss (1969) revisited: a psychosis continuum in the general population?" Schizophrenia Research, vol. 45, no. 1-2, pp. 11-20, 2000.

[330] J. Van Os, M. Hanssen, R. V. Bijl, and W. Vollebergh, "Prevalence of psychotic disorder and community level of psychotic symptoms: An urban-rural comparison," Archives of General Psychiatry, vol. 58, no. 7, pp. 663-668, 2001.

[331] J. Spauwen, L. Krabbendam, R. Lieb, H. Wittchen, and J. van Os, "Sex differences in psychosis: normal or pathological?" Schizophrenia Research, vol. 62, no. 1-2, pp. 45-49, 2003.

[332] M. Hanssen, M. Bak, R. Bijl, W. Vollebergh, and J. van Os, "The incidence and outcome of subclinical psychotic experiences in the general population," British Journal of Clinical Psychology, vol. 44, no. 2, pp. 181-191, 2005.

[333] J. Allardyce and J. van Os, "The natural history of the course and outcome of Schizophrenia," in Advances in Schizophrenia Research 2009, W. F. Gattaz and G. Busatto, Eds., pp. 51-66, Springer, New York, NY, USA, 2010.

[334] M. D. G. Dominguez, M. Wichers, R. Lieb, H. Wittchen, and J. van Os, "Evidence that onset of clinical psychosis is an outcome of progressively more persistent subclinical psychotic experiences: an 8-year cohort study," Schizophrenia Bulletin, vol. 37, no. 1, pp. 84-93, 2011.

[335] M. S. S. Hanssen, M. Bak, R. Bijl, W. Vollebergh, and J. Os, "Is prediction of psychosis in the general population feasible?" European Psychiatry, vol. 17, supplement 1, p. 74, 2002.

[336] N. Haroun, L. Dunn, A. Haroun, and K. S. Cadenhead, "Risk and protection in prodromal schizophrenia: ethical implications for clinical practice and future research," Schizophrenia Bulletin, vol. 32, no. 1, pp. 166-178, 2006.

[337] T. D. Cannon, K. Cadenhead, B. Cornblatt et al., "Prediction of psychosis in youth at high clinical risk: a multisite longitudinal study in North America," Archives of General Psychiatry, vol. 65, no. 1, pp. 28-37, 2008.

[338] J. Lyne, L. Renwick, K. Madigan et al., "Do psychosis prodrome onset negative symptoms predict first presentation negative symptoms?" European Psychiatry, vol. 29, pp. 153-159, 2014.

[339] I. van Rossum, M. Dominguez, R. Lieb, H. Wittchen, and J. van Os, "Affective dysregulation and reality distortion: a 10-year prospective study of their association and clinical relevance," Schizophrenia Bulletin, vol. 37, no. 3, pp. 561-571, 2011.

[340] L. Krabbendam, I. Myin-Germeys, M. Hanssen et al., "Development of depressed mood predicts onset of psychotic disorder in individuals who report hallucinatory experiences," The British Journal of Clinical Psychology, vol. 44, no. 1, pp. 113-125, 2005.

[341] J. Klosterkötter, M. Hellmich, and F. Schultze-Lutter, "Ist die Diagnose schizophrener Störungen schon in der initialen Prodromalphase vor der psychotischen Erstmanifestation möglich?” Fortschritte der Neurologie Psychiatrie, vol. 68, Sonderheft 1, pp. S13-S21, 2000 (German).

[342] J. Klosterkötter, M. Hellmich, E. M. Steinmeyer, and F. SchultzeLutter, "Diagnosing schizophrenia in the initial prodromal phase," Archives of General Psychiatry, vol. 58, no. 2, pp. 158-164, 2001.

[343] G. Gross, G. Huber, J. Klosterkötter, and M. Linz, Bonner Skala für die Beurteilung von Basissymptomen (BSABS), Springer, Berlin, Germany, 1987 (German).

[344] J. Addington, K. S. Cadenhead, T. D. Cannon et al., "North American prodrome longitudinal study: a collaborative multisite approach to prodromal schizophrenia research," Schizophrenia Bulletin, vol. 33, no. 3, pp. 665-672, 2007.

[345] P. Fusar-Poli, I. Bonoldi, A. R. Yung et al., "Predicting psychosis: Meta-analysis of transition outcomes in individuals at high clinical risk," Archives of General Psychiatry, vol. 69, no. 3, pp. 220-229, 2012. 
[346] A. R. Yung, L. J. Phillips, H. P. Yuen, and P. D. McGorry, "Risk factors for psychosis in an ultra high-risk group: psychopathology and clinical features," Schizophrenia Research, vol. 67, no. 2-3, pp. 131-142, 2004.

[347] P. Fusar-Poli, S. Borgwardt, A. Bechdolf et al., "The psychosis high-risk state: a comprehensive state-of-the-art review," The Journal of the American Medical Association Psychiatry, vol. 70, no. 1, pp. 107-120, 2013.

[348] P. F. Liddle and T. R. E. Barnes, "Syndromes of chronic schizophrenia," The British Journal of Psychiatry, vol. 157, pp. 558-561, 1990.

[349] P. F. Liddle, "Syndromes of schizophrenia on factor analysis," The British Journal of Psychiatry, vol. 161, p. 861, 1992.

[350] H. Häfner, K. Maurer, W. Löffler, W. an der Heiden, M. Hambrecht, and F. Schultze-Lutter, "Modeling the early course of schizophrenia," Schizophrenia Bulletin, vol. 29, no. 2, pp. 325340, 2003.

[351] A. Serretti and P. Olgiati, "Dimensions of major psychoses: a confirmatory factor analysis of six competing models," Psychiatry Research, vol. 127, no. 1-2, pp. 101-109, 2004.

[352] M. Ruggeri, M. Koeter, A. Schene et al., "Factor solution of the BPRS-expanded version in schizophrenic outpatients living in five European countries," Schizophrenia Research, vol. 75, no. 1, pp. 107-117, 2005.

[353] S. Z. Levine and J. Rabinowitz, "Revisiting the 5 dimensions of the positive and negative syndrome scale," Journal of Clinical Psychopharmacology, vol. 27, no. 5, pp. 431-436, 2007.

[354] A. Picardi, C. Viroli, L. Tarsitani et al., "Heterogeneity and symptom structure of schizophrenia," Psychiatry Research, vol. 198, no. 3, pp. 386-394, 2012.

[355] N. C. Andreasen, The Scale for the Assessment of Negative Symptoms (SANS), University of Iow, Iowa City, Iowa, USA, 1983.

[356] M. J. Cuesta and V. Peralta, "Psychopathological dimensions in schizophrenia," Schizophrenia Bulletin, vol. 21, no. 3, pp. 473482, 1995.

[357] W. P. Horan, A. M. Kring, and J. J. Blanchard, "Anhedonia in schizophrenia: a review of assessment strategies," Schizophrenia Bulletin, vol. 32, no. 2, pp. 259-273, 2006.

[358] G. Foussias and G. Remington, "Negative symptoms in schizophrenia: avolition and Occam's razor," Schizophrenia Bulletin, vol. 36, no. 2, pp. 359-369, 2010.

[359] S. M. Stahl and P. F. Buckley, "Negative symptoms of schizophrenia: a problem that will not go away," Acta Psychiatrica Scandinavica, vol. 115, no. 1, pp. 4-11, 2007.

[360] W. Löffler and H. Häfner, "Dimensionen der schizophrenen Symptomatik. Vergleichende Modellprüfung an einem Erstepisodensample," Der Nervenarzt, vol. 70, no. 5, pp. 416-429, 1999 (German).

[361] S. R. Kay and S. Sevy, "Pyramidical model of schizophrenia," Schizophrenia Bulletin, vol. 16, no. 3, pp. 537-545, 1990.

[362] A. Arora, A. Avasthi, and P. Kulhara, "Subsyndromes of chronic schizophrenia: a phenomenological study," Acta Psychiatrica Scandinavica, vol. 96, no. 3, pp. 225-229, 1997.

[363] L. Davidson and T. H. McGlashan, "The varied outcomes of schizophrenia," Canadian Journal of Psychiatry, vol. 42, no. 1, pp. 34-43, 1997.

[364] R. K. R. Salokangas, "Structure of schizophrenic symptomatology and its changes over time: prospective factor-analytical study," Acta Psychiatrica Scandinavica, vol. 95, no. 1, pp. 32-39, 1997.

[365] L. White, P. D. Harvey, L. Opler, and J. P. Lindenmayer, "Empirical assessment of the factorial structure of clinical symptoms in schizophrenia. A multisite, multimodel evaluation of the factorial structure of the positive and negative syndrome scale. The PANSS Study Group," Psychopathology, vol. 30, no. 5, pp. 263274, 1997.

[366] D. Freeman, "Cognitive and social processes in psychosis: recent developments," in Advances in Schizophrenia Research 2009, W. F. Gattaz and G. Busatto, Eds., pp. 283-298, Springer, New York, NY, USA, 2010.

[367] I. Myin-Germeys, M. Birchwood, and T. Kwapil, "From environment to therapy in psychosis: a real-world momentary assessment approach," Schizophrenia Bulletin, vol. 37, no. 2, pp. 244-247, 2011.

[368] J. J. Blanchard, M. Aghevli, A. Wilson, and M. Sargeant, "Developmental instability in social anhedonia: an examination of minor physical anomalies and clinical characteristics," Schizophrenia Research, vol. 118, no. 1-3, pp. 162-167, 2010.

[369] T. Laughren and R. Levin, "Food and drug administration commentary on methodological issues in negative symptom trials," Schizophrenia Bulletin, vol. 37, no. 2, pp. 255-256, 2011.

[370] P. D. Harvey, D. Koren, A. Reichenberg, and C. R. Bowie, "Negative symptoms and cognitive deficits: what is the nature of their relationship?" Schizophrenia Bulletin, vol. 32, no. 2, pp. 250-258, 2006.

[371] K. H. Nuechterlein, M. F. Green, and R. S. Kern, "Schizophrenia as a cognitive disorder. Recent approaches to identifying its core cognitive components to aid treatment development," in Advances in Schizophrenia Research 2009, W. F. Gattaz and G. Busatto, Eds., pp. 267-282, Springer, New York, NY, USA, 2010.

[372] T. E. Goldberg, A. David, and J. M. Gold, "Neurocognitive impairments in schizophrenia: their character and role in symptom formation," in Schizophrenia, D. R. Weinberger and P. J. Harrison, Eds., pp. 142-162, Wiley-Blackwell, Oxford, UK, 3rd edition, 2011.

[373] R. S. E. Keefe, "Should cognitive impairment be included in the diagnostic criteria for schizophrenia?" World Psychiatry, vol. 7, no. 1, pp. 22-28, 2008.

[374] American Psychiatric Association, Diagnostic and Statistical Manual of Mental Disorders (DSM-5), American Psychiatric Publishing, Washington, DC, USA, 5th edition, 2013.

[375] J. M. Kane and T. Lencz, "Cognitive deficits in schizophrenia: short-term and long-term," World Psychiatry, vol. 7, no. 13, pp. 29-30, 2008 .

[376] A. Simning, Y. Conwell, and E. van Wijngaarden, "Cognitive impairment in public housing residents living in Western New York," Social Psychiatry and Psychiatric Epidemiology, vol. 49, no. 3, pp. 477-485, 2014.

[377] S. R. Marder, D. G. Daniel, L. Alphs, A. G. Awad, and R. S. E. Keefe, "Methodological issues in negative symptom trials," Schizophrenia Bulletin, vol. 37, no. 2, pp. 250-254, 2011.

[378] J. M. Gold, "Cognitive deficits as treatment targets in Schizophrenia," Schizophrenia Research, vol. 72, no. 1, pp. 21-28, 2004.

[379] S. E. Hyman and W. S. Fenton, "Medicine: what are the right targets for psychopharmacology?" Science, vol. 299, no. 5605, pp. 350-351, 2003.

[380] W. Wölwer, N. Frommann, S. Halfmann, A. Piaszek, M. Streit, and W. Gaebel, "Remediation of impairments in facial affect recognition in schizophrenia: Efficacy and specificity of a new training program," Schizophrenia Research, vol. 80, no. 2-3, pp. 295-303, 2005.

[381] D. N. Allen, G. P. Strauss, B. Donohue, and D. P. van Kammen, "Factor analytic support for social cognition as a separable 
cognitive domain in schizophrenia," Schizophrenia Research, vol. 93, no. 1-3, pp. 325-333, 2007.

[382] M. F. Green, D. L. Penn, R. Bentall et al., "Social cognition in schizophrenia: an NIMH workshop on definitions, assessment, and research opportunities," Schizophrenia Bulletin, vol. 34, no. 6, pp. 1211-1220, 2008.

[383] W. P. Horan, R. S. Kern, K. Shokat-Fadai, M. J. Sergi, J. K. Wynn, and M. F. Green, "Social cognitive skills training in schizophrenia: an initial efficacy study of stabilized outpatients," Schizophrenia Research, vol. 107, no. 1, pp. 47-54, 2009.

[384] W. Gaebel, W. Wölwer, M. Riesbeck, and J. Zilasek, "The crosssectional and longitudinal architecture of schizophrenia: significance for diagnosis and intervention," in Advances in Schizophrenia Research 2009, W. F. Gattaz and G. Busatto, Eds., pp. 317-330, Springer, New York, NY, USA, 2010.

[385] G. Fervaha, G. Foussias, O. Agid, and G. Remington, "Impact of primary negative symptoms on functional outcomes in schizophrenia," European Psychiatry, 2014.

[386] R. Bottlender, T. Sato, M. Jäger et al., "Does considering duration of negative symptoms increase their specificity for schizophrenia?" Schizophrenia Research, vol. 60, no. 2-3, pp. 321-322, 2003.

[387] A. K. Malla, R. M. G. Norman, J. Takhar et al., "Can patients at risk for persistent negative symptoms be identified during their first episode of psychosis?" Journal of Nervous and Mental Disease, vol. 192, no. 7, pp. 455-463, 2004.

[388] H. Häfner, W. an der Heiden, and K. Maurer, "Evidence for separate diseases? Stages of one disease or different combinations of symptom dimensions?" European Archives of Psychiatry and Clinical Neuroscience, vol. 258, no. 2, pp. 85-96, 2008.

[389] J. Mäkinen, J. Miettunen, M. Isohanni, and H. Koponen, "Negative symptoms in schizophrenia: a review," Nordic Journal of Psychiatry, vol. 62, no. 5, pp. 334-341, 2008.

[390] J. A. Husted, M. Beiser, and W. G. Iacono, "Negative symptoms and the early course of schizophrenia," Psychiatry Research, vol. 43, no. 3, pp. 215-222, 1992.

[391] W. an der Heiden, R. Könnecke, K. Maurer, D. Ropeter, and H. Häfner, "Depression in the long-term course of schizophrenia," European Archives of Psychiatry and Clinical Neuroscience, vol. 255, no. 3, pp. 174-184, 2005.

[392] W. an der Heiden and H. Häfner, "Course and outcome," in Schizophrenia, D. R. Weinberger and P. J. Harrison, Eds., pp. 104-141, Wiley-Blackwell, Oxford, UK, 3rd edition, 2011.

[393] M. F. Pogue-Geile and J. Zubin, "Negative symptomatology and schizophrenia: a conceptual and empirical review," International Journal of Mental Health, vol. 16, no. 4, pp. 3-45, 1988.

[394] J. M. Gold and M. F. Green, "Neurocognition in schizophrenia," in Kaplan \& Sadocks Comprehensive Textbook of Psychiatry, B. J. Sadock and V. A. Sadock, Eds., vol. 8, Baltimore, Md, USA, pp. 1436-1448, Kaplan Lippincott, Williams \& Williams, 2005.

[395] G. P. Strauss, D. N. Allen, P. Miski, R. W. Buchanan, B. Kirkpatrick, and W. T. Carpenter, "Differential patterns of premorbid social and academic deterioration in deficit and nondeficit schizophrenia," Schizophrenia Research, vol. 135, no. 1-3, pp. 134-138, 2012.

[396] H. Häfner, K. Maurer, and W. an der Heiden, "ABC Schizophrenia study: an overview of results since 1996," Social Psychiatry and Psychiatric Epidemiology, vol. 48, no. 7, pp. 1021-1031, 2013.

[397] V. A. Morgan, J. J. McGrath, A. Jablensky et al., "Psychosis prevalence and physical, metabolic and cognitive co-morbidity: data from the second Australian national survey of psychosis," Psychological Medicine, vol. 23, pp. 1-14, 2013.
[398] J. J. Blanchard, A. M. Kring, W. P. Horan, and R. Gur, “Toward the next generation of negative symptom assessments: The collaboration to advance negative symptom assessment in schizophrenia," Schizophrenia Bulletin, vol. 37, no. 2, pp. 291-299, 2011.

[399] L. Schwarz, T. P. Roskos, and G. T. Grossberg, "Answers to 7 questions about using neuropsychological testing in your practice," Current Psychiatry, vol. 13, pp. 33-39, 2014.

[400] K. H. Nuechterlein, R. E. Asarnow, K. L. Subotnik et al., "Neurocognitive vulnerability factors for schizophrenia: convergence across genetic risk studies and longitudinal trait/state studies," in Origins and Development of Schizophrenia: Advances in Experimental Psychopathology, M. F. Lenzenweger and R. H. Dworkin, Eds., pp. 299-327, American Psychological Association, Washington, DC, USA, 1998.

[401] R. E. Gur, M. E. Calkins, R. C. Gur et al., "The consortium on the genetics of schizophrenia: neurocognitive endophenotypes," Schizophrenia Bulletin, vol. 33, no. 1, pp. 49-68, 2007.

[402] B. E. Snitz, A. W. MacDonald III, and C. S. Carter, "Cognitive deficits in unaffected first-degree relatives of schizophrenia patients: a meta-analytic review of putative endophenotypes," Schizophrenia Bulletin, vol. 32, no. 1, pp. 179-194, 2006.

[403] A. L. Hoff, M. Sakuma, M. Wieneke, R. Horon, M. Kushner, and L. E. DeLisi, "Longitudinal neuropsychological follow-up study of patients with first-episode schizophrenia," The American Journal of Psychiatry, vol. 156, no. 9, pp. 1336-1341, 1999.

[404] A. Reichenberg, M. Weiser, M. A. Rapp et al., "Premorbid intra-individual variability in intellectual performance and risk for schizophrenia: a population-based study," Schizophrenia Research, vol. 85, no. 1-3, pp. 49-57, 2006.

[405] A. Reichenberg, P. D. Harvey, C. R. Bowie et al., "Neuropsychological function and dysfunction in schizophrenia and psychotic affective disorders," Schizophrenia Bulletin, vol. 35, no. 5, pp. 1022-1029, 2009.

[406] M. Albus, W. Hubmann, J. Scherer et al., "A prospective 2-year follow-up study of neurocognitive functioning in patients with first-episode schizophrenia," European Archives of Psychiatry and Clinical Neuroscience, vol. 252, no. 6, pp. 262-267, 2002.

[407] K. Maurer and H. Häfner, "Negativsymptomatik im Frühverlauf der Schizophrenie und im Verlauf über drei Jahre nach Ersthospitalisation," in Befunderhebung in der Psychiatrie: Lebensqualität, Negativsymptomatik und andere aktuelle Entwicklungen, H.-J. Möller, R. R. Engel, and P. Hoff, Eds., pp. 225-240, Springer, Vienna, Austria, 1996, (German).

[408] P. D. Harvey, E. Howanitz, M. Parrella et al., "Symptoms, cognitive functioning, and adaptive skills in geriatric patients with lifelong schizophrenia: a comparison across treatment sites," The American Journal of Psychiatry, vol. 155, no. 8, pp. 10801086, 1998.

[409] P. D. Harvey, M. Parrella, L. White, R. C. Mohs, M. Davidson, and K. L. Davis, "Convergence of cognitive and adaptive decline in late-life schizophrenia," Schizophrenia Research, vol. 35, no. 1, pp. 77-84, 1999.

[410] D. M. Barch, J. Bustillo, W. Gaebel et al., "Logic and justification for dimensional assessment of symptoms and related clinical phenomena in psychosis: relevance to DSM-5," Schizophrenia Research, vol. 150, no. 1, pp. 20-25, 2013.

[411] W. T. Carpenter Jr., D. W. Heinrichs, and A. M. I. Wagman, "Deficit and nondeficit forms of schizophrenia: the concept," The American Journal of Psychiatry, vol. 145, no. 5, pp. 578-583, 1988.

[412] A. Marneros, N. C. Andreasen, and M. T. Tsuang, Eds., Negative versus Positive Schizophrenia, Springer, Berlin, Germany, 1991. 
[413] W. T. Carpenter, R. W. Buchanan, B. Kirkpatrick, G. Thaker, and C. Tamminga, "Negative symptoms: a critique of current approaches," in Negative Versus Positive Schizophrenia, A. Marneros, N. C. Andreasen, and M. T. Tsuang, Eds., pp. 126-133, Springer, Berlin, Germany, 1991.

[414] B. Kirkpatrick and S. Galderisi, "Deficit schizophrenia: an update," World Psychiatry, vol. 7, no. 3, pp. 143-147, 2008.

[415] W. T. Carpenter Jr. and B. Kirkpatrick, "The heterogeneity of the long-term course of schizophrenia," Schizophrenia Bulletin, vol. 14, no. 4, pp. 645-652, 1988.

[416] J. K. Wing and G. W. Brown, Institutionalism and Schizophrenia. A Comparative Study of Three Mental Hospitals 1960-1968, Cambridge University Press, Cambridge, UK, 1970.

[417] W. W. Eaton, R. Thara, B. Federman, B. Melton, and K. Y. Liang, "Structure and course of positive and negative symptoms in schizophrenia," Archives of General Psychiatry, vol. 52, no. 2, pp. 127-134, 1995.

[418] E. S. Herbener and M. Harrow, "Longitudinal assessment of negative symptoms in schizophrenia/schizoaffective patients, other psychotic patients, and depressed patients," Schizophrenia Bulletin, vol. 27, no. 3, pp. 527-537, 2001.

[419] R. M. Murray and S. W. Lewis, "Is schizophrenia a neurodevelopmental disorder?” British Medical Journal, vol. 295, no. 6600, pp. 681-682, 1987.

[420] D. R. Weinberger, "Schizophrenia as a neurodevelopmental disorder," in Schizophrenia, S. R. Hirsch and D. R. Weinberger, Eds., pp. 293-323, Blackwell, Oxford, UK, 1995.

[421] T. H. McGlashan and R. E. Hoffman, "Schizophrenia as a disorder of developmentally reduced synaptic connectivity," Archives of General Psychiatry, vol. 57, no. 7, pp. 637-648, 2000.

[422] M. V. Zanetti, M. S. Schaufelberger, and J. A. S. Crippa, "Brain anatomical abnormalities in schizophrenia: neurodevelopmental origins and patterns of progression over time," in Advances in Schizophrenia Research 2009, W. F. Gattaz and G. Busatto, Eds., pp. 113-148, Springer, New York, NY, USA, 2010.

[423] M. K. Stachowiak, A. Kucinski, R. Curl et al., "Schizophrenia: a neurodevelopmental disorder-integrative genomic hypothesis and therapeutic implications from a transgenic mouse model," Schizophrenia Research, vol. 143, no. 2-3, pp. 367-376, 2013.

[424] T. J. Crow, "The two-syndrome concept: origins and current status," Schizophrenia Bulletin, vol. 11, no. 3, pp. 471-486, 1985.

[425] T. J. Crow, "Discussion: The genetics of psychosis is the genetics of the speciation of Homo sapiens," in Search for the Causes of Schizophrenia, W. F. Gattaz and H. Häfner, Eds., vol. 5, pp. 297312, Steinkopff, Darmstadt, Germany, 2004.

[426] S. R. Kay, A. Fiszbein, and L. A. Opler, "The positive and negative syndrome scale (PANSS) for schizophrenia," Schizophrenia Bulletin, vol. 13, no. 2, pp. 261-276, 1987.

[427] B. Kirkpatrick, W. S. Fenton, W. T. Carpenter Jr., and S. R. Marder, "The NIMH-MATRICS consensus statement on negative symptoms," Schizophrenia Bulletin, vol. 32, no. 2, pp. 214219, 2006.

[428] C. Forbes, J. J. Blanchard, M. Bennett, W. P. Horan, A. Kring, and R. Gur, "Initial development and preliminary validation of a new negative symptom measure: the Clinical Assessment Interview for Negative Symptoms (CAINS)," Schizophrenia Research, vol. 124, no. 1-3, pp. 36-42, 2010.

[429] S. R. Marder and B. Kirkpatrick, "Defining and measuring negative symptoms of schizophrenia in clinical trials," European Neuropsychopharmacology, vol. 24, no. 5, pp. 737-743, 2014.
[430] W. S. Fenton and T. H. McGlashan, "Natural history of schizophrenia subtypes: II. Positive and negative symptoms and long-term course," Archives of General Psychiatry, vol. 48, no. 11, pp. 978-986, 1991.

[431] T. E. Goldberg, T. M. Hyde, J. E. Kleinman, and D. R. Weinberger, "Course of schizophrenia: neuropsychological evidence for a static encephalopathy," Schizophrenia Bulletin, vol. 19, no. 4, pp. 797-804, 1993.

[432] T. W. Weickert and T. E. Goldberg, "Neuropsychologie der Schizophrenie," in Psychiatrie der Gegenwart, H. Helmchen, F. Henn, H. Lauter et al., Eds., vol. 5, pp. 163-180, Springer, New York, NY, USA, 4th edition, 2000, (German).

[433] C. L. Marvel and S. Paradiso, "Cognitive and neurological impairment in mood disorders," Psychiatric Clinics of North America, vol. 27, no. 1, pp. 19-36, 2004.

[434] S. H. Sullivan, "The onset of schizophrenia," The American Journal of Psychiatry, vol. 6, pp. 105-134, 1927.

[435] D. E. Cameron, "Early schizophrenia," The American Journal of Psychiatry, vol. 95, pp. 567-578, 1938.

[436] K. Conrad, Die beginnende Schizophrenie. Versuch einer Gestaltanalyse des Wahns, Thieme-Verlag, Stuttgart, Germany, 1958 (German).

[437] J. P. Docherty, D. P. van Kammen, S. G. Siris, and S. R. Marder, "Stages of onset of schizophrenic psychosis," The American Journal of Psychiatry, vol. 135, no. 4, pp. 420-426, 1978.

[438] M. Hambrecht and H. Häfner, ““Trema, Apophänie, Apokalypse"-Ist Conrads Phasenmodell empirisch begründbar?" Fortschritte der Neurologie Psychiatrie, vol. 61, no. 12, pp. 418423, 1993 (German).

[439] F. Schultze-Lutter, W. Löffler, and H. Häfner, “Testing models of the early course of schizophrenia," in Risk and Protective Factors in Schizophrenia, H. Häfner, Ed., pp. 229-241, Steinkopff, Darmstadt, Germany, 2002.

[440] P. D. McGorry, J. Edwards, C. Mihalopoulos, S. M. Harrigan, and H. J. Jackson, "EPPIC: an evolving system of early detection and optimal management," Schizophrenia Bulletin, vol. 22, no. 2, pp. 305-326, 1996.

[441] P. D. McGorry, A. R. Yung, and L. J. Phillips, “The "close-in" or ultra high-risk model: a safe and effective strategy for research and clinical intervention in prepsychotic mental disorder," Schizophrenia Bulletin, vol. 29, no. 4, pp. 771-790, 2003.

[442] A. R. Yung, L. J. Phillips, and P. McGorry, Treating Schizophrenia in the Prodromal Phase, Taylor \& Francis, London, UK, 2004.

[443] A. R. Yung, H. P. Yuen, P. D. McGorry et al., "Mapping the onset of psychosis: the comprehensive assessment of at-risk mental states," Australian \& New Zealand Journal of Psychiatry, vol. 39, no. 11-12, pp. 964-971, 2005.

[444] H. Häfner, K. Maurer, W. Löffler et al., "Onset and prodromal phase as determinants of the course," in Search for the Causes of Schizophrenia, Vol. IV: Balance of the Century, W. F. Gattaz and H. Häfner, Eds., pp. 1-24, Steinkopff, Darmstadt, Germany, 1999.

[445] D. O. Perkins, H. Gu, K. Boteva, and J. A. Lieberman, "Relationship between duration of untreated psychosis and outcome in first-episode schizophrenia: a critical review and metaanalysis," The American Journal of Psychiatry, vol. 162, no. 10, pp. 1785-1804, 2005.

[446] F. Schultze-Lutter, S. Ruhrmann, H. Picker, H. G. von Reventlow, A. Brockhaus-Dumke, and J. Klosterkötter, "Basic symptoms in early psychotic and depressive disorders," The British Journal of Psychiatry, vol. 191, no. 51, supplement, pp. s31-s37, 2007. 
[447] F. Schultze-Lutter, S. Ruhrmann, J. Berning, W. Maier, and J. Klosterkötter, "Basic symptoms and ultrahigh risk criteria: symptom development in the initial prodromal state," Schizophrenia Bulletin, vol. 36, no. 1, pp. 182-191, 2010.

[448] F. Schultze-Lutter, J. Klosterkötter, and S. Ruhrmann, "Improving the clinical prediction of psychosis by combining ultrahigh risk criteria and cognitive basic symptoms," Schizophrenia Research, vol. 154, no. 1-3, pp. 100-106, 2014.

[449] R. K. R. Salokangas and T. McGlashan, "Early detection and intervention of psychosis. A review," Nordic Journal of Psychiatry, vol. 62, no. 2, pp. 92-105, 2008.

[450] J. Rietdijk, S. J. Hogerzeil, A. M. van Hemert, P. Cuijpers, D. H. Linszen, and M. van der Gaag, "Pathways to psychosis: Helpseeking behavior in the prodromal phase," Schizophrenia Research, vol. 132, no. 2-3, pp. 213-219, 2011.

[451] W. Rössler, M. P. Hengartner, V. Ajdacic-Gross, H. Haker, A. Gamma, and J. Angst, "Sub-clinical psychosis symptoms in young adults are risk factors for subsequent common mental disorders," Schizophrenia Research, vol. 131, no. 1-3, pp. 18-23, 2011.

[452] J. Addington and R. Heinssen, "Prediction and prevention of psychosis in youth at clinical high risk," Annual Review of Clinical Psychology, vol. 8, pp. 269-289, 2012.

[453] H. Häfner, K. Maurer, G. Trendler, W. an der Heiden, M. Schmidt, and R. Könnecke, "Schizophrenia and depression: challenging the paradigm of two separate diseases-a controlled study of schizophrenia, depression and healthy controls," Schizophrenia Research, vol. 77, no. 1, pp. 11-24, 2005.

[454] T. H. McGlashan, "Duration of untreated psychosis in firstepisode schizophrenia: marker or determinant of course?" Biological Psychiatry, vol. 46, no. 7, pp. 899-907, 1999.

[455] R. M. G. Norman and A. K. Malla, "Duration of untreated psychosis: a critical examination of the concept and its importance," Psychological Medicine, vol. 31, no. 3, pp. 381-400, 2001.

[456] E. C. Johnstone, T. J. Crow, A. L. Johnson, and J. F. MacMillan, "The Northwick Park study of first episodes of schizophrenia. I. Presentation of the illness and problems relating to admission," The British Journal of Psychiatry, vol. 148, pp. 115-120, 1986.

[457] J. P. McEvoy, N. R. Schooler, and W. H. Wilson, "Predictors of therapeutic response to haloperidol in acute schizophrenia," Psychopharmacology Bulletin, vol. 27, no. 2, pp. 97-101, 1991.

[458] M. Birchwood and F. Macmillan, "Early intervention in schizophrenia," Australian \& New Zealand Journal of Psychiatry, vol. 27, no. 3, pp. 374-378, 1993.

[459] A. D. Loebel, J. A. Lieberman, J. M. J. Alvir, D. I. Mayerhoff, S. H. Geisler, and S. R. Szymanski, "Duration of psychosis and outcome in first-episode schizophrenia," The American Journal of Psychiatry, vol. 149, no. 9, pp. 1183-1188, 1992.

[460] D. Linszen, M. Lenior, L. De Haan, P. Dingemans, and B. Gersons, "Early intervention, untreated psychosis and the course of early schizophrenia," The British Journal of Psychiatry, vol. 172, no. 33, pp. 84-89, 1998.

[461] H. Häfner and K. Maurer, "Early detection of schizophrenia: current evidence and future perspectives," World Psychiatry, vol. 5, pp. 130-138, 2006.

[462] A. C. Altamura, R. Bassetti, F. Sassella, D. Salvadori, and E. Mundo, "Duration of untreated psychosis as a predictor of outcome in first-episode schizophrenia: a retrospective study," Schizophrenia Research, vol. 52, no. 1-2, pp. 29-36, 2001.

[463] A. R. Yung, E. J. Kollackey, B. Nelson, and P. McGorry, "The impact of early intervention in schizophrenia," in Advances in
Schizophrenia Research 2009, W. F. Gattaz and G. Busatto, Eds., pp. 299-316, Springer, New York, NY, USA, 2010.

[464] C. Rapp, E. Studerus, H. Bugra et al., "Duration of untreated psychosis and cognitive functioning," Schizophrenia Research, vol. 145, no. 1-3, pp. 43-49, 2013.

[465] R. J. Wyat, "Neuroleptics and the natural course of schizophrenia," Schizophrenia Bulletin, vol. 17, no. 2, pp. 325-351, 1991.

[466] R. J. Wyatt, "Early intervention with neuroleptics may decrease the long-term morbidity of schizophrenia," Schizophrenia Research, vol. 5, no. 3, pp. 201-202, 1991.

[467] J. A. Lieberman, B. B. Sheitman, and B. J. Kinon, "Neurochemical sensitization in the pathophysiology of schizophrenia: deficits and dysfunction in neuronal regulation and plasticity," Neuropsychopharmacology, vol. 17, no. 4, pp. 205-229, 1997.

[468] J. A. Lieberman, G. Tollefson, and M. Tohen, "Comparative efficacy and safety of atypical and coventional antipsychotic drugs in first-episode psychosis: a randomized, double-blind trial of olanzapine versus haloperidol," The American Journal of Psychiatry, vol. 160, pp. 1396-1404, 2003.

[469] R. J. Wyatt and I. D. Henter, "The effects of early and sustained intervention on the long-term morbidity of schizophrenia," Journal of Psychiatric Research, vol. 32, no. 3-4, pp. 169-177, 1998.

[470] N. Tandon, J. Shah, M. S. Keshavan, and R. Tandon, "Attenuated psychosis and the schizophrenia prodrome: current status of risk identification and psychosis prevention," Neuropsychiatry, vol. 2, pp. 345-353, 2012.

[471] M. T. Tsuang, J. van Os, R. Tandon et al., "Attenuated psychosis syndrome in DSM-5," Schizophrenia Research, vol. 150, pp. 3135, 2013.

[472] J. O. Johannessen, T. K. Larsen, M. Horneland et al., "The TIPS Project. A systematized program ro reduce duration of untreated psychosis in first episode psychosis," in Early Intervention in Psychotic Disorders, T. Miller, S. A. Mednick, T. H. McGlashan, J. Libiger, and J. O. Johannessen, Eds., pp. 151-166, Kluwer Academic Pubishers, Dordrecht, The Netherlands, 2001.

[473] P. McGorry, "A stitch in time ... the scope for preventive strategies in early psychosis," in The Recognition and Management of Early Psychosis, P. D. McGorry and H. J. Jackson, Eds., pp. 3-23, Cambridge University Press, Cambridge, UK, 1999.

[474] P. D. McGorry, A. R. Yung, L. J. Phillips et al., "Randomized controlled trial of interventions designed to reduce the risk of progression to first-episode psychosis in a clinical sample with subthreshold symptoms," Archives of General Psychiatry, vol. 59, no. 10, pp. 921-928, 2002.

[475] S. Ruhrmann, K. U. Kühn, M. Streit, R. Bottlender, W. Maier, and J. Klosterkötter, "Pharmakologische und psychologische Frühintervention bei Risikopersonen mit psychosenahen Prodromen: erste Ergebnisse einer kontrollierten Studie," Nervenarz, vol. 73, no. 1, p. 9, 2002 (German).

[476] T. H. McGlashan, R. B. Zipursky, D. Perkins et al., “The PRIME North America randomized double-blind clinical trial of olanzapine versus placebo in patients at risk of being prodromally symptomatic for psychosis: I. Study rationale and design," Schizophrenia Research, vol. 61, no. 1, pp. 7-18, 2003.

[477] J. Klosterkötter, "Prävention psychotischer Störungen," Nervenarzt, vol. 84, pp. 1299-1309, 2013 (German).

[478] M. Hambrecht, M. Wagner, A. Bechdolf, S. Maier, and C. Schröder, Psychologische Frühintervention bei Risikopersonen/ Personen mit psychosefernen Prodromen. Manual für die Durchführung der Studieninterventionen im Projekt 1.1.2 des Kompetenznetz Schizophrenie, (KNS-Zentrale, Rheinische Landes- und 
Hochschulklinik Düsseldorf, Postfach 1205 10, D-40605 Düs-s eldorf), 2000 (German).

[479] S. Lewis, N. Tarrier, G. Haddock et al., "Randomised controlled trial of cognitive-behavioural therapy in early schizophrenia: acute-phase outcomes," The British Journal of Psychiatry, vol. 181, no. 43, pp. s91-s97, 2002.

[480] V. Bird, P. Premkumar, T. Kendall, C. Whittington, J. Mitchell, and E. Kuipers, "Early intervention services, cognitive-behavioural therapy and family intervention in early psychosis: systematic review," The British Journal of Psychiatry, vol. 197, no. 5, pp. 350-356, 2010.

[481] G. Lee, C. Barrowclough, and F. Lobban, "Positive affect in the family environment protects against relapse in first-episode psychosis," Social Psychiatry and Psychiatric Epidemiology, vol. 49, no. 3, pp. 367-376, 2014.

[482] A. Bechdolf, D. Köhn, B. Knost, R. Pukrop, and J. Klosterkötter, "A randomized comparison of group cognitive-behavioural therapy and group psychoeducation in acute patients with schizophrenia: outcome at 24 months," Acta Psychiatrica Scandinavica, vol. 112, no. 3, pp. 173-179, 2005.

[483] A. Bechdolf, V. Veith, D. Schwarzer et al., "Cognitive-behavioral therapy in the pre-psychotic phase: an exploratory study," Psychiatry Research, vol. 136, no. 2-3, pp. 251-255, 2005.

[484] A. P. Morrison, P. French, L. Walford et al., "Cognitive therapy for the prevention of psychosis in people at ultra-high risk: randomised controlled trial," The British Journal of Psychiatry, vol. 185, pp. 291-297, 2004.

[485] S. J. Bartels and R. E. Drake, "Depressive symptoms in schizophrenia: comprehensive differential diagnosis," Comprehensive Psychiatry, vol. 29, no. 5, pp. 467-483, 1988.

[486] S. G. Siris and C. Bench, "Depression and schizophrenia," in Schizophrenia, S. R. Hirsch and D. R. Weinberger, Eds., pp. 142167, Blackwell Publishing Company, Oxford, UK, 2nd edition, 2003.

[487] H. Häfner, "The early Kraepelin's dichotomy of schizophrenia and affective disorder-evidence for separate diseases?" European Journal of Psychiary, vol. 24, no. 2, pp. 98-113, 2010.

[488] E. Kraepelin, Psychiatrie, vol. 1-4, Barth, Leipzig, Germany, 8th edition, 1909-1915 (German).

[489] A. Jablensky, H. Hugler, M. von Cranach, and K. Kalinov, "Kraepelin revisited: a reassessment and statistical analysis of dementia praecox and manic-depressive insanity in 1908," Psychological Medicine, vol. 23, no. 4, pp. 843-858, 1993.

[490] M. C. Angermeyer and L. Kühn, "Gender differences in age at onset of schizophrenia: an overview," European Archives of Psychiatry and Neurological Sciences, vol. 237, no. 6, pp. 351-364, 1988.

[491] R. R. J. Lewine, "Gender and Schizophrenia," in Handbook of Schizophrenia, H. A. Nasrallah, Ed., vol. 3, pp. 379-397, Elsevier, Amsterdam, The Netherlands, 1988.

[492] J. M. Goldstein, "The impact of gender on understanding the epidemiology of schizopohrenia," in Gender and Psychopathology, M. W. Seeman, Ed., pp. 159-199, American Psychiatric Press, Washington, DC, USA, 1995.

[493] D. J. Castle, "Women and schizophrenia: an epidemiological perspective," in Women and Schizophrenia, D. J. Castle, J. McGrath, and J. Kulkarni, Eds., pp. 19-34, Cambridge University Press, Cambridge, UK, 2000.

[494] H. Häfner, A. Riecher-Rössler, W. an der Heiden, K. Maurer, B. Fätkenheuer, and W. Löffler, "Generating and testing a causal explanation of the gender difference in age at first onset of schizophrenia," Psychological Medicine, vol. 23, no. 4, pp. 925940, 1993.

[495] H. Häfner, K. Maurer, W. Löffler et al., “The epidemiology of early schizophrenia. Influence of age and gender on onset and early course," The British Journal of Psychiatry, vol. 164, no. 23, pp. 29-38, 1994.

[496] H. Häfner, A. Riecher, K. Maurer, W. Löffler, P. MunkJörgensen, and E. Strömgren, "How does gender influence age at first hospitalization for schizophrenia? A transnational case register study," Psychological Medicine, vol. 19, no. 4, pp. 903-918, 1989.

[497] S. V. Eranti, J. H. MacCabe, H. Bundy, and R. M. Murray, "Gender difference in age at onset of schizophrenia: a metaanalysis," Psychological Medicine, vol. 43, no. 1, pp. 155-167, 2013.

[498] B. N. Gangadhar, C. Panner Selvan, D. K. Subbakrishna, and N. Janakiramaiah, "Age-at-onset and schizophrenia: reversed gender effect," Acta Psychiatrica Scandinavica, vol. 105, no. 4, pp. 317-319, 2002.

[499] G. V. S. Murthy, N. Janakiramaiah, B. N. Gangadhar, and D. K. Subbakrishna, "Sex difference in age at onset of schizophrenia: discrepant findings from India," Acta Psychiatrica Scandinavica, vol. 97, no. 5, pp. 321-325, 1998.

[500] G. Stöber, E. Franzek, I. Haubitz, B. Pfuhlmann, and H. Beckmann, "Gender differences and age of onset in the catatonic subtypes of schizophrenia," Psychopathology, vol. 31, no. 6, pp. 307-312, 1998.

[501] K. Leonhard, Aufteilung der endogenen Psychosen, AkademieVerlag, Berlin, Germany, 5th edition, 1980 (German).

[502] M. Hambrecht, K. Maurer, H. Häfner, and N. Sartorius, “Transnational stability of gender differences in schizophrenia? An analysis based on the WHO study on determinants of outcome of severe mental disorders," European Archives of Psychiatry and Clinical Neuroscience, vol. 242, no. 1, pp. 6-12, 1992.

[503] M. Hambrecht, K. Maurer, and H. Häfner, "Gender differences in schizophrenia in three cultures. Results of the WHO collaborative study on psychiatric disability," Social Psychiatry and Psychiatric Epidemiology, vol. 27, no. 3, pp. 117-121, 1992.

[504] S. O. Moldin, "Gender and schizophrenia," in Gender and Its Effects on Psychopathology, E. Frank, Ed., pp. 169-186, American Psychiatric Press, Washington, DC, USA, 2000.

[505] S. V. Faraone, W. J. Chen, J. M. Goldstein, and M. T. Tsuang, "Gender differences in age at onset of schizophrenia," The British Journal of Psychiatry, vol. 164, pp. 625-629, 1994.

[506] W. F. Gattaz, S. Behrens, J. de Vry, and H. Häfner, "Estradiol inhibits dopamine mediated behavior in rats-an animal model of sex-specific differences in schizophrenia," Fortschritte der Neurologie Psychiatrie, vol. 60, pp. 8-16, 1992.

[507] H. Häfner, S. Behrens, J. De Vry, and W. F. Gattaz, "An animal model for the effects of estradiol on dopamine-mediated behavior: implications for sex differences in schizophrenia," Psychiatry Research, vol. 38, no. 2, pp. 125-134, 1991.

[508] M. Laruelle, A. Abi-Dargham, C. H. van Dyck et al., "Single photon emission computerized tomography imaging of amphetamine-induced dopamine release in drug-free schizophrenic subjects," Proceedings of the National Academy of Sciences of the United States of America, vol. 93, no. 17, pp. 92359240, 1996.

[509] A. Breier, T. P. Su, R. Saunders et al., "Schizophrenia is associated with elevated amphetamine-induced synaptic dopamine concentrations: Evidence from a novel positron emission tomography method," Proceedings of the National Academy of Sciences of the United States of America, vol. 94, no. 6, pp. 2569-2574, 1997. 
[510] A. Abi-Dargham, R. Gil, J. Krystal et al., "Increased striatal dopamine transmission in schizophrenia: confirmation in a second cohort," The American Journal of Psychiatry, vol. 155, no. 6, pp. 761-767, 1998.

[511] L. H. Lindström, O. Gefvert, G. Hagberg et al., "Increased dopamine synthesis rate in medial prefrontal cortex and striatum in schizophrenia indicated by L- $(\beta-11 \mathrm{C})$ DOPA and PET," Biological Psychiatry, vol. 46, no. 5, pp. 681-688, 1999.

[512] S. Kapur and D. Mamo, "Half a century of antipsychotics and still a central role for dopamine D2 receptors," Progress in Neuro-Psychopharmacology \& Biological Psychiatry, vol. 27, no. 7, pp. 1081-1090, 2003.

[513] G. J. Lyon, A. Abi-Dargham, H. Moore, J. A. Lieberman, J. A. Javitch, and D. Sulzer, "Presynaptic regulation of dopamine transmission in schizophrenia," Schizophrenia Bulletin, vol. 37, no. 1, pp. 108-117, 2011.

[514] D. Eyles, J. Feldon, and U. Meyer, "Schizophrenia: Do all roads lead to dopamine or is this where they start? Evidence from two epidemiologically informed developmental rodent models," Translational Psychiatry, vol. 2, article e81, 2012.

[515] J. Kulkarni and G. Fink, "Hormones and psychoses," in Women and Schizophrenia, D. J. Castle, J. McGrath, and J. Kulkarni, Eds., pp. 51-66, Cambridge University Press, Cambridge, UK, 2000.

[516] S. Akhondzadeh, A. A. Nejatisafa, H. Amini et al., "Adjunctive estrogen treatment in women with chronic schizophrenia: a double-blind, randomized, and placebo-controlled trial," Progress in Neuro-Psychopharmacology and Biological Psychiatry, vol. 27, no. 6, pp. 1007-1012, 2003.

[517] J. Kulkarni, A. De Castella, P. B. Fitzgerald et al., "Estrogen in severe mental illness: a potential new treatment approach," Archives of General Psychiatry, vol. 65, no. 8, pp. 955-960, 2008.

[518] J. Kulkarni, E. Gavrilidis, W. Wang et al., "Estradiol for treatment-resistant schizophrenia: a large-scale randomized-controlled trial in women of child-bearing age," Molecular Psychiatry, 2014.

[519] L. E. DeLisi, N. Bass, A. Boccio, G. Shields, C. Morganti, and A. Vita, "Age of onset in familial schizophrenia," Archives of General Psychiatry, vol. 51, no. 4, pp. 334-335, 1994.

[520] M. Albus and W. Maier, "Lack of gender differences in age at onset in familial schizophrenia," Schizophrenia Research, vol. 18, no. 1, pp. 51-59, 1995.

[521] M. Alda, B. Ahrens, W. Lit et al., "Age of onset in familial and sporadic schizophrenia," Acta Psychiatrica Scandinavica, vol. 93, no. 6, pp. 447-450, 1996.

[522] R. Könnecke, H. Häfner, K. Maurer, W. Löffler, and W. an der Heiden, "Main risk factors for schizophrenia: increased familial loading and pre- and peri-natal complications antagonize the protective effect of oestrogen in women," Schizophrenia Research, vol. 44, no. 1, pp. 81-93, 2000.

[523] R. L. Spitzer, J. Endicott, and E. Robins, Research Diagnostic Criteria (RDC) for a Selected Group of Functional Disorders, New York State Psychiatric Institute, New York, NY, USA, 3rd edition, 1977.

[524] J. van Os, R. Howard, N. Takei, and R. Murray, "Increasing age is a risk factor for psychosis in the elderly," Social Psychiatry and Psychiatric Epidemiology, vol. 30, no. 4, pp. 161-164, 1995.

[525] D. J. Castle, S. Wessely, J. van Os, and R. M Murray, Psychosis in the Inner City, Psychology Press, East Sussex, UK, 1998.

[526] H. Häfner, W. an der Heiden, S. Behrens et al., "Causes and consequences of the gender difference in age at onset of schizophrenia," Schizophrenia Bulletin, vol. 24, no. 1, pp. 99-113, 1998.
[527] D. J. Castle, "Preface," in Women and Schizophrenia, D. J. Castle, J. McGrath, and J. Kulkarni, Eds., p. 11, Cambridge University Press, Cambridge, UK, 2000.

[528] P. Jörgensen and P. Munk-Jörgensen, "Paranoid psychoses in the elderly," Acta Psychiatrica Scandinavica, vol. 72, pp. 358-363, 1985.

[529] D. J. Castle and R. M. Murray, “The epidemiology of late-onset schizophrenia," Schizophrenia Bulletin, vol. 19, no. 4, pp. 691700, 1993.

[530] O. P. Almeida, R. J. Howard, R. Levy, and A. S. David, “Psychotic states arising in late life (Late paraphrenia): psychopathology and nosology," The British Journal of Psychiatry, vol. 166, pp. 205-214, 1995.

[531] H. Häfner, W. Löffler, A. Riecher-Rössler, and W. HäfnerRanabauer, "Schizophrenie und Wahn im höheren und hohen Lebensalter," Nervenarzt, vol. 72, pp. 347-357, 2001 (German).

[532] M. Roth, "The natural history of mental disorder in old age," Journal of Mental Science, vol. 101, pp. 281-301, 1955.

[533] D. W. K. Kay and M. Roth, "Environmental and hereditary factors in the schizophrenia of old age ("late paraphrenia") and their bearing on the general problem of causation in schizophrenia," Journal of Mental Science, vol. 107, pp. 649-686, 1961.

[534] M. J. Harris and D. V. Jeste, "Late-onset schizophrenia: an overview," Schizophrenia Bulletin, vol. 14, no. 1, pp. 39-55, 1988.

[535] H. Häfner, M. Hambrecht, W. Löffler, P. Munk-Jørgensen, and A. Riecher-Rössler, "Is schizophrenia a disorder of all ages? A comparison of first episodes and early course across the lifecycle," Psychological Medicine, vol. 28, no. 2, pp. 351-365, 1998.

[536] H. Remschmidt, Schizophrene Erkrankungen im Kindes-und Jugendalter, Schattauer, Stuttgart, Germany, 2004 (German).

[537] S. Luoma, H. Hakko, T. Ollinen, M. R. Jarvelin, and S. Lindeman, "Association between age at onset and clinical features of schizophrenia," European Psychiatry, vol. 23, pp. 331-335, 2008.

[538] C. Eggers, Schizophrenie des Kindes-und Jugendalters, MWV Medizinisch Wissenschaftliche Verlagsgesellschaft, Berlin, Germany, 2011, (German).

[539] R. P. Bentall, R. Corcoran, R. Howard, N. Blackwood, and P. Kinderman, "Persecutory delusions: a review and theoretical integration," Clinical Psychology Review, vol. 21, no. 8, pp. 11431192, 2001.

[540] H. Häfner and W. an der Heiden, "Epidemiology of schizophrenia," The Canadian Journal of Psychiatry, vol. 42, no. 2, pp. 139151, 1997.

[541] T. H. McGlashan, "The Chestnut Lodge follow-up study. I. Follow-up methodology and study sample," Archives of General Psychiatry, vol. 41, no. 6, pp. 573-585, 1984.

[542] T. H. McGlashan, "The Chestnut Lodge follow-up study. II. Long-term outcome of schizophrenia and the affective disorders," Archives of General Psychiatry, vol. 41, no. 6, pp. 586-601, 1984.

[543] C. M. Harding, G. W. Brooks, T. Ashikaga, J. S. Strauss, and A. Breier, "The Vermont longitudinal study of persons with severe mental illness, I: methodology, study sample, and overall status 32 years later," The American Journal of Psychiatry, vol. 144, no. 6, pp. 718-726, 1987.

[544] C. M. Harding, G. W. Brooks, T. Ashikaga, J. S. Strauss, and A. Breier, "The Vermont longitudinal study of persons with severe mental illness. II: long-term outcome of subjects who retrospectively met DSM-III criteria for schizophrenia," The American Journal of Psychiatry, vol. 144, no. 6, pp. 727-735, 1987. 
[545] W. T. Carpenter Jr. and J. S. Strauss, “The prediction of outcome in schizophrenia IV: eleven-year follow-up of the Washington IPSS cohort," Journal of Nervous and Mental Disease, vol. 179, no. 9, pp. 517-525, 1991.

[546] A. Breier, J. L. Schreiber, J. Dyer, and D. Pickar, "National Institute of Mental Health longitudinal study of chronic schizophrenia: prognosis and predictors of outcome," Archives of General Psychiatry, vol. 48, no. 3, pp. 239-246, 1991.

[547] J. Leff, N. Sartorius, A. Jablensky, A. Korten, and G. Ernberg, "The International Pilot Study of Schizophrenia: five-year follow-up findings," Psychological Medicine, vol. 22, no. 1, pp. 131-145, 1992.

[548] W. an der Heiden, B. Krumm, S. Müller, I. Weber, H. Biehl, and M. Schäfer, "The Mannheim long-term schizophrenia project: initial results on course and outcome 14 years after first admission," Nervenarzt, vol. 66, no. 11, pp. 820-827, 1995.

[549] W. an der Heiden, B. Krumm, S. Müller, I. Weber, H. Biehl, and M. Schäfer, "Eine prospektive Studie zum Langzeitverlauf schizophrener Psychosen: Ergebnisse der 14-Jahres-Katamnese," Zeitschrift für Medizinische Psychologie, vol. 5, pp. 66-75, 1996 (German).

[550] W. an der Heiden, "Der Langzeitverlauf schizophrener Psychosen-eine Literaturübersicht," Zeitschrift für Medizinische Psychologie, vol. 5, pp. 8-21, 1996 (German).

[551] K. Hopper, G. Harrison, A. Janca, and N. Sartorius, Recovery from Schizophrenia-An International Perspective. A Report from the WHO Collaborative Project, the International Study of Schizophrenia, Oxford University Press, Oxford, UK, 2007.

[552] E. Jääskeläinen, P. Juola, N. Hirvonen et al., "A systematic review and meta-analysis of recovery in schizophrenia," Schizophrenia Bulletin, vol. 39, no. 6, pp. 1296-1306, 2013.

[553] J. Marengo, M. Harrow, J. Sands, and C. Galloway, "European versus U.S. data on the course of schizophrenia," The American Journal of Psychiatry, vol. 148, no. 5, pp. 606-611, 1991.

[554] A. Marneros, A. Deister, and A. Rohde, Affektive, schizoaffektive und schizophrene Psychosen. Eine vergleichende Langzeitstudie, Springer, Berlin, Germany, 1991 (German).

[555] M. Bleuler, Die schizophrenen Geistesstörungen im Lichte langjähriger Kranken- und Familiengeschichten, Thieme, Stuttgart, Germany, 1972, (German).

[556] H. Hinterhuber, “Zur Katamnese der Schizophrenien," Fortschritte der Neurologie Psychiatrie, vol. 41, no. 10, pp. 527-558, 1973 (German).

[557] L. Ciompi and C. H. Müller, Lebensweg und Alter der Schizophrenen. Eine katamnestische Langzeitstudie bis ins Senium, vol. 12 of Monographien aus dem Gesamtgebiet der Psychiatrie, Springer, Berlin, Germany, 1976, (German).

[558] G. Huber, G. Gross, and R. Schüttler, Schizophrenie. Eine Verlaufs- und sozialpsychiatrische Langzeitstudie, Springer, Berlin, Germany, 1979 (German).

[559] H. Häfner and W. an der Heiden, "The course of schizophrenia in the light of modern follow-up studies: the ABC and WHO studies," European Archives of Psychiatry and Clinical Neuroscience, vol. 249, supplement 4, pp. IV14-IV26, 1999.

[560] N. Sartorius, W. Gulbinat, G. Harrison, E. Laska, and C. Siegel, "Long-term follow up of schizophrenia in 16 countries: a description of the International Study of Schizophrenia conducted by the World Health Organization," Social Psychiatry and Psychiatric Epidemiology, vol. 31, no. 5, pp. 249-258, 1996.

[561] P. Mason, G. Harrison, C. Glazebrook, I. Medley, and T. Croudace, "The course of schizophrenia over 13 years: a report from the International Study on Schizophrenia (ISoS) coordinated by the World Health Organization," The British Journal of Psychiatry, vol. 169, no. 5, pp. 580-586, 1996.

[562] D. Wiersma, F. J. Nienhuis, C. J. Slooff, and R. Giel, "Natural course of schizophrenic disorders: a 15-year followup of a Dutch incidence cohort," Schizophrenia Bulletin, vol. 24, no. 1, pp. 7585, 1998.

[563] N. Sartorius, A. Jablensky, A. Korten et al., "Early manifestations and first-contact incidence of schizophrenia in different cultures," Psychological Medicine, vol. 16, no. 4, pp. 909-928, 1986.

[564] G. Harrison, K. Hopper, T. Craig et al., "Recovery from psychotic illness: a 15- and 25-year international follow-up study," The British Journal of Psychiatry, vol. 178, pp. 506-517, 2001.

[565] N. M. Menezes, T. Arenovich, and R. B. Zipursky, "A systematic review of longitudinal outcome studies of first-episode psychosis," Psychological Medicine, vol. 36, no. 10, pp. 1349-1362, 2006.

[566] H. Häfner, W. Löffler, K. Maurer, A. Riecher-Rössler, and A. Stein, Interview für die retrospektive Erfassung des Erkrankungsbeginns und-verlaufs bei Schizophrenie und anderen Psychosen, Huber, Bern, Switzerland, 1999 (German).

[567] H. Häfner, W. Löffler, K. Maurer, A. Riecher-Rössler, and A. Stein, IRAOS-Interview for the Retrospective Assessment of the Onset and Course of Schizophrenia and Other Psychoses, Hogrefe \& Huber, Göttingen, Germany, 2003.

[568] A. Jablensky, "The epidemiological horizon," in Schizophrenia, S. R. Hirsch and D. Weinberger, Eds., pp. 203-231, Blackwell, Oxford, UK, 2nd edition, 2003.

[569] R. A. Bressan, A. C. Chaves, L. S. Pilowsky, I. Shirakawa, and J. J. Mari, "Depressive episodes in stable schizophrenia: critical evaluation of the DSM-IV and ICD-10 diagnostic criteria," Psychiatry Research, vol. 117, no. 1, pp. 47-56, 2003.

[570] C. M. Harding, "Course types in schizophrenia: an analysis of European and American studies," Schizophrenia Bulletin, vol. 14, no. 4, pp. 633-643, 1988.

[571] H. Häfner and W. an der Heiden, "Course and outcome of schizophrenia," in Schizophrenia, S. R. Hirsch and D. Weinberger, Eds., pp. 124-147, Blackwell Science, Oxford, UK, 2nd edition, 2003.

[572] M. Shepherd, D. Watt, I. Falloon, and N. Smeeton, The Natural History of Schizophrenia: A Five-Year Follow-up Study of Outcome and Prediction in a Representative Sample of Schizophrenics, Psychological Medicine Monograph, supplement 15, Cambridge University Press, London, UK, 1989.

[573] J. W. Newcomer and S. Leucht, "Metabolic adverse effects associated with antipsychotic medications," in Schizophrenia, D. R. Weinberger and P. J. Harrison, Eds., pp. 577-598, WileyBlackwell, Oxford, UK, 3rd edition, 2011.

[574] S. Brown, "Excess mortality of schizophrenia. A meta-analysis," The British Journal of Psychiatry, vol. 171, pp. 502-508, 1997.

[575] S. Brown, M. Kim, C. Mitchell, and H. Inskip, "Twenty-five year mortality of a community cohort with schizophrenia," The British Journal of Psychiatry, vol. 196, no. 2, pp. 116-121, 2010.

[576] M. V. Seeman, "An outcome measure in schizophrenia: mortality," The Canadian Journal of Psychiatry, vol. 52, no. 1, pp. 55-60, 2007.

[577] C. W. Colton and R. W. Manderscheid, "Congruencies in increased mortality rates, years of potential life lost, and causes of death among public mental health clients in eight states," Preventing Chronic Disease, vol. 3, no. 2, article A42, 2006. 
[578] T. M. Laursen, "Life expectancy among persons with schizophrenia or bipolar affective disorder," Schizophrenia Research, vol. 131, no. 1-3, pp. 101-104, 2011.

[579] H. Häfner and S. Kasper, "Akute lebensbedrohliche Katatonie: epidemiologische und klinische Befunde," Nervenarzt, vol. 53, pp. 385-394, 1982 (German).

[580] J. Höffler and P. Bräunig, "Abnahme der Häufigkeit katatoner Schizophrenien im Epochenvergleich," in Differenzierung Katatoner und Neuroleptika-Induzierter Bewegungsstörungen, P. Bräunig, Ed., pp. 32-35, Thieme, Stuttgart, Germany, 1995, (German).

[581] Ö. Ödegård, "Mortality in Norwegian psychiatric hospitals 1950-1962," Acta Genetica et Statistica Medica, vol. 17, no. 1, pp. 137-153, 1967.

[582] P. Allebeck, "Schizophrenia: a life-shortening disease," Schizophrenia Bulletin, vol. 15, no. 1, pp. 81-89, 1989.

[583] D. Healy, J. Le Noury, M. Harris et al., "Mortality in schizophrenia and related psychoses: data from two cohorts," British Medical Journal, vol. 2, Article ID e001810, 2012.

[584] S. Leucht, T. Burkard, J. Henderson, M. Maj, and N. Sartorius, "Physical illness and schizophrenia: a review of the literature," Acta Psychiatrica Scandinavica, vol. 116, no. 5, pp. 317-333, 2007.

[585] T. M. Laursen, T. Munk-Olsen, E. Agerbo, C. Gasse, and P. B. Mortensen, "Somatic hospital contacts, invasive cardiac procedures, and mortality from heart disease in patients with severe mental disorder," Archives of General Psychiatry, vol. 66, no. 7, pp. 713-720, 2009.

[586] T. M. Laursen, T. Munk-Olsen, and C. Gasse, "Chronic somatic comorbidity and excess mortality due to natural causes in persons with schizophrenia or bipolar affective disorder," PLOS ONE, vol. 6, no. 9, Article ID e24597, 2011.

[587] B. G. Druss and T. H. Bornemann, "Improving health and health care for persons with serious mental illness: the window for US federal policy change," The Journal of the American Medical Association, vol. 303, no. 19, pp. 1972-1973, 2010.

[588] J. W. Newcomer and C. H. Hennekens, "Severe mental illness and risk of cardiovascular disease," The Journal of the American Medical Association, vol. 298, no. 15, pp. 1794-1796, 2007.

[589] S. M. Grundy, "Obesity, metabolic syndrome, and coronary atherosclerosis," Circulation, vol. 105, no. 23, pp. 2696-2698, 2002.

[590] D. E. Casey, D. W. Haupt, J. W. Newcomer et al., "Antipsychoticinduced weight gain and metabolic abnormalities: implications for increased mortality in patients with schizophrenia," Journal of Clinical Psychiatry, vol. 65, no. 7, pp. 4-18, 2004.

[591] J. P. Despres, I. Lemieuz, and J. Bergeron, "Abdominal obesity and the metabolic syndrome: contribution to global cardiometabolic risk," Arteriosclerosis, Thrombosis, and Vascular Biology, vol. 28, pp. 1039-1049, 2008.

[592] D. B. Allison, K. R. Fontaine, J. E. Manson, J. Stevens, and T. B. VanItallie, "Annual deaths attributable to obesity in the United States," The Journal of the American Medical Association, vol. 282, no. 16, pp. 1530-1538, 1999.

[593] M. T. Susce, N. Villanueva, F. J. Diaz, and J. de Leon, “Obesity and associated complications in patients with severe mental illnesses: a cross-sectional survey," Journal of Clinical Psychiatry, vol. 66, no. 2, pp. 167-273, 2005.

[594] R. G. McCreadie, "Diet, smoking and cardiovascular risk in people with schizophrenia: descriptive study," The British Journal of Psychiatry, vol. 183, pp. 534-539, 2003.

[595] T. Cohn, D. Prud'homme, D. Streiner, H. Kameh, and G. Remington, "Characterizing coronary heart disease risk in chronic schizophrenia: high prevalence of the metabolic syndrome," The
Canadian Journal of Psychiatry, vol. 49, no. 11, pp. 753-760, 2004.

[596] K. Hawton, L. Sutton, C. Haw, J. Sinclair, and J. J. Deeks, "Schizophrenia and suicide: systematic review of risk factors," The British Journal of Psychiatry, vol. 187, pp. 9-20, 2005.

[597] C. B. Caldwell and I. I. Gottesman, "Schizophrenics kill themselves too: a review of risk factors for suicide," Schizophrenia Bulletin, vol. 16, no. 4, pp. 571-590, 1990.

[598] S. J. Bartels, R. E. Drake, and G. J. McHugo, "Alcohol abuse, depression, and suicidal behavior in schizophrenia," The American Journal of Psychiatry, vol. 149, no. 3, pp. 394-395, 1992.

[599] A. McGirr, M. Tousignant, D. Routhier et al., "Risk factors for completed suicide in schizophrenia and other chronic psychotic disorders: a case-control study," Schizophrenia Research, vol. 84, no. 1, pp. 132-143, 2006.

[600] H. Häfner and W. an der Heiden, "Schizophrenia and depression-challenging the paradigm of two separate diseases," in Textbook of Schizophrenia Spectrum Disorders, M. S. Ritsner, Ed., pp. 389-402, Springer, London, UK, 2011.

[601] W. S. Fenton, "Depression, suicide, and suicide prevention in schizophrenia," Suicide and Life-Threatening Behavior, vol. 30, no. 1, pp. 34-49, 2000.

[602] N. Crumlish, P. Whitty, M. Kamali et al., "Early insight predicts depression and attempted suicide after 4 years in first-episode schizophrenia and schizophreniform disorder," Acta Psychiatrica Scandinavica, vol. 112, no. 6, pp. 449-455, 2005.

[603] J. D. López-Morínigo, R. Ramos-Ríos, A. S. David, and R. Dutta, "Insight in schizophrenia and risk of suicide: a systematic update," Comprehensive Psychiatry, vol. 53, no. 4, pp. 313-322, 2012.

[604] J. van Os, "Is there a continuum of psychotic experiences in the general population?" Epidemiologia e Psichiatria Sociale, vol. 12, no. 4, pp. 242-252, 2003.

[605] J. Allardyce, R. G. McCreadie, G. Morrison, and J. van Os, “Do symptom dimensions or categorical diagnoses best discriminate between known risk factors for psychosis?" Social Psychiatry and Psychiatric Epidemiology, vol. 42, no. 6, pp. 429-437, 2007.

[606] W. Gaebel and J. Zielasek, "The DSM-V initiative "deconstructing psychosis" in the context of Kraepelin's concept on nosology," European Archives of Psychiatry and Clinical Neuroscience, vol. 258, no. 2, pp. 41-47, 2008.

[607] S. Arndt, N. C. Andreasen, M. Flaum, D. Miller, and P. Nopoulos, "A longitudinal study of symptom dimensions in schizophrenia: prediction and patterns of change," Archives of General Psychiatry, vol. 52, no. 5, pp. 352-360, 1995.

[608] H. Häfner, "Psychose, Depression und manische Symptomatik-Leitsyndrome eigener Krankheiten oder Kontinuum?" in Schizophrenie-Zukunftsperspektiven in Klinik und Forschung, H.-J. Möller and N. Müller, Eds., pp. 3-30, Springer, Vienna, Germany, 2010 (German).

[609] N. Sartorius, "Stigma: what can psychiatrists do about it?" The Lancet, vol. 352, no. 9133, pp. 1058-1059, 1998.

[610] B. G. Link, J. C. Phelan, M. Bresnahan, A. Stueve, and B. A. Pescosolido, "Public conceptions of mental illness: labels, causes, dangerousness, and social distance," American Journal of Public Health, vol. 89, no. 9, pp. 1328-1333, 1999.

[611] B. Mueller, C. Nordt, C. Lauber, P. Rueesch, P. C. Meyer, and W. Roessler, "Social support modifies perceived stigmatization in the first years of mental illness: a longitudinal approach," Social Science \& Medicine, vol. 62, no. 1, pp. 30-49, 2006. 
[612] V. Gentil, "More for the same?" Revista Brasileira de Psiquiatria, vol. 29, no. 2, pp. 193-194, 2007.

[613] W. Rössler, "Does stigma impair treatment response and rehabilitation in schizophrenia? The "contribution" of mental health professionals," in Advances in Schizophrenia Research 2009, W. F. Gattaz and G. Busatto, Eds., pp. 429-439, Springer, New York, NY, USA, 2010.

[614] M. Sato, "Renaming schizophrenia: a Japanese perspective," World Psychiatry, vol. 5, no. 1, pp. 53-55, 2006.

[615] H. Takahashi, T. Ideno, S. Okubo et al., "Impact of changing the Japanese term for "schizophrenia" for reasons of stereotypical beliefs of schizophrenia in Japanese youth," Schizophrenia Research, vol. 112, no. 1-3, pp. 149-152, 2009.

[616] M. C. Angermeyer, H. Matschinger, M. G. Carta, and C. Schomerus, "Changes in the perception of mental illness stigma in Germany over the last two decades," European Psychiatry, 2013.

[617] C. Thornicroft, A. Wyllie, G. Thornicroft, and N. Mehta, "Impact of the "Like Minds, Like Mine" anti-stigma and discrimination campaign in New Zealand on anticipated and experienced discrimination," Australian \& New Zealand Journal of Psychiatry, vol. 48, no. 4, pp. 360-370, 2014. 


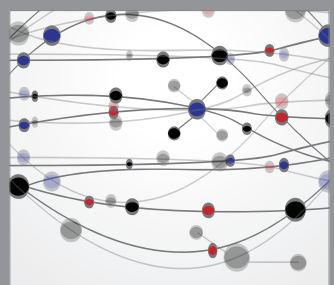

The Scientific World Journal
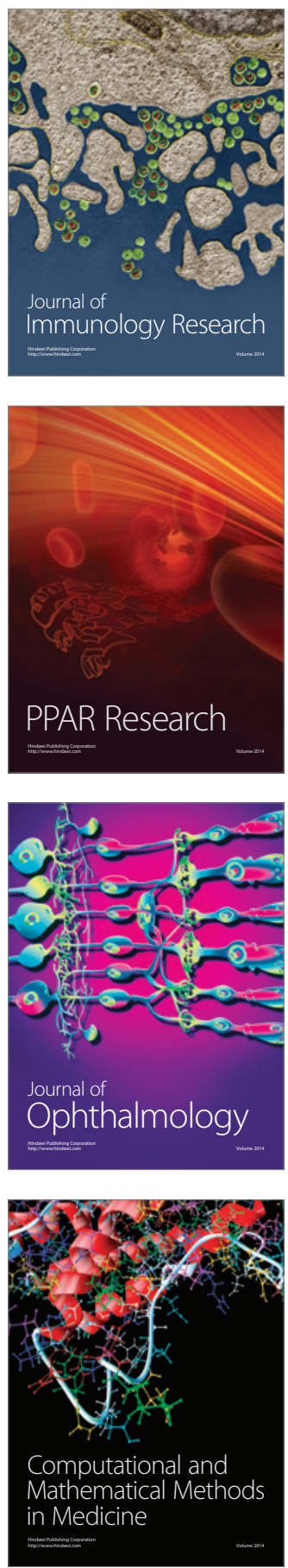

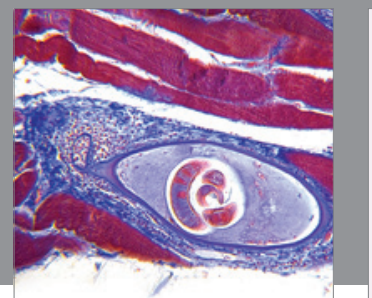

Gastroenterology

Research and Practice
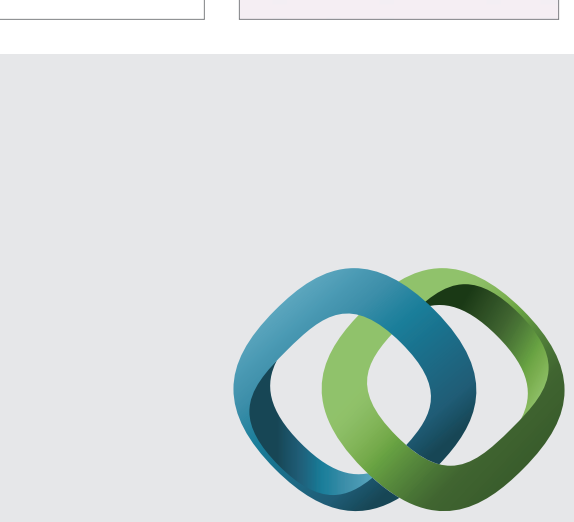

\section{Hindawi}

Submit your manuscripts at

http://www.hindawi.com
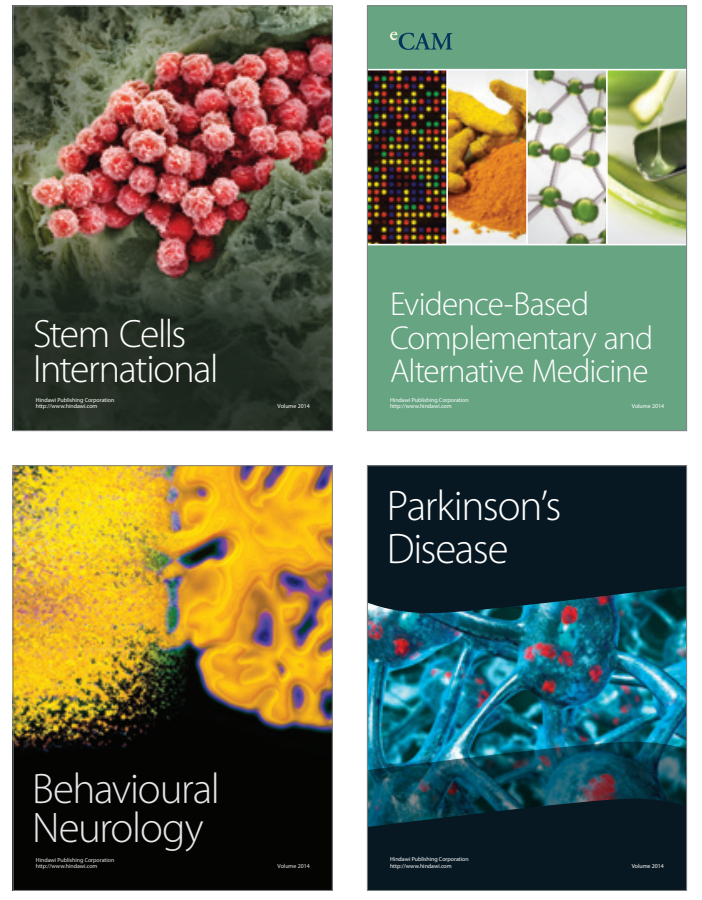
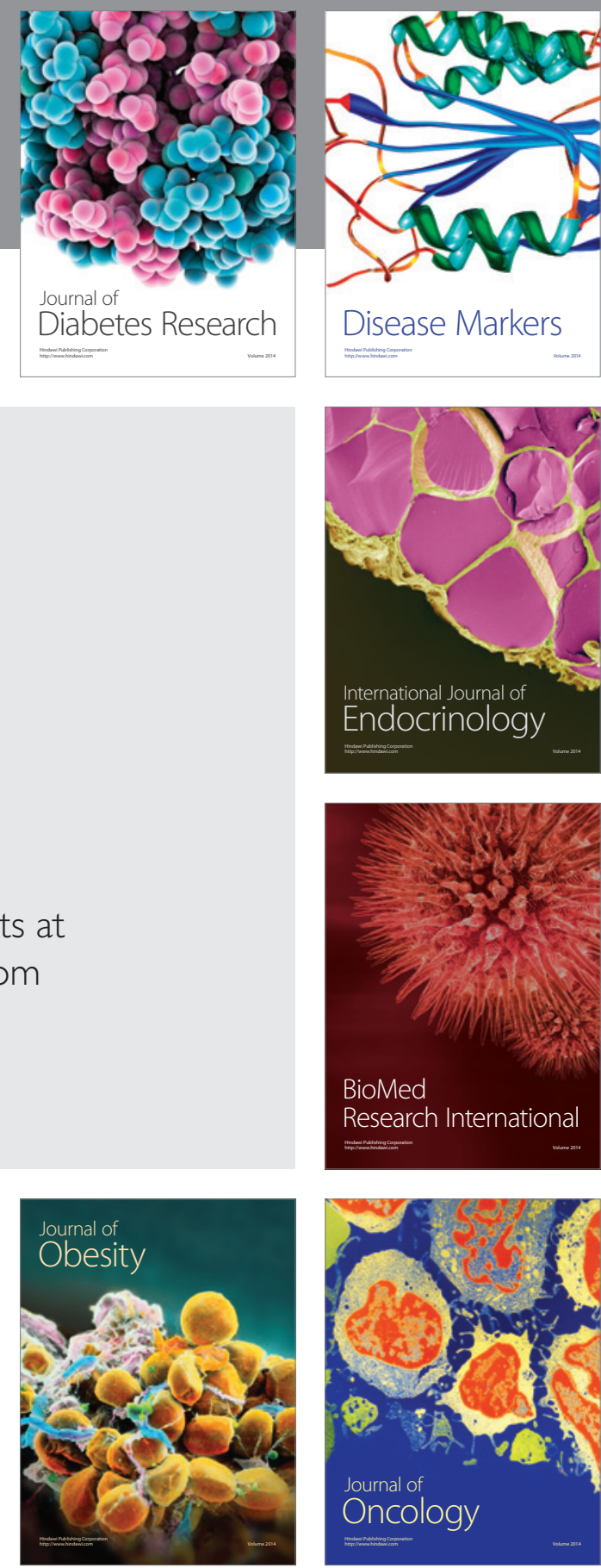

Disease Markers
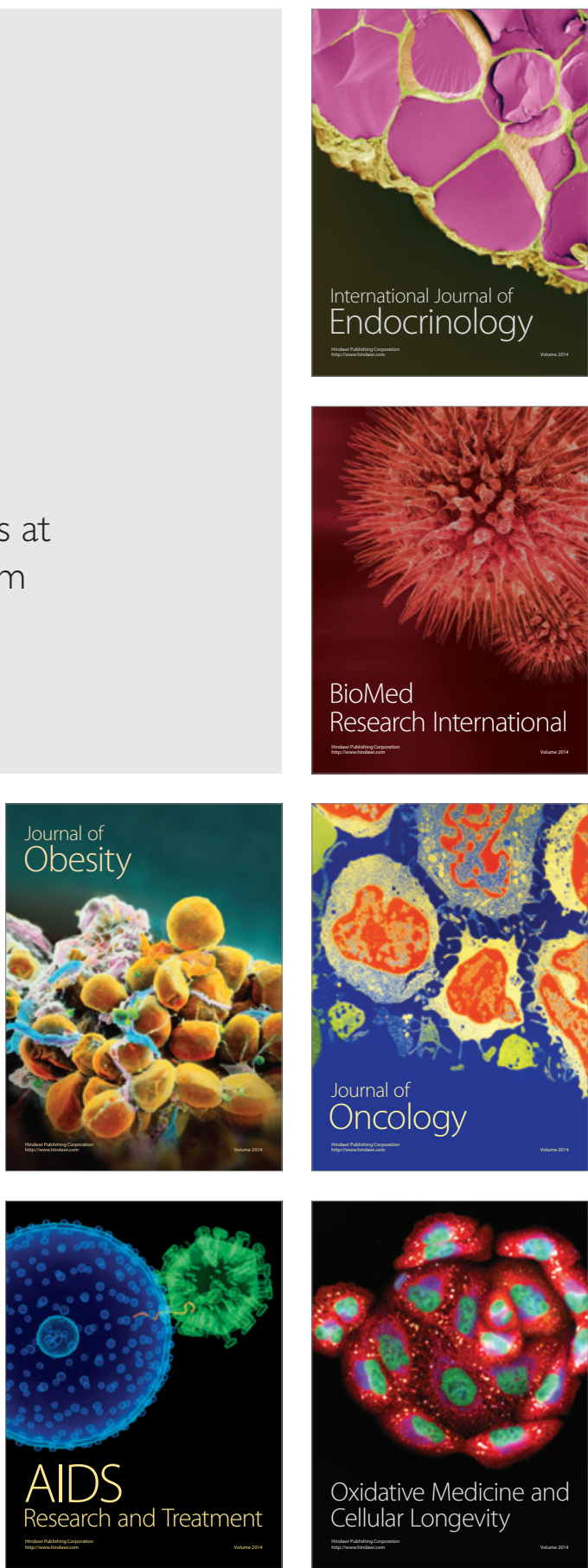